Supporting Information for

\title{
Ring-Fused Firefly Luciferins: Expanded Palette of Near- Infrared Emitting Bioluminescent Substrates
}

Yuma Ikeda, ${ }^{\dagger}$ Takahiro Nomoto, ${ }^{\ddagger}$ Yuki Hiruta, ${ }^{\dagger}$ Nobuhiro Nishiyama,${ }^{\ddagger}$ Daniel Citterio ${ }^{\dagger *}$

† Department of Applied Chemistry, Keio University, 3-14-1 Hiyoshi, Kohoku-ku, Yokohama, Kanagawa, 223-8522, Japan.

‡ Laboratory for Chemistry and Life Science, Institute of Innovative Research, Tokyo Institute of Technology, 4259 Nagatsutacho, Midori-ku, Yokohama, Kanagawa, 226-8503, Japan.

${ }^{*}$ Correspondence should be addressed to citterio@applc.keio.ac.jp

\section{Table of Contents}

Materials and Methods $\quad$ S2

Synthetic Procedures: Scheme S1 Synthesis of NIRLucs $\quad$ S6

$\begin{array}{ll}\text { Supplemental Figure S1 Normalized fluorescence spectra } & \text { S17 }\end{array}$

Supplemental Figure S2 Photomultiplier spectral sensitivity $\quad$ S18

Supplemental Figure S3 Luciferin saturation assay $\quad$ S19

Supplemental Figure S4 pH-Dependence of bioluminescence spectra S20

Supplemental Figure S5 pH-Dependence of bioluminescence emission intensities S21

Supplemental Figure S6 Chemical structures of oxidized form of luciferins $\quad$ S22

Supplemental Table S1 Calculated frontier orbitals and oscillator strengths S23

Supplemental Figure S7 Experimental and computational emission wavelengths $\quad$ S24

Supplemental Figure S8 Cell number-dependent bioluminescence S25

Supplemental Table S2 Fraction of NIR emission from luciferase expressing cells $\quad$ S26

Supplemental Figure S9 Time-dependent photon output from cells $\quad$ S27

Supplemental Figure S10 Time course of bioluminescent photon flux in vivo S28

$\begin{array}{ll}\text { References } & \text { S29 }\end{array}$

$\begin{array}{ll}\text { NMR Spectra } & \text { S30 }\end{array}$ 


\section{Materials and Methods:}

\section{General}

Reagents and solvents were of the best grade available, supplied by Tokyo Chemical Industries (Japan), Wako Pure Chemical (Japan), Aldrich Chemical Co. (USA), Kanto Chemical Co. (Japan) or Watanabe Chemical Industries (Japan) and were used without further purification. NMR spectra were recorded on a JEOL ECA-500 instrument at $500 \mathrm{MHz}$ for ${ }^{1} \mathrm{H}$ NMR and at $125 \mathrm{MHz}$ for ${ }^{13} \mathrm{C} \mathrm{NMR}$. All chemical shifts $(\delta)$ are reported in ppm relative to tetramethylsilane $(\delta=0.0 \mathrm{ppm})$ or residual nondeuterated NMR solvent $\mathrm{CDCl}_{3}\left(7.26 \mathrm{ppm}\right.$ for ${ }^{1} \mathrm{H}, 77.16 \mathrm{ppm}$ for ${ }^{13} \mathrm{C}$ ), $\mathrm{CD}_{3} \mathrm{OD}\left(3.31 \mathrm{ppm}\right.$ for ${ }^{1} \mathrm{H}, 49.00$ ppm for ${ }^{13} \mathrm{C}$ ), or DMSO-d 6 (2.50 ppm for ${ }^{1} \mathrm{H}, 39.52$ ppm for $\left.{ }^{13} \mathrm{C}\right)$ and coupling constants $(J)$ are provided in $\mathrm{Hz}$. Mass spectra (MS) were measured on a Waters LCT Premier XE (ESI-TOF). A $1.0 \mathrm{mg} / \mathrm{mL}$ stock solution of commercially available luciferase (Promega, QuantiLum ${ }^{\circledR}$ recombinant Photinus pyralis luciferase, E1701) in GTA buffer (50 mM, pH 8.0) containing 10\% glycerol was prepared and stored at $-80{ }^{\circ} \mathrm{C}$. The composition of the $50 \mathrm{mM}$ GTA buffer is $50 \mathrm{mM}$ 3,3-dimethylglutaric acid, $50 \mathrm{mM}$ tris(hydroxymethyl)aminomethane, $50 \mathrm{mM}$ 2-amino-2-methyl-1,3-propanediol and the $\mathrm{pH}$ was adjusted with $2 \mathrm{M} \mathrm{HCl}$ or $1 \mathrm{M} \mathrm{NaOH}$ solution. The enantiopurity was analyzed on an analytical HPLC (Agilent 1100 Series, USA) using CHIRALCEL ${ }^{\circledR}$ OZ-3R (150 X $4.6 \mathrm{~mm}$ ID, DAICEL, Japan) with a linear gradient of $10 \%-90 \% \mathrm{CH}_{3} \mathrm{CN}$ in $\mathrm{H}_{2} \mathrm{O}$ over $30 \mathrm{~min}$ (flow rate $0.6 \mathrm{~mL} / \mathrm{min}$ ) as eluent. $\mathrm{A} U \mathrm{VV}$ detector set at $370 \mathrm{~nm}$ was used for peak detection. GraphPad Prism (version 7.03 for Windows, GraphPad Software) was used to analyze data and generate graphs. The calculated logP (ClogP) values were calculated by ChemDraw 13.0.

\section{Chemiluminescence spectra}

The chemiluminescence emission spectra for all luciferins with $n$-propylphosphonic anhydride (T3P) and triethylamine (TEA) in DMF were measured on an AB-1850 spectrophotometer (ATTO, Japan). A solution of the luciferins $(2 \mathrm{mM})$ in DMF $(20 \mu \mathrm{L})$ and TEA $(2 \mathrm{M})$ in DMF $(20 \mu \mathrm{L})$ were placed in a polystyrene tube. This solution was treated with T3P $(110 \mathrm{mM})$ in DMF $(60 \mu \mathrm{L})$, which was injected with a syringe, to initiate the chemiluminescence reaction. Emission data were collected for $5 \mathrm{~s}$ (slit width: $1.0 \mathrm{~mm}$ ), and the luminescence intensities were normalized. 


\section{Fluorescence spectroscopy}

The fluorescence spectra for luciferins $(10 \mu \mathrm{M})$ in $50 \mathrm{mM}$ GTA buffer $(\mathrm{pH} 8.0)$ were measured using a VARIOSKAN FLASH (Thermo Scientific, USA) microplate reader with the excitation light and excitation/emission slit widths set to $375 \mathrm{~nm}$ and $1 \mathrm{~nm}$, respectively. Spectral data were recorded at $25^{\circ} \mathrm{C}$ in a clear bottom 96-well microplate over the wavelength range of 400-750 nm.

The absolute fluorescence quantum yields were collected using a Quantaurus-QY (Hamamatsu Photonics, Japan) with the excitation light set to $375 \mathrm{~nm}$.

\section{Bioluminescence emission spectra}

The bioluminescence emission spectra for all luciferins were recorded on an $A B-1850$ spectrophotometer (ATTO, Japan). A solution of the luciferins $(100 \mu \mathrm{M})$ in GTA buffer $(50 \mathrm{mM}, \mathrm{pH} 8.0$, $5 \mu \mathrm{L})$ and Fluc $(1.0 \mathrm{mg} / \mathrm{mL})$ in GTA buffer $(50 \mathrm{mM}, \mathrm{pH} 8.0)$ containing $10 \%$ glycerol $(5 \mu \mathrm{L})$ were placed in a polystyrene tube. The bioluminescence reaction was initiated by injection of $90 \mu \mathrm{L}$ of reaction buffer (4 mM ATP-2Na, $8 \mathrm{mM} \mathrm{MgSO}_{4}$ in 50 mM GTA buffer, pH 8.0). Emission data were collected for $60 \mathrm{~s}$ (slit width: $0.25 \mathrm{~mm}$ ), and the luminescence intensities were normalized. The $\mathrm{pH}$ dependence of the spectra was assessed in a similar manner in GTA buffer (50 mM, pH5.5-8.5).

\section{Bioluminescence kinetic measurements}

Measurements were acquired on a $\operatorname{TriStar}^{2}$ LB942 luminometer (BERTHOLD, Germany) without filter. The spectral-sensitivity of the luminometer was evaluated with standard LED light sources (WSL1200 KohshiFundam, ATTO, Japan). Reactions were performed in white 96-well flat-bottom plates (Grenier). Solutions of luciferins in GTA buffer $(50 \mathrm{mM}, \mathrm{pH} 7.0)$ were prepared $(0.5 \mu \mathrm{M}-100 \mu \mathrm{M}$ luciferin), and $10 \mu \mathrm{L}$ was added to each well. Following the addition of Fluc $(0.05 \mathrm{mg} / \mathrm{mL})$ in GTA buffer (50 mM, pH 8.0) containing $10 \%$ glycerol $(10 \mu \mathrm{L})$, the luminescence reaction was initiated by injection of $80 \mu \mathrm{L}$ of reaction buffer (4 mM ATP-2Na, 8 mM MgSO 4 in 50 mM GTA buffer, pH 8.0). Emission data was recorded every $1 \mathrm{~s}$ over a $60 \mathrm{~s}$ period. Samples were analyzed in triplicate and three runs of each compound-enzyme pair were performed. Initial velocities were estimated as integrated values of the light emission intensities for $30 \mathrm{~s}$. $K_{\mathrm{m}}$ and relative $V_{\max }$ values were determined using nonlinear regression analyses and robust fit outlier removal in GraphPad Prism (version 7.03 for Windows, GraphPad Software). The $\mathrm{pH}$ dependence of luminescence intensities was assessed with $10 \mu \mathrm{M}$ luciferins in GTA buffer (50 mM, pH5.5-8.5). 


\section{Quantum chemical calculation}

All calculations of HOMO and LUMO energy levels were carried out using the Gaussian 09 program. The geometries of the ground state and excited state structures were optimized using Density Functional Theory (DFT) and Time-Dependent Density Functional Theory (TD-DFT) at the B3LYP level. The $6-31+G(d)$ basis set was adopted for all atoms.

\section{Cellular bioluminescence assays}

B16-F10 cells expressing luciferase (B16-F10/CMV-Luc cells) were obtained from Japanese Collection of Research Bioresources Cell Bank (Ibaraki, Japan). B16-F10/CMV-Luc cells were cultured in DMEM medium supplemented with FBS (10\%), penicillin (100 U/mL) and streptomycin $(100 \mu \mathrm{g} / \mathrm{mL})$ at $37{ }^{\circ} \mathrm{C}$ in $5 \% \mathrm{CO}_{2}$. For bioluminescence emission assays, approximately $3.5 \times 10^{5}$ cells/well were plated in black 96 -well plates in $75 \mu \mathrm{L}$ of DMEM containing $10 \%$ FBS. The cells then incubated with $75 \mu \mathrm{L}$ of luciferins (0.5-500 $\mu \mathrm{M})$ in PBS (-). Bioluminescence images were acquired on an IVIS Spectrum (PerkinEImer, USA) system equipped with a cooled CCD camera with following conditions; OPEN for total or $680 \pm 10 \mathrm{~nm}$ emission filter for NIR bioluminescence, exposure time: 180 sec, binning: medium 8, and f/stop: 1 . The bioluminescence images were analyzed by Living Image 4.4 software (PerkinElmer, USA).

For cell number-dependent assays, $7.5 \times 10^{3}-2.4 \times 10^{5}$ cells/well were plated in black 96 -well plates in $50 \mu \mathrm{L}$ of DMEM containing 10\% FBS. The cells then incubated with $50 \mu \mathrm{L}$ of luciferins $(50 \mu \mathrm{M})$ in PBS. Bioluminescence images were acquired $1 \mathrm{~min}$ after adding the luciferins and analyzed as above.

\section{Mice}

The ICR mice (female, 4 weeks old) and C57BL/6J mice (female, 4 weeks old) were obtained from Japan SLC, Inc (Hamamatsu, Japan). The mice were provided access to food and water ad libitum.

All the animal experiments were approved by the Animal Care and Use Committee of Tokyo Institute of Technology. The experiments were performed in accordance with the Guidelines for the Care and Use of Laboratory Animals as stated by Tokyo Institute of Technology. 


\section{Measurements of blood retention}

$100 \mu \mathrm{L}$ of luciferins (5 mM) in PBS (-) containing 5\% DMSO were intravenously injected to ICR mice (female, 4 weeks old). $5 \mu \mathrm{L}$ of blood was sampled from tail vein at each time point and then mixed with $45 \mu \mathrm{L}$ of PBS (-) in a black 96-well plate. The bioluminescence was initiated by adding 25 $\mu \mathrm{L}$ of ATP-Mg $(80 \mu \mathrm{M})$ and $25 \mu \mathrm{L}$ of Fluc $(20 \mu \mathrm{g} / \mathrm{mL})$ and the bioluminescence images were taken immediately on an IVIS Spectrum (PerkinEImer, USA) system equipped with a cooled CCD camera with following conditions; OPEN, exposure time: $10 \mathrm{sec}$, binning: medium 8, and f/stop: 1. The bioluminescence images were analyzed by Living Image 4.4 software (PerkinElmer, USA). The results were normalized by the photon flux at the 3 min after intravenous injection in each individual.

\section{In vivo subcutaneous tumor imaging}

A subcutaneous tumor model was prepared by subcutaneously inoculating a C57BL/6J mouse with B16-F10/CMV-Luc cells $\left(5 \times 10^{5}\right.$ cells/mouse). The experiments were performed 14 days after engraftment. The mice were anesthetized with $2 \%$ isoflurane and placed on a temperature-controlled stage. $100 \mu \mathrm{L}$ of luciferins ( $5 \mathrm{mM}$ ) in PBS (-) containing 5\% DMSO were intravenously injected to mice and bioluminescence images were acquired on an IVIS Spectrum (PerkinElmer, USA) system equipped with a cooled CCD camera with following conditions; OPEN for total or $680 \pm 10 \mathrm{~nm}$ emission filter for NIR bioluminescence, exposure time: $60 \mathrm{sec}$, binning: medium 8, and f/stop: 1. The bioluminescence images were analyzed by Living Image 4.4 software (PerkinElmer, USA).

The photon flux from a subcutaneous tumor were normalized by the tumor volume $(V)$ estimated by the following equation:

$$
V=a \times b^{2} / 2
$$

where $a$ and $b$ are the major and minor axes of the tumor, respectively, as measured by a caliper. The statistical significance was determined by two-tailed Student's $t$-test. The results were considered statistically significance if the $P$-values were lower than 0.05 . 


\section{Synthetic Procedures:}

Scheme S1. Synthesis of NIRLucs
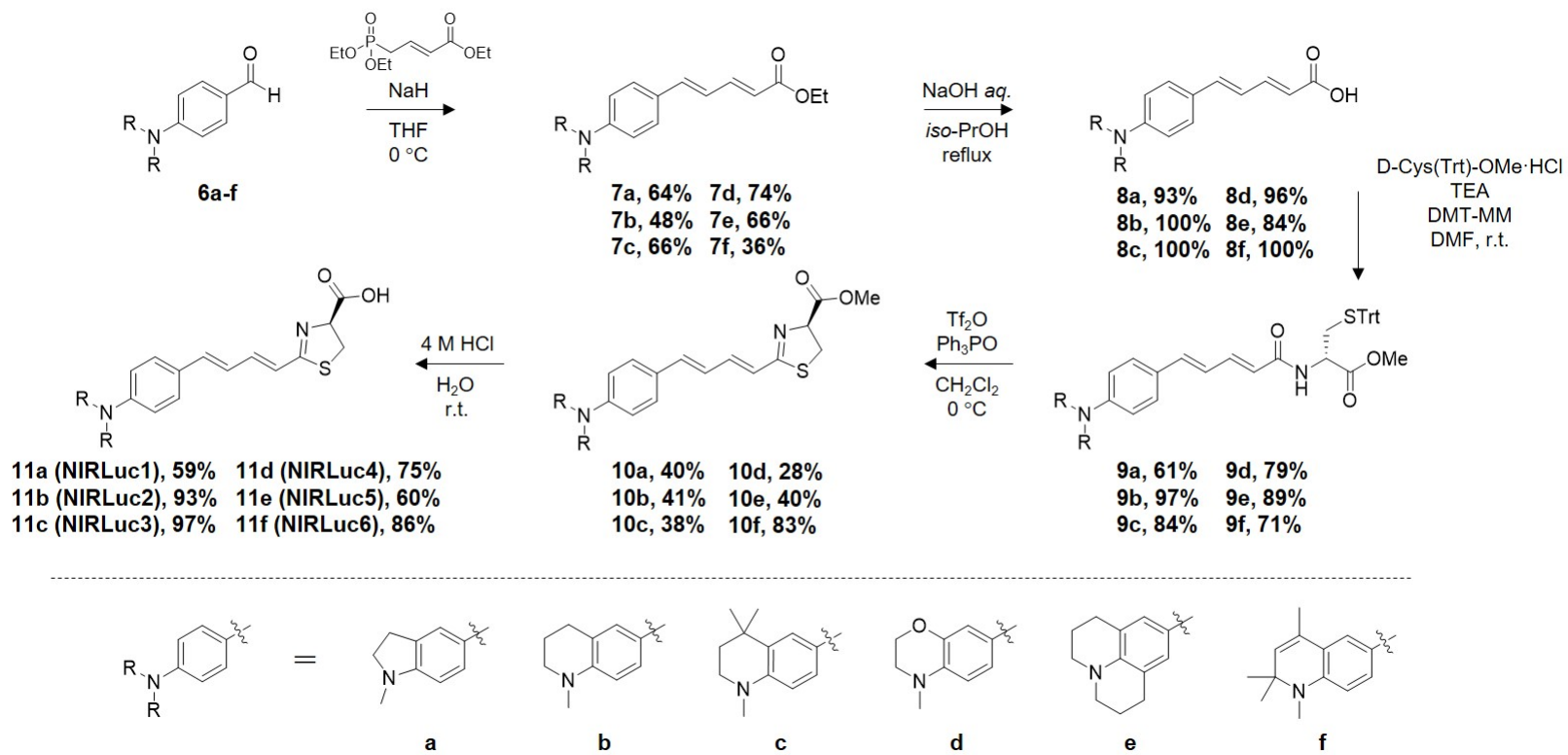

The benzaldehydes $(\mathbf{6})$ were synthesized as previously reported $\left(\mathbf{6} \mathbf{a}-\mathbf{b}^{1}, \mathbf{6} \mathbf{c}^{2}, \mathbf{6} \mathbf{d}^{3}, \mathbf{6} \mathbf{f}^{4}\right)$. Compound $\mathbf{6 e}$ is commercially available from Tokyo Chemical Industries (Japan).

\section{Compound $7 a$}<smiles>CCOC(=O)/C=C/C=C/c1ccc2c(c1)CCN2C</smiles>

To a suspension of $60 \% \mathrm{NaH}$ ( $273 \mathrm{mg}, 6.83 \mathrm{mmol}, 2.0$ eq.) in anhydrous THF $(3.8 \mathrm{~mL})$ at $0{ }^{\circ} \mathrm{C}$ was added triethyl 4-phosphonocrotonate $(1.28 \mathrm{~g}, 5.13 \mathrm{mmol}$, 1.5 eq.). Stirring for $20 \mathrm{~min}$ yielded an orange colored solution. To this solution was added $6 \mathbf{6}(548 \mathrm{mg}, 3.40 \mathrm{mmol})$ in anhydrous THF $(3.0 \mathrm{~mL})$ dropwise over $5 \mathrm{~min}$ at $0{ }^{\circ} \mathrm{C}$. The reaction was stirred for $3 \mathrm{~h}$ at room temperature, quenched with water (ca. $20 \mathrm{~mL}$ ) and extracted with EtOAc $(3 \times 50 \mathrm{~mL})$. The combined organic layer was washed with brine, dried over $\mathrm{Na}_{2} \mathrm{SO}_{4}$ and filtered. The filtrate was concentrated under reduced pressure. The crude material was purified by silica gel column chromatography (11-32\% ethyl acetate/n-hexane) to afford 7 a (561 $\mathrm{mg}, 64 \%$ ) as a yellow solid. ${ }^{1} \mathrm{H}$ NMR $\left(500 \mathrm{MHz}, \mathrm{CDCl}_{3}\right) \delta 7.43(\mathrm{dd}, J=15.0,11.0 \mathrm{~Hz}, 1 \mathrm{H}), 7.24(\mathrm{~s}, 1 \mathrm{H}), 7.16(\mathrm{~d}, J=$ $8.0 \mathrm{~Hz}, 1 \mathrm{H}), 6.81(\mathrm{~d}, J=15.5 \mathrm{~Hz}, 1 \mathrm{H}), 6.66(\mathrm{dd}, J=15.5,11.0 \mathrm{~Hz}, 1 \mathrm{H}), 6.38(\mathrm{~d}, J=8.0 \mathrm{~Hz}, 1 \mathrm{H}), 5.85$ (d, $J=15.5 \mathrm{~Hz}, 1 \mathrm{H}$ ), 4.21 (q, $J=7.2 \mathrm{~Hz}, 2 \mathrm{H}$ ), 3.39 (t, $J=8.0 \mathrm{~Hz}, 2 \mathrm{H}), 2.97(\mathrm{t}, J=8.0 \mathrm{~Hz}, 2 \mathrm{H}), 2.79$ (s, $3 \mathrm{H}), 1.31(\mathrm{t}, J=7.0 \mathrm{~Hz}, 3 \mathrm{H}) \mathrm{ppm} ;{ }^{13} \mathrm{C} \mathrm{NMR}\left(125 \mathrm{MHz}, \mathrm{CDCl}_{3}\right) \delta 167.8,154.5,146.0,141.8,131.0$, 128.9, 125.9, 122.7, 121.6, 118.2, 106.4, 60.2, 55.7, 35.4, 28.3, 14.5 ppm; HRMS (ESI+) calcd for $\mathrm{C}_{16} \mathrm{H}_{20} \mathrm{NO}_{2}[\mathrm{M}+\mathrm{H}]^{+}: 258.1494$, found: $\mathrm{m} / \mathrm{z} 258.1484$. 


\section{Compound $\mathbf{7 b}$}

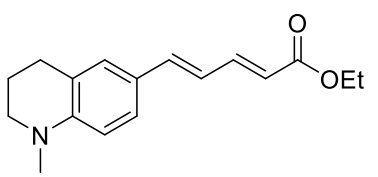

7b was synthesized in the same manner as described for the preparation of

$7 \mathrm{a}$; yield $48 \%$, a yellow oil. ${ }^{1} \mathrm{H}$ NMR $\left(500 \mathrm{MHz}, \mathrm{CDCl}_{3}\right) \delta 7.43(\mathrm{dd}, J=15.0$, $11.0 \mathrm{~Hz}, 1 \mathrm{H}), 7.18(\mathrm{dd}, J=8.0,2.0 \mathrm{~Hz}, 1 \mathrm{H}), 7.09(\mathrm{~s}, 1 \mathrm{H}), 6.78(\mathrm{~d}, J=15.0$ $\mathrm{Hz}, 1 \mathrm{H}), 6.66(\mathrm{dd}, J=15.0,11.0 \mathrm{~Hz}, 1 \mathrm{H}), 6.51(\mathrm{~d}, J=8.0 \mathrm{~Hz}, 1 \mathrm{H}), 5.85(\mathrm{~d}, J=15.0 \mathrm{~Hz}, 1 \mathrm{H}), 4.21$ (q, $J=7.2 \mathrm{~Hz}, 2 \mathrm{H}$ ), $3.28(\mathrm{t}, J=5.8 \mathrm{~Hz}, 2 \mathrm{H}$ ), $2.92(\mathrm{~s}, 3 \mathrm{H}), 2.75(\mathrm{t}, J=6.5 \mathrm{~Hz}, 2 \mathrm{H}$ ), 1.97 (quint, $J=6.1 \mathrm{~Hz}$, $2 \mathrm{H}), 1.30(\mathrm{t}, J=7.2 \mathrm{~Hz}, 3 \mathrm{H}) \mathrm{ppm} ;{ }^{13} \mathrm{C} \mathrm{NMR}\left(125 \mathrm{MHz}, \mathrm{CDCl}_{3}\right) \delta 167.8,147.6,146.1,141.6,127.8$, 127.4, 123.9, 122.7, 121.4, 117.8, 110.6, 60.2, 51.3, 39.0, 27.9, 22.2, 14.5 ppm; HRMS (ESI+) calcd for $\mathrm{C}_{17} \mathrm{H}_{22} \mathrm{NO}_{2}[\mathrm{M}+\mathrm{H}]^{+}: 272.1651$, found: $\mathrm{m} / \mathrm{z} 272.1638$.

Compound 7c

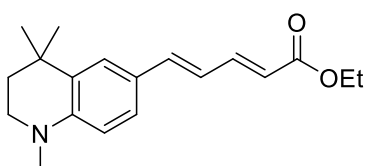

7c was synthesized in the same manner as described for the preparation of $7 \mathrm{a}$; yield $66 \%$, a yellow oil. ${ }^{1} \mathrm{H}$ NMR $\left(500 \mathrm{MHz}, \mathrm{CDCl}_{3}\right) \delta 7.44(\mathrm{dd}, J=15.0$, $11.0 \mathrm{~Hz}, 1 \mathrm{H}), 7.29(\mathrm{~d}, J=2.0 \mathrm{~Hz}, 1 \mathrm{H}), 7.20(\mathrm{dd}, J=8.5,2.5 \mathrm{~Hz}, 1 \mathrm{H}), 6.81(\mathrm{~d}$, $J=15.0 \mathrm{~Hz}, 1 \mathrm{H}), 6.67(\mathrm{dd}, J=15.0,11.0 \mathrm{~Hz}, 1 \mathrm{H}), 6.52(\mathrm{~d}, J=8.5 \mathrm{~Hz}, 1 \mathrm{H}), 5.86(\mathrm{~d}, J=15.0,1 \mathrm{H}), 4.21$ (q, J = 7.2 Hz, 2H), $3.30(\mathrm{t}, J=6.0 \mathrm{~Hz}, 2 \mathrm{H}), 2.95(\mathrm{~s}, 3 \mathrm{H}), 1.75(\mathrm{t}, J=6.0 \mathrm{~Hz}, 2 \mathrm{H}), 1.32-1.27(\mathrm{~m}, 9 \mathrm{H})$ ppm; ${ }^{13} \mathrm{C}$ NMR $\left(125 \mathrm{MHz}, \mathrm{CDCl}_{3}\right) \delta 167.8,146.4,146.2,142.0,131.4,126.8,125.1,123.8,121.2$, $117.8,110.8,60.2,47.7,39.2,36.9,32.1,30.6,14.5$ ppm; HRMS (ESI+) calcd for $\mathrm{C}_{19} \mathrm{H}_{26} \mathrm{NO}_{2}$ $[\mathrm{M}+\mathrm{H}]^{+}: 300.1964$, found: $m / z 300.1960$.

\section{Compound 7d}

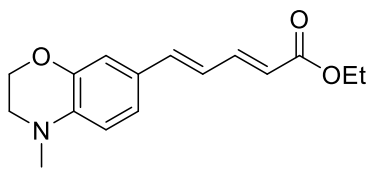

7d was synthesized in the same manner as described for the preparation of $7 \mathrm{a}$; yield $74 \%$, a yellow oil. ${ }^{1} \mathrm{H}$ NMR $\left(500 \mathrm{MHz} \mathrm{CDCl}_{3}\right) \delta 7.42(\mathrm{dd}, J=15.0$, $11.0 \mathrm{~Hz}, 1 \mathrm{H}), 6.95(\mathrm{dd}, J=8.0,2.0 \mathrm{~Hz}, 1 \mathrm{H}), 6.92(\mathrm{~d}, J=2.0 \mathrm{~Hz}, 1 \mathrm{H}), 6.77(\mathrm{~d}$, $J=15.5 \mathrm{~Hz}, 1 \mathrm{H}), 6.66(\mathrm{dd}, J=15.0,11.0 \mathrm{~Hz}, 1 \mathrm{H}), 6.60(\mathrm{~d}, J=8.5 \mathrm{~Hz}, 1 \mathrm{H}), 5.88(\mathrm{~d}, J=15.0,1 \mathrm{H}), 4.28$ (t, $J=4.5 \mathrm{~Hz}, 2 \mathrm{H}$ ), 4.21 (q, $J=7.0 \mathrm{~Hz}, 2 \mathrm{H}), 3.32(\mathrm{t}, J=4.5 \mathrm{~Hz}, 2 \mathrm{H}), 2.93(\mathrm{~s}, 3 \mathrm{H}), 1.30$ (t, $J=7.3 \mathrm{~Hz}$, $3 \mathrm{H}) \mathrm{ppm} ;{ }^{13} \mathrm{C} \mathrm{NMR}\left(125 \mathrm{MHz}, \mathrm{CDCl}_{3}\right) \delta 167.6,145.6,144.1,141.0,137.8,126.2,122.8,122.2,118.9$, 113.9, 111.9, 64.7, 60.2, 49.1, 38.6, 14.5 ppm; HRMS (ESI+) calcd for $\mathrm{C}_{16} \mathrm{H}_{20} \mathrm{NO}_{3}[\mathrm{M}+\mathrm{H}]^{+}: 274.1443$, found: $m / z 274.1438$.

\section{Compound $7 e$}

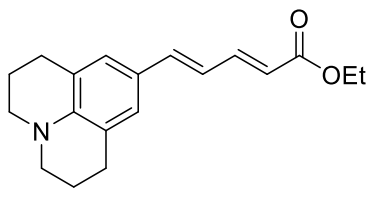

7e was synthesized in the same manner as described for the preparation of $7 a$; yield $66 \%$, an orange solid. ${ }^{1} \mathrm{H}$ NMR $\left(500 \mathrm{MHz}^{\left.-\mathrm{CDCl}_{3}\right)} \delta 7.42(\mathrm{dd}, \mathrm{J}=\right.$ 15.0, $10.5 \mathrm{~Hz}, 1 \mathrm{H}), 6.92(\mathrm{~s}, 2 \mathrm{H}), 6.73$ (d, $J=15.0 \mathrm{~Hz}, 1 \mathrm{H}), 6.62$ (dd, $J=15.0$, $10.5 \mathrm{~Hz}, 1 \mathrm{H}), 5.82(\mathrm{~d}, J=15.0,1 \mathrm{H}), 4.20(\mathrm{q}, J=7.0 \mathrm{~Hz}, 2 \mathrm{H}), 3.20(\mathrm{t}, J=5.6$ 
$\mathrm{Hz}, 4 \mathrm{H}), 2.73(\mathrm{t}, J=6.3 \mathrm{~Hz}, 4 \mathrm{H}), 1.98-1.93(\mathrm{~m}, 4 \mathrm{H}), 1.30(\mathrm{t}, J=7.0 \mathrm{~Hz}, 3 \mathrm{H}) \mathrm{ppm} ;{ }^{13} \mathrm{C}$ NMR $(125 \mathrm{MHz}$, $\left.\mathrm{CDCl}_{3}\right) \delta 167.9,146.3,144.0,141.8,126.6,123.3,121.3,121.0,117.5,60.1,50.1,27.8,21.9,14.5$ ppm; HRMS (ESI+) calcd for $\mathrm{C}_{19} \mathrm{H}_{24} \mathrm{NO}_{2}[\mathrm{M}+\mathrm{H}]^{+}: 298.1807$, found: $m / z$ 298.1794.

Compound $7 f$

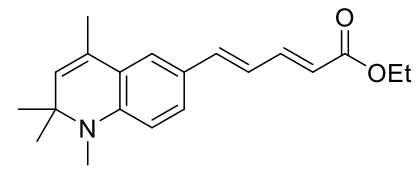

7f was synthesized in the same manner as described for the preparation of $7 \mathrm{a}$; yield $36 \%$, a yellow oil. ${ }^{1} \mathrm{H}$ NMR $\left(500 \mathrm{MHz}, \mathrm{CDCl}_{3}\right) \delta 7.44$ (dd, $J=$ 15.0, $11.0 \mathrm{~Hz}, 1 \mathrm{H}), 7.22$ (dd, $J=8.5,2.0 \mathrm{~Hz}, 1 \mathrm{H}), 7.15(\mathrm{~d}, J=2.0 \mathrm{~Hz}, 1 \mathrm{H})$, $6.81(\mathrm{~d}, J=15.5,1 \mathrm{H}), 6.68(\mathrm{dd}, J=15.0,11.0 \mathrm{~Hz}, 1 \mathrm{H}), 6.47(\mathrm{~d}, J=8.5 \mathrm{~Hz}, 1 \mathrm{H}), 5.87(\mathrm{~d}, J=15.0 \mathrm{~Hz}$, $1 \mathrm{H}), 5.31(\mathrm{~d}, J=1.5 \mathrm{~Hz}, 1 \mathrm{H}), 4.21(\mathrm{q}, J=7.2 \mathrm{~Hz}, 2 \mathrm{H}), 2.84(\mathrm{~s}, 3 \mathrm{H}), 2.01(\mathrm{~d}, J=1.5 \mathrm{~Hz}, 3 \mathrm{H}), 1.32(\mathrm{~s}$, $6 \mathrm{H}), 1.31(\mathrm{t}, J=7.0 \mathrm{~Hz}, 3 \mathrm{H}) \mathrm{ppm} ;{ }^{13} \mathrm{C} \mathrm{NMR}\left(125 \mathrm{MHz}, \mathrm{CDCl}_{3}\right) \delta 167.8,146.4,146.0,141.6,130.3$, 128.8 , 127.7, 124.0, 122.9, 122.3, 121.6, 118.1, 110.5, 60.2, 56.9, 31.0, 28.0, 18.8, 14.5 ppm; HRMS $(\mathrm{ESI}+)$ calcd for $\mathrm{C}_{20} \mathrm{H}_{26} \mathrm{NO}_{2}[\mathrm{M}+\mathrm{H}]^{+}: 312.1964$, found: $\mathrm{m} / \mathrm{z} 312.1955$.

\section{Compound 8a}

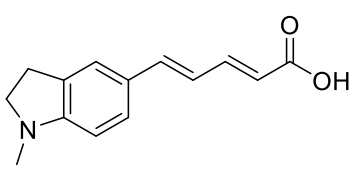

To a solution of $7 \mathrm{a}(499 \mathrm{mg}, 1.94 \mathrm{mmol})$ in iso-PrOH $(15.6 \mathrm{~mL})$ was added 1 $\mathrm{M} \mathrm{NaOH}$ aqueous solution $(3.9 \mathrm{~mL})$, and the mixture was stirred at reflux temperature for $8 \mathrm{~h}$. After cooling to room temperature, iso-PrOH was removed under reduced pressure. The residue was acidified with $1 \mathrm{~N} \mathrm{HCl}$ aqueous solution, and extracted with $\mathrm{CHCl}_{3}(3 \times 50 \mathrm{~mL})$. The combined organic layer was washed with brine, dried over $\mathrm{Na}_{2} \mathrm{SO}_{4}$ and filtered. The filtrate was concentrated under reduced pressure to afford $8 \mathrm{a}(445 \mathrm{mg}, 93 \%)$ as a yellow-brown solid. This crude product was used for the next reaction without further purification. ${ }^{1} \mathrm{H}$ NMR (500 MHz, DMSO-d6) $\delta 7.23(\mathrm{~s}, 1 \mathrm{H}), 7.10(\mathrm{~d}, J=8.0 \mathrm{~Hz}, 1 \mathrm{H}), 6.84(\mathrm{dd}, J=15.0,11.0 \mathrm{~Hz}$, $1 \mathrm{H}), 6.66(\mathrm{dd}, J=15.5,11.0 \mathrm{~Hz}, 1 \mathrm{H}), 6.55(\mathrm{~d}, J=15.5 \mathrm{~Hz}, 1 \mathrm{H}), 6.43(\mathrm{~d}, J=8.0 \mathrm{~Hz}, 1 \mathrm{H}), 5.79(\mathrm{~d}, J=$ $15.0 \mathrm{~Hz}, 1 \mathrm{H}), 3.28(\mathrm{t}, J=8.0 \mathrm{~Hz}, 2 \mathrm{H}), 2.87(\mathrm{t}, J=8.0 \mathrm{~Hz}, 2 \mathrm{H}), 2.71(\mathrm{~s}, 3 \mathrm{H}) \mathrm{ppm} ;{ }^{13} \mathrm{C} \mathrm{NMR}(125 \mathrm{MHz}$, DMSO-d $) \delta 167.9,154.2,145.6,141.4,130.1,128.7,125.2,122.5,121.2,118.6,106.2,55.0,34.9$, 27.6 ppm; HRMS (ESI+) calcd for $\mathrm{C}_{14} \mathrm{H}_{16} \mathrm{NO}_{2}[\mathrm{M}+\mathrm{H}]^{+}: 230.1181$, found: $\mathrm{m} / \mathrm{z} 230.1180$.

\section{Compound $\mathbf{8 b}$}

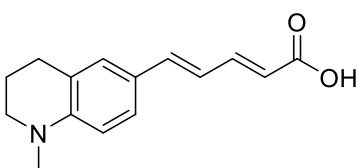

$\mathbf{8 b}$ was synthesized in the same manner as described for the preparation of 8a; yield $100 \%$, a yellow solid. ${ }^{1} \mathrm{H}$ NMR $\left(500 \mathrm{MHz}, \mathrm{DMSO}-\mathrm{d}_{6}\right) \delta 12.00(\mathrm{br}$, $1 \mathrm{H}), 7.29$ (dd, $J=15.0,11.0 \mathrm{~Hz}, 1 \mathrm{H}), 7.19(\mathrm{dd}, J=8.5,2.0 \mathrm{~Hz}, 1 \mathrm{H}), 7.12$ (s, $1 \mathrm{H}), 6.85(\mathrm{~d}, J=15.0 \mathrm{~Hz}, 1 \mathrm{H}), 6.78(\mathrm{dd}, J=15.5,10.5 \mathrm{~Hz}, 1 \mathrm{H}), 6.54(\mathrm{~d}, J=8.5 \mathrm{~Hz}, 1 \mathrm{H}), 5.81(\mathrm{~d}, J=$ $15.0 \mathrm{~Hz}, 1 \mathrm{H}$ ), $3.25(\mathrm{t}, J=5.5 \mathrm{~Hz}, 2 \mathrm{H}), 2.87(\mathrm{~s}, 3 \mathrm{H}), 2.68(\mathrm{t}, J=6.3 \mathrm{~Hz}, 2 \mathrm{H}), 1.86$ (quint, $J=6.0 \mathrm{~Hz}, 2 \mathrm{H}$ ) ppm; ${ }^{13} \mathrm{C}$ NMR (125 MHz, DMSO-d 6 ) $\delta$ 168.0, 147.3, 145.6, 141.2, 127.5, 127.3, 123.3, 122.2, 121.0, 
118.3, 110.4, 50.4, 38.5, 27.2, 21.6 ppm; HRMS $\left(E S I^{+}\right)$calcd for $\mathrm{C}_{15} \mathrm{H}_{18} \mathrm{NO}_{2}[\mathrm{M}+\mathrm{H}]^{+}: 244.1338$, found: $\mathrm{m} / \mathrm{z} 244.1330$.

Compound 8c

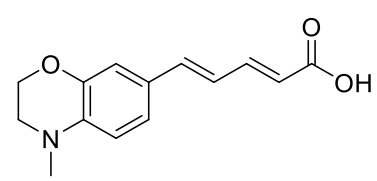

8c was synthesized in the same manner as described for the preparation of 8a; yield $100 \%$, a yellow solid. ${ }^{1} \mathrm{H}$ NMR $\left(500 \mathrm{MHz}, \mathrm{DMSO}-\mathrm{d}_{6}\right) \delta 12.00(\mathrm{br}, 1 \mathrm{H})$, $7.34(\mathrm{~d}, J=2.0 \mathrm{~Hz}, 1 \mathrm{H}), 7.29(\mathrm{dd}, J=15.0,10.5 \mathrm{~Hz}, 1 \mathrm{H}), 7.21(\mathrm{dd}, J=8.5$, $2.0 \mathrm{~Hz}, 1 \mathrm{H}), 6.89(\mathrm{~d}, J=15.5 \mathrm{~Hz}, 1 \mathrm{H}), 6.82(\mathrm{dd}, J=15.0,10.5 \mathrm{~Hz}, 1 \mathrm{H}), 6.54$ $(\mathrm{d}, J=9.0 \mathrm{~Hz}, 1 \mathrm{H}), 5.83(\mathrm{~d}, J=15.0 \mathrm{~Hz}, 1 \mathrm{H}), 3.26(\mathrm{t}, J=6.0 \mathrm{~Hz}, 2 \mathrm{H}), 2.90(\mathrm{~s}, 3 \mathrm{H}), 1.68(\mathrm{t}, J=6.0 \mathrm{~Hz}$, 2H), 1.24 (s, 6H) ppm; ${ }^{13} \mathrm{C}$ NMR (125 MHz, DMSO-d6) $\delta 168.0,146.1,145.7,141.5,130.8,126.7$, $124.9,123.3,120.9,118.3,110.7,46.8,38.8,36.3,31.6,30.4$ ppm; HRMS (ESI+) calcd for $\mathrm{C}_{17} \mathrm{H}_{22} \mathrm{NO}_{2}$ $[\mathrm{M}+\mathrm{H}]^{+}: 272.1651$, found: $m / z 272.1644$.

Compound 8d

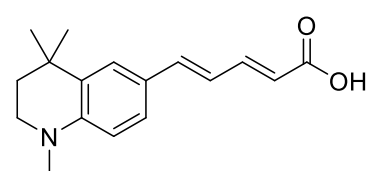

$\mathbf{8 d}$ was synthesized in the same manner as described for the preparation of

8a; yield 96\%, a brown solid. ${ }^{1} \mathrm{H}$ NMR (500 MHz, DMSO-d 6$) \delta 12.07(\mathrm{br}, 1 \mathrm{H})$, $7.28(\mathrm{dd}, J=15.0,9.5 \mathrm{~Hz}, 1 \mathrm{H}), 6.97(\mathrm{dd}, J=8.0,2.0 \mathrm{~Hz}, 1 \mathrm{H}), 6.91$ (d, $J=1.5$ $\mathrm{Hz}, 1 \mathrm{H}), 6.87-6.79(\mathrm{~m}, 2 \mathrm{H}), 6.66(\mathrm{~d}, J=8.5 \mathrm{~Hz}, 1 \mathrm{H}), 5.85(\mathrm{~d}, J=15.0 \mathrm{~Hz}, 1 \mathrm{H}), 4.20(\mathrm{t}, J=4.5 \mathrm{~Hz}, 2 \mathrm{H})$,

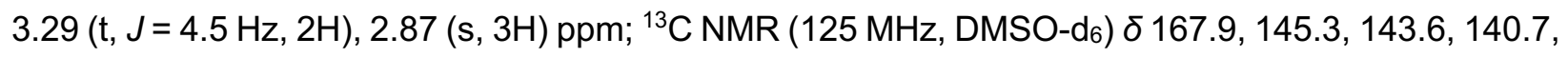
$137.8,125.3,122.4,122.1,119.3,113.3,111.9,64.2,48.2,38.0$ ppm; HRMS (ESI+) calcd for $\mathrm{C}_{14} \mathrm{H}_{16} \mathrm{NO}_{3}[\mathrm{M}+\mathrm{H}]^{+}: 246.1130$, found: $\mathrm{m} / \mathrm{z} 246.1125$.

\section{Compound 8e}

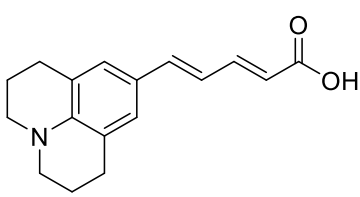

$\mathbf{8 e}$ was synthesized in the same manner as described for the preparation of 8a; yield $84 \%$, a deep red solid. ${ }^{1} \mathrm{H}$ NMR (500 MHz, DMSO-d 6$) \delta 11.90(\mathrm{br}$, $1 \mathrm{H}$ ), 7.27 (dd, $J=15.0,10.5 \mathrm{~Hz}, 1 \mathrm{H}), 6.93(\mathrm{~s}, 2 \mathrm{H}), 6.76$ (d, $J=7.5 \mathrm{~Hz}, 1 \mathrm{H}$ ), $6.72(\mathrm{dd}, J=15.0,10.5 \mathrm{~Hz}, 1 \mathrm{H}), 5.78(\mathrm{~d}, J=15.0,1 \mathrm{H}), 3.17(\mathrm{t}, J=5.5 \mathrm{~Hz}$, 4H), $2.66(\mathrm{t}, J=6.3 \mathrm{~Hz}, 4 \mathrm{H}), 1.88-1.83(\mathrm{~m}, 4 \mathrm{H}) \mathrm{ppm} ;{ }^{13} \mathrm{C}$ NMR (125 MHz, DMSO-d 6$) \delta$ 168.0, 145.7, 143.6, 141.4, 126.3, 122.5, 120.6, 120.6, 117.9, 49.2, 27.1, 21.2 ppm; HRMS (ESI+) calcd for $\mathrm{C}_{17} \mathrm{H}_{20} \mathrm{NO}_{2}[\mathrm{M}+\mathrm{H}]^{+}: 270.1494$, found: $\mathrm{m} / \mathrm{z} 270.1483$.

Compound $8 \mathbf{f}$<smiles>CC1=CC(C)(C)N(C)c2ccc(/C=C/C=C/C(=O)O)cc21</smiles>

$8 \mathrm{f}$ was synthesized in the same manner as described for the preparation of 8a; yield $100 \%$, a yellow solid. ${ }^{1} \mathrm{H}$ NMR $\left(500 \mathrm{MHz}, \mathrm{CDCl}_{3}\right) \delta 7.54(\mathrm{dd}, J=$ 15.0,11.0 Hz, 1H), 7.24 (dd, $J=8.5,2.0 \mathrm{~Hz}, 1 \mathrm{H}), 7.16$ (d, $J=2.5 \mathrm{~Hz}, 1 \mathrm{H}$ ), 
$6.86(\mathrm{~d}, J=15.0 \mathrm{~Hz}, 1 \mathrm{H}), 6.71(\mathrm{dd}, J=15.5,11.0 \mathrm{~Hz}, 1 \mathrm{H}), 6.48(\mathrm{~d}, J=8.5 \mathrm{~Hz}, 1 \mathrm{H}), 5.88(\mathrm{~d}, J=15.0$ $\mathrm{Hz}, 1 \mathrm{H}), 5.32$ (d, J = $1.0 \mathrm{~Hz}, 1 \mathrm{H}), 2.85(\mathrm{~s}, 3 \mathrm{H}), 2.02$ (d, J = $1.0 \mathrm{~Hz}, 3 \mathrm{H}), 1.33(\mathrm{~s}, 6 \mathrm{H}) \mathrm{ppm} ;{ }^{13} \mathrm{C}$ NMR $\left(125 \mathrm{MHz}, \mathrm{CDCl}_{3}\right) \delta 172.9,148.4,146.6,142.9,130.3,129.2,127.6,123.8,122.9,122.5,121.3,116.9$, 110.5, 57.0, 31.0, 28.1, 18.8 ppm; HRMS (ESI+) calcd for $\mathrm{C}_{18} \mathrm{H}_{22} \mathrm{NO}_{2}[\mathrm{M}+\mathrm{H}]^{+}: 284.1651$, found: $\mathrm{m} / \mathrm{z}$ 284.1655 .

\section{Compound 9a}

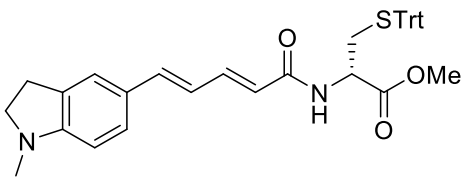

To a solution of $8 \mathrm{a}(304 \mathrm{mg}, 1.33 \mathrm{mmol}$ ) and D-Cys(Trt)-OMe hydrochloric acid (658 mg, $1.59 \mathrm{mmol}, 1.2 \mathrm{eq}$.) in anhydrous DMF (13.3 $\mathrm{mL}$ ) were added DMT-MM (442 mg, $1.60 \mathrm{mmol}, 1.2$ eq.) and TEA (0.22 $\mathrm{mL}, 1.58 \mathrm{mmol}, 1.2$ eq.), and the mixture was stirred at $0{ }^{\circ} \mathrm{C}$ for $3 \mathrm{~h}$. The reaction was diluted with water (ca. $20 \mathrm{~mL}$ ) at $0{ }^{\circ} \mathrm{C}$ and then extracted with EtOAc $(3 \times 100 \mathrm{~mL})$. The combined organic layer was washed with brine, dried over $\mathrm{Na}_{2} \mathrm{SO}_{4}$ and filtered. The crude material was purified by silica gel column chromatography (30-50\% ethyl acetate/n-hexane) to afford 9 a $(477 \mathrm{mg}, 61 \%)$ as a yellow solid. ${ }^{1} \mathrm{H}$ $\operatorname{NMR}\left(500 \mathrm{MHz}, \mathrm{CDCl}_{3}\right) \delta$ 7.39-7.16 (m, 17H), $6.80(\mathrm{~d}, J=15.0,1 \mathrm{H}), 6.65(\mathrm{dd}, J=15.5,11.0 \mathrm{~Hz}, 1 \mathrm{H})$, $6.39(\mathrm{~d}, J=8.0 \mathrm{~Hz}, 1 \mathrm{H}), 5.96(\mathrm{~d}, J=7.5 \mathrm{~Hz}, 1 \mathrm{H}), 5.81(\mathrm{~d}, J=14.5,1 \mathrm{H}), 4.76-4.73(\mathrm{~m}, 1 \mathrm{H}), 3.72(\mathrm{~s}$, $3 \mathrm{H}), 3.39(\mathrm{t}, J=8.5 \mathrm{~Hz}, 2 \mathrm{H}), 2.97(\mathrm{t}, J=8.5 \mathrm{~Hz}, 2 \mathrm{H}), 2.79(\mathrm{~s}, 3 \mathrm{H}), 2.73-2.66(\mathrm{~m}, 2 \mathrm{H}) \mathrm{ppm} ;{ }^{13} \mathrm{C}$ NMR $\left(125 \mathrm{MHz}, \mathrm{CDCl}_{3}\right) \delta 171.3,166.1,154.3,144.4,143.2,141.1,131.0,129.6,128.6,128.1,127.0,126.1$, 122.6, 121.6, 120.1, 106.4, 67.0, 55.8, 52.8, 51.2, 35.5, 34.2, 28.4 ppm; HRMS (ESI+) calcd for $\mathrm{C}_{37} \mathrm{H}_{37} \mathrm{~N}_{2} \mathrm{O}_{3} \mathrm{~S}[\mathrm{M}+\mathrm{H}]^{+}: 589.2525$, found: $\mathrm{m} / \mathrm{z} 589.2528$.

\section{Compound 9b}

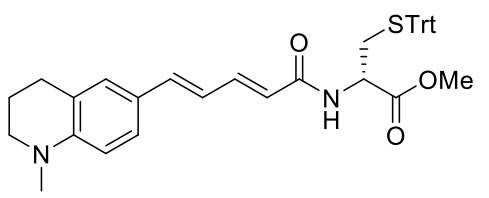

9b was synthesized in the same manner as described for the preparation of 9 a; yield $97 \%$, a yellow solid. ${ }^{1} \mathrm{H} \mathrm{NMR}\left(500 \mathrm{MHz}, \mathrm{CDCl}_{3}\right)$ $\delta 7.39-7.18(\mathrm{~m}, 16 \mathrm{H}), 7.09(\mathrm{~s}, 1 \mathrm{H}), 6.76(\mathrm{~d}, J=15.5,1 \mathrm{H}), 6.64$ (dd, $J$ $=15.5,11.0 \mathrm{~Hz}, 1 \mathrm{H}), 6.52(\mathrm{~d}, J=8.5 \mathrm{~Hz}, 1 \mathrm{H}), 5.95(\mathrm{~d}, J=8.0 \mathrm{~Hz}, 1 \mathrm{H})$, $5.80(\mathrm{~d}, J=15.0,1 \mathrm{H}), 4.76-4.73(\mathrm{~m} .1 \mathrm{H}), 3.71(\mathrm{~s}, 3 \mathrm{H}), 3.28(\mathrm{t}, J=5.7 \mathrm{~Hz}, 2 \mathrm{H}), 2.93(\mathrm{~s}, 3 \mathrm{H}), 2.76(\mathrm{t}, J$ $=6.4 \mathrm{~Hz}, 2 \mathrm{H}$ ), 2.73-2.66 (m, 2H), 1.97 (quint, $J=6.4 \mathrm{~Hz}, 2 \mathrm{H}) \mathrm{ppm} ;{ }^{13} \mathrm{C} \mathrm{NMR}\left(125 \mathrm{MHz}, \mathrm{CDCl}_{3}\right) \delta$ 171.3, 166.1, 147.5, 144.5, 143.3, 141.0, 129.6, 128.1, 127.7, 127.2, 127.0, 124.2, 122.7, 121.4, 119.8, 110.6, 67.0, 52.8, 51.3, 51.2, 39.0, 34.3, 27.9, 22.3 ppm; HRMS (ESI+) calcd for $\mathrm{C}_{38} \mathrm{H}_{39} \mathrm{~N}_{2} \mathrm{O}_{3} \mathrm{~S}$ $[\mathrm{M}+\mathrm{H}]^{+}: 603.2681$, found: $m / z$ 603.2675. 
Compound 9c

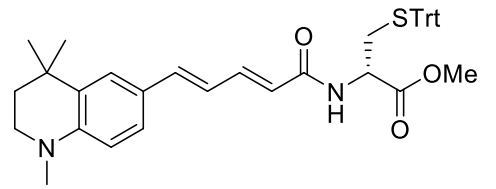

9c was synthesized in the same manner as described for the preparation of $9 \mathbf{a}$; yield $84 \%$, a yellow solid. ${ }^{1} \mathrm{H} \mathrm{NMR}\left(500 \mathrm{MHz}, \mathrm{CDCl}_{3}\right)$ $\delta 7.39-7.20(\mathrm{~m}, 17 \mathrm{H}), 6.80(\mathrm{~d}, J=15.5,1 \mathrm{H}), 6.66(\mathrm{dd}, J=15.0,11.0$ $\mathrm{Hz}, 1 \mathrm{H}), 6.53(\mathrm{~d}, J=8.5 \mathrm{~Hz}, 1 \mathrm{H}), 5.97(\mathrm{~d}, J=8.0 \mathrm{~Hz}, 1 \mathrm{H}), 5.82(\mathrm{~d}, J=14.5,1 \mathrm{H}), 4.77-4.73(\mathrm{~m} .1 \mathrm{H})$, $3.72(\mathrm{~s}, 3 \mathrm{H}), 3.30(\mathrm{t}, J=6.0 \mathrm{~Hz}, 2 \mathrm{H}), 2.95(\mathrm{~s}, 3 \mathrm{H}), 2.73-2.66(\mathrm{~m}, 2 \mathrm{H}), 1.76(\mathrm{t}, J=6.0 \mathrm{~Hz}, 2 \mathrm{H}), 1.30(\mathrm{~s}$, $6 \mathrm{H}) \mathrm{ppm} ;{ }^{13} \mathrm{C}$ NMR $\left(125 \mathrm{MHz}, \mathrm{CDCl}_{3}\right) \delta 171.3,166.1,146.2,144.5,143.3,141.3,131.4,129.6,128.1$, 127.0, 126.5, 125.1, 124.0, 121.2, 119.7, 110.9, 67.0, 52.8, 51.2, 47.7, 39.3, 36.9, 34.3, 32.1, 30.6 ppm; HRMS (ESI+) calcd for $\mathrm{C}_{40} \mathrm{H}_{43} \mathrm{~N}_{2} \mathrm{O}_{3} \mathrm{~S}[\mathrm{M}+\mathrm{H}]^{+}: 631.2994$, found: $m / z$ 631.2981.

Compound 9d

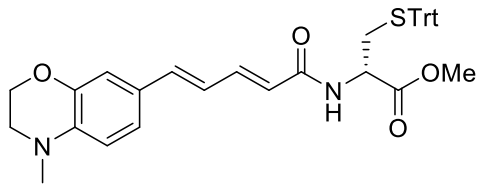

9d was synthesized in the same manner as described for the preparation of $9 \mathrm{a}$; yield $79 \%$, a yellow solid. ${ }^{1} \mathrm{H} \mathrm{NMR}\left(500 \mathrm{MHz}, \mathrm{CDCl}_{3}\right)$ $\delta 7.39-7.20(\mathrm{~m}, 16 \mathrm{H}), 6.93(\mathrm{~s}, 1 \mathrm{H}), 6.75(\mathrm{~d}, J=15.5,1 \mathrm{H}), 6.65(\mathrm{dd}, J$ $=15.0,10.5 \mathrm{~Hz}, 1 \mathrm{H}), 6.60(\mathrm{~d}, J=8.0 \mathrm{~Hz}, 1 \mathrm{H}), 5.95(\mathrm{~d}, J=7.5 \mathrm{~Hz}, 1 \mathrm{H}), 5.82(\mathrm{~d}, J=14.5,1 \mathrm{H}), 4.75-$ $4.72(\mathrm{~m} .1 \mathrm{H}), 4.28(\mathrm{t}, J=4.5 \mathrm{~Hz}, 2 \mathrm{H}), 3.71(\mathrm{~s}, 3 \mathrm{H}), 3.31(\mathrm{t}, J=4.5 \mathrm{~Hz}, 2 \mathrm{H}), 2.92(\mathrm{~s}, 3 \mathrm{H}), 2.73-2.66(\mathrm{~m}$, 2H) ppm; ${ }^{13} \mathrm{C} \mathrm{NMR}\left(125 \mathrm{MHz}, \mathrm{CDCl}_{3}\right) \delta 171.2,165.9,144.5,144.2,142.8,140.3,137.6,129.6,128.1$, 127.0, 126.4, 122.8, 122.1, 120.8, 113.8, 112.0, 67.0, 64.7, 52.8, 51.2, 49.1, 38.6, 34.2 ppm; HRMS $\left(\mathrm{ESI}+\right.$ ) calcd for $\mathrm{C}_{22} \mathrm{H}_{27} \mathrm{~N}_{2} \mathrm{O}_{2} \mathrm{~S}[\mathrm{M}+\mathrm{H}]^{+}: 605.2474$, found: $\mathrm{m} / \mathrm{z} 605.2495$.

Compound $9 e$

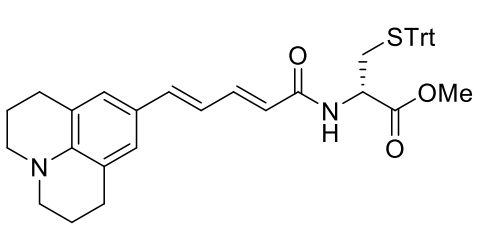

9e was synthesized in the same manner as described for the preparation of 9 a; yield $89 \%$, a yellow solid. ${ }^{1} \mathrm{H} \mathrm{NMR}\left(500 \mathrm{MHz}, \mathrm{CDCl}_{3}\right)$ $\delta 7.38-7.18(\mathrm{~m}, 15 \mathrm{H}), 6.90(\mathrm{~s}, 2 \mathrm{H}), 6.70(\mathrm{~d}, J=15.0,1 \mathrm{H}), 6.59$ (dd, $J$ $=15.5,11.0 \mathrm{~Hz}, 1 \mathrm{H}), 5.91(\mathrm{~d}, J=8.0 \mathrm{~Hz}, 1 \mathrm{H}), 5.76(\mathrm{~d}, J=15.0 \mathrm{~Hz}$, $1 \mathrm{H}), 4.75-4.71(\mathrm{~m} .1 \mathrm{H}), 3.70(\mathrm{~s}, 3 \mathrm{H}), 3.18(\mathrm{t}, J=5.8 \mathrm{~Hz}, 4 \mathrm{H}), 2.72(\mathrm{t}, J=6.3 \mathrm{~Hz}, 4 \mathrm{H}), 2.70-2.64(\mathrm{~m}$, 2H), 1.94 (quint, $J=6.1 \mathrm{~Hz}, 4 \mathrm{H}$ ) ppm; ${ }^{13} \mathrm{C} \mathrm{NMR}\left(125 \mathrm{MHz}, \mathrm{CDCl}_{3}\right) \delta 171.3,166.2,144.5,143.9,143.4$, 141.2, 129.7, 128.2, 127.0, 126.4, 123.5, 121.3, 121.0, 119.5, 67.1, 52.7, 51.2, 50.1, 34.3, 27.8, 22.0 ppm; HRMS (ESI+) calcd for $\mathrm{C}_{40} \mathrm{H}_{41} \mathrm{~N}_{2} \mathrm{O}_{3} \mathrm{~S}[\mathrm{M}+\mathrm{H}]^{+}: 629.2838$, found: $\mathrm{m} / \mathrm{z}$ 629.2822.

Compound $9 f$

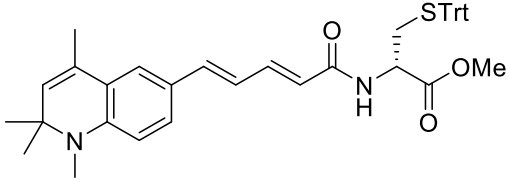

9f was synthesized in the same manner as described for the preparation of $9 \mathrm{a}$; yield $71 \%$, a yellow solid. ${ }^{1} \mathrm{H}$ NMR $(500 \mathrm{MHz}$, $\left.\mathrm{CDCl}_{3}\right) \delta 7.39-7.20(\mathrm{~m}, 16 \mathrm{H}), 7.15(\mathrm{~d}, J=2.0,1 \mathrm{H}), 6.80(\mathrm{~d}, J=15.5$ $\mathrm{Hz}, 1 \mathrm{H}), 6.67(\mathrm{dd}, J=15.5,11.0 \mathrm{~Hz}, 1 \mathrm{H}), 6.48(\mathrm{~d}, J=8.5 \mathrm{~Hz}, 1 \mathrm{H}), 5.97(\mathrm{~d}, J=7.5,1 \mathrm{H}), 5.83(\mathrm{~d}, J=$ 
$15.0 \mathrm{~Hz}, 1 \mathrm{H}), 5.32(\mathrm{~d}, J=1.5 \mathrm{~Hz}, 1 \mathrm{H}), 4.77-4.73(\mathrm{~m} .1 \mathrm{H}), 3.72(\mathrm{~s}, 3 \mathrm{H}), 2.84(\mathrm{~s}, 3 \mathrm{H}), 2.73-2.67(\mathrm{~m}, 2 \mathrm{H})$, $2.02(\mathrm{~d}, J=1.0 \mathrm{~Hz}, 3 \mathrm{H}), 1.33(\mathrm{~s}, 6 \mathrm{H}) \mathrm{ppm} ;{ }^{13} \mathrm{C} \operatorname{NMR}\left(125 \mathrm{MHz}, \mathrm{CDCl}_{3}\right) \delta 171.3,166.1,146.2,144.5$, 143.2, 141.0, 130.3, 129.6, 128.6, 128.1, 127.8, 127.0, 124.2, 122.9, 122.3, 121.6, 120.0, 110.6, 67.0, 56.9, 52.8, 51.2, 34.3, 31.0, 27.9, 18.8 ppm; HRMS (ESI+) calcd for $\mathrm{C}_{41} \mathrm{H}_{43} \mathrm{~N}_{2} \mathrm{O}_{3} \mathrm{~S}[\mathrm{M}+\mathrm{H}]^{+}: 643.2994$, found: $m / z 643.3004$.

\section{Compound 10a}

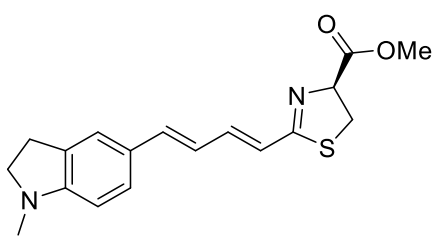

To a solution of triphenylphosphine oxide (TPPO) $(213 \mathrm{mg}, 0.765 \mathrm{mmol}$, 3.0 eq.) in anhydrous $\mathrm{CH}_{2} \mathrm{Cl}_{2}(2.5 \mathrm{~mL})$ was added trifluoromethane sulfonic anhydride $\left(\mathrm{Tf}_{2} \mathrm{O}\right)(63.0 \mu \mathrm{L}, 0.384 \mathrm{mmol}, 1.5$ eq. $)$ slowly dropwise at $0{ }^{\circ} \mathrm{C}$. After stirring for $30 \mathrm{~min}$, a solution of $9 \mathrm{a}(150 \mathrm{mg}, 0.255 \mathrm{mmol}$, 1.0 eq. $)$ in anhydrous $\mathrm{CH}_{2} \mathrm{Cl}_{2}(2.7 \mathrm{~mL})$ was added dropwise carefully at $0{ }^{\circ} \mathrm{C}$, at which point the reaction solution turned deep red in color, and the reaction mixture was stirred for $10 \mathrm{~min}$. The reaction was quenched with saturated aqueous $\mathrm{NaHCO}_{3}$ solution and extracted with $\mathrm{CH}_{2} \mathrm{Cl}_{2}(3 \times 50 \mathrm{~mL})$. The combined organic layer was washed with brine, dried over $\mathrm{Na}_{2} \mathrm{SO}_{4}$ and filtered. The filtrate was concentrated under reduced pressure. The crude material was purified by silica gel column chromatography (47-68\% ethyl acetate/n-hexane) to afford $10 \mathrm{a}(33.1 \mathrm{mg}, 40 \%)$ as a yellow oil. ${ }^{1} \mathrm{H}$ $\operatorname{NMR}\left(500 \mathrm{MHz}, \mathrm{CDCl}_{3}\right) \delta 7.25(\mathrm{~s}, 1 \mathrm{H}), 7.15(\mathrm{dd}, J=8.0,1.5 \mathrm{~Hz}, 1 \mathrm{H}), 6.93(\mathrm{dd}, J=15.5,10.0 \mathrm{~Hz}, 1 \mathrm{H})$, $6.75(\mathrm{~d}, J=15.5 \mathrm{~Hz}, 1 \mathrm{H}), 6.68(\mathrm{dd}, J=15.5,10.0 \mathrm{~Hz}, 1 \mathrm{H}), 6.52(\mathrm{~d}, J=15.0 \mathrm{~Hz}, 1 \mathrm{H}), 6.38(\mathrm{~d}, J=8.0$ $\mathrm{Hz}, 1 \mathrm{H}), 5.16(\mathrm{t}, J=9.0 \mathrm{~Hz}, 1 \mathrm{H}), 3.82(\mathrm{~s}, 3 \mathrm{H}), 3.60-3.50(\mathrm{~m}, 2 \mathrm{H}), 3.39(\mathrm{t}, J=8.3 \mathrm{~Hz}, 2 \mathrm{H}), 2.97(\mathrm{t}, J=$ $8.3 \mathrm{~Hz}, 2 \mathrm{H}), 2.79$ (s, 3H) ppm; ${ }^{13} \mathrm{C}$ NMR $\left(125 \mathrm{MHz}, \mathrm{CDCl}_{3}\right) \delta 171.6,170.4,154.3,144.0,140.1,131.0$, 128.7, 126.0, 122.6, 122.5, 122.4, 106.4, 78.0, 55.7, 52.9, 35.4, 34.7, 28.3 ppm; HRMS (ESI+) calcd for $\mathrm{C}_{18} \mathrm{H}_{21} \mathrm{~N}_{2} \mathrm{O}_{2} \mathrm{~S}[\mathrm{M}+\mathrm{H}]^{+}: 329.1324$, found: $m / z$ 329.1308.

\section{Compound 10b}

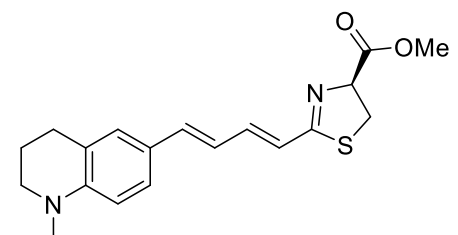

10b was synthesized in the same manner as described for the preparation of 10 a; yield $41 \%$, a yellow oil. ${ }^{1} \mathrm{H}$ NMR $\left(500 \mathrm{MHz}, \mathrm{CDCl}_{3}\right) \delta$ 7.17 (dd, $J=8.0,1.5 \mathrm{~Hz}, 1 \mathrm{H}), 7.09(\mathrm{~s}, 1 \mathrm{H}), 6.93$ (dd, $J=15.5,9.5 \mathrm{~Hz}$, $1 \mathrm{H}), 6.73-6.64(\mathrm{~m}, 2 \mathrm{H}), 6.52(\mathrm{~d}, J=3.0 \mathrm{~Hz}, 1 \mathrm{H}), 6.50(\mathrm{~d}, J=4.0 \mathrm{~Hz}, 1 \mathrm{H})$, $5.15(\mathrm{t}, J=9.0 \mathrm{~Hz}, 1 \mathrm{H}), 3.82(\mathrm{~s}, 3 \mathrm{H}), 3.60-3.50(\mathrm{~m}, 2 \mathrm{H}), 3.28(\mathrm{t}, J=5.6 \mathrm{~Hz}, 2 \mathrm{H}), 2.93(\mathrm{~s}, 3 \mathrm{H}), 2.76(\mathrm{t}$, $J=6.3 \mathrm{~Hz}, 2 \mathrm{H}$ ), 1.97 (quint, $J=6.0 \mathrm{~Hz}, 2 \mathrm{H}$ ) ppm; ${ }^{13} \mathrm{C} \mathrm{NMR}\left(125 \mathrm{MHz}, \mathrm{CDCl}_{3}\right) \delta 171.6,170.4,147.5$, 144.1, 139.9, 127.6, 127.3, 124.1, 122.8, 122.3, 122.2, 110.6, 78.0, 52.9, 51.2, 39.0, 34.6, 27.9, 22.3 ppm; HRMS (ESI+) calcd for $\mathrm{C}_{19} \mathrm{H}_{23} \mathrm{~N}_{2} \mathrm{O}_{2} \mathrm{~S}[\mathrm{M}+\mathrm{H}]^{+}: 343.1480$, found: $m / z$ 343.1483. 
Compound 10c

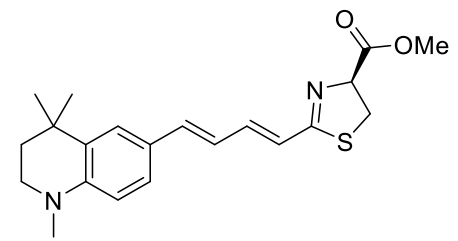

10c was synthesized in the same manner as described for the preparation of $10 \mathrm{a}$; yield $38 \%$, a yellow oil. ${ }^{1} \mathrm{H} \mathrm{NMR}\left(500 \mathrm{MHz}, \mathrm{CDCl}_{3}\right) \delta$ $7.28(\mathrm{~d}, J=1.5 \mathrm{~Hz}, 1 \mathrm{H}), 7.20$ (dd, $J=8.5,1.5 \mathrm{~Hz}, 1 \mathrm{H}), 6.94$ (dd, $J=15.5$, $10.0 \mathrm{~Hz}, 1 \mathrm{H}), 6.75$ (d, $J=15.0 \mathrm{~Hz}, 1 \mathrm{H}), 6.67$ (dd, $J=15.5,10.0 \mathrm{~Hz}, 1 \mathrm{H})$, 6.53-6.50 (m, 2H), $5.16(\mathrm{t}, J=9.0 \mathrm{~Hz}, 1 \mathrm{H}), 3.82(\mathrm{~s}, 3 \mathrm{H}), 3.60-3.50(\mathrm{~m}, 2 \mathrm{H}), 3.30(\mathrm{t}, J=6.0 \mathrm{~Hz}, 2 \mathrm{H})$, $2.95(\mathrm{~s}, 3 \mathrm{H}), 1.75(\mathrm{t}, J=6.0 \mathrm{~Hz}, 2 \mathrm{H}), 1.30(\mathrm{~s}, 6 \mathrm{H}) \mathrm{ppm} ;{ }^{13} \mathrm{C} \mathrm{NMR}\left(125 \mathrm{MHz}, \mathrm{CDCl}_{3}\right) \delta 171.6,170.4$, 146.2, 144.2, 140.3, 131.4, 126.7, 125.0, 124.0, 122.1, 121.9, 110.8, 78.0, 52.9, 47.6, 39.2, 36.9, 34.6, 32.1, 30.6 ppm; HRMS (ESI+) calcd for $\mathrm{C}_{21} \mathrm{H}_{27} \mathrm{~N}_{2} \mathrm{O}_{2} \mathrm{~S}[\mathrm{M}+\mathrm{H}]^{+}: 371.1793$, found: $\mathrm{m} / \mathrm{z} 371.1784$

Compound 10d

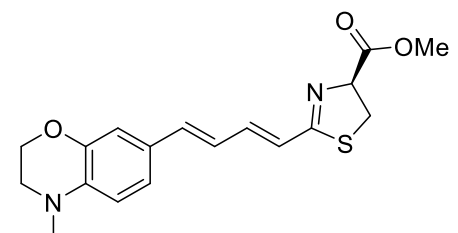

10d was synthesized in the same manner as described for the preparation of 10 a; yield $28 \%$, a yellow oil. ${ }^{1} \mathrm{H}$ NMR $\left(500 \mathrm{MHz}, \mathrm{CDCl}_{3}\right) \delta$ 6.95 (dd, $J=8.0,2.0 \mathrm{~Hz}, 1 \mathrm{H}), 6.93-6.89(\mathrm{~m}, 2 \mathrm{H}), 6.72-6.64(\mathrm{~m}, 2 \mathrm{H}), 6.60$ $(\mathrm{d}, J=8.0 \mathrm{~Hz}, 1 \mathrm{H}), 6.53(\mathrm{~d}, J=15.0 \mathrm{~Hz}, 1 \mathrm{H}), 5.16(\mathrm{t}, J=9.0 \mathrm{~Hz}, 1 \mathrm{H})$, $4.28(\mathrm{t}, J=4.5 \mathrm{~Hz}, 1 \mathrm{H}), 3.82(\mathrm{~s}, 3 \mathrm{H}), 3.61-3.50(\mathrm{~m}, 2 \mathrm{H}), 3.32(\mathrm{t}, J=4.5 \mathrm{~Hz}, 2 \mathrm{H}), 2.92(\mathrm{~s}, 3 \mathrm{H}) \mathrm{ppm} ;{ }^{13} \mathrm{C}$ $\operatorname{NMR}\left(125 \mathrm{MHz}, \mathrm{CDCl}_{3}\right) \delta 171.6,170.3,144.1,143.6,139.3,137.6,126.4,123.6,123.2,122.0,113.9$, 112.0, 78.0, 64.7, 51.9, 49.1, 38.6, 34.7 ppm; HRMS (ESI+) calcd for $\mathrm{C}_{18} \mathrm{H}_{21} \mathrm{~N}_{2} \mathrm{O}_{3} \mathrm{~S}[\mathrm{M}+\mathrm{H}]^{+}: 345.1273$, found: $m / z 345.1270$.

Compound 10e

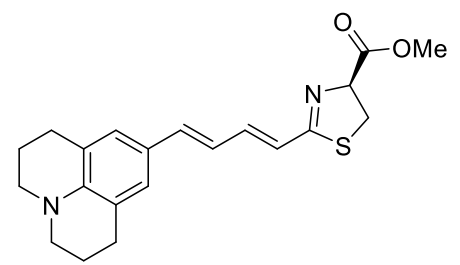

10e was synthesized in the same manner as described for the preparation of $10 \mathrm{a}$; yield $40 \%$, an orange oil. ${ }^{1} \mathrm{H} \mathrm{NMR}\left(500 \mathrm{MHz}, \mathrm{CDCl}_{3}\right)$ $\delta$ 6.94-6.89 (comp,3H), 6.68-6.64 (m, 2H), $6.49(\mathrm{~d}, J=15.0,1 \mathrm{H}), 5.15(\mathrm{t}$, $J=9.0 \mathrm{~Hz}, 1 \mathrm{H}$ ), $3.82(\mathrm{~s}, 3 \mathrm{H}), 3.57$ (dd, $J=11.0,9.0 \mathrm{~Hz}, 1 \mathrm{H}), 3.51$ (dd, $J$ $=11.0,9.0 \mathrm{~Hz}, 1 \mathrm{H}), 3.19(\mathrm{t}, J=5.6 \mathrm{~Hz}, 4 \mathrm{H}), 2.73(\mathrm{t}, J=6.4 \mathrm{~Hz}, 4 \mathrm{H})$, 1.99-1.92 (m, 4H) ppm; ${ }^{13} \mathrm{C}$ NMR $\left(125 \mathrm{MHz}, \mathrm{CDCl}_{3}\right) \delta 171.7,170.4,144.2,143.9,140.1,126.4,123.5$, 122.0, 121.8, 121.3, 78.0, 52.9, 50.1, 34.7, 27.8, 21.9 ppm; HRMS (ESI+) calcd for $\mathrm{C}_{21} \mathrm{H}_{25} \mathrm{~N}_{2} \mathrm{O}_{2} \mathrm{~S}$ $[\mathrm{M}+\mathrm{H}]^{+}: 369.1637$, found: $m / z$ 369.1625. 
Compound $10 f$

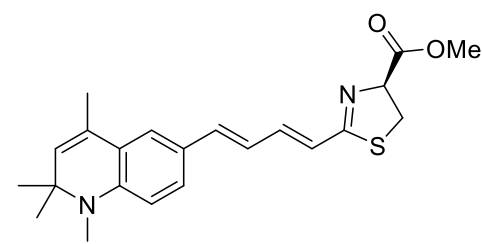

$10 \mathrm{f}$ was synthesized in the same manner as described for the preparation of $10 \mathrm{a}$; yield $83 \%$, a yellow oil. ${ }^{1} \mathrm{H} \mathrm{NMR}\left(500 \mathrm{MHz}, \mathrm{CDCl}_{3}\right)$ $\delta 7.21(\mathrm{dd}, J=8.5,2.0,1 \mathrm{H}), 7.14(\mathrm{~d}, J=2.0 \mathrm{~Hz}, 1 \mathrm{H}), 6.94(\mathrm{dd}, J=$ $15.5,10.0 \mathrm{~Hz}, 1 \mathrm{H}), 6.75$ (d, $J=15.0 \mathrm{~Hz}, 1 \mathrm{H}), 6.68$ (dd, $J=15.5,10.0$ $\mathrm{Hz}, 1 \mathrm{H}), 6.52(\mathrm{~d}, J=15.0 \mathrm{~Hz}, 1 \mathrm{H}), 6.46(\mathrm{~d}, J=8.5 \mathrm{~Hz}, 1 \mathrm{H}), 5.31(\mathrm{~d}, J=1.0,1 \mathrm{H}), 5.16(\mathrm{t}, J=9.0 \mathrm{~Hz}$, 1H), $3.82(\mathrm{~s}, 3 \mathrm{H}), 3.60-3.50(\mathrm{~m}, 2 \mathrm{H}), 2.83(\mathrm{~s}, 3 \mathrm{H}), 2.01(\mathrm{~d}, J=1.5 \mathrm{~Hz}, 3 \mathrm{H}), 1.32(\mathrm{~s}, 6 \mathrm{H}) \mathrm{ppm} ;{ }^{13} \mathrm{C}$ NMR $\left(125 \mathrm{MHz}, \mathrm{CDCl}_{3}\right) \delta 171.6,170.4,146.2,144.0,140.0,130.3,128.7,127.7,124.2,122.9,122.4,122.3$, 122.2, 110.5, 78.0, 56.9, 52.9, 34.6, 31.0, 27.9, 18.8 ppm; HRMS (ESI+) calcd for $\mathrm{C}_{22} \mathrm{H}_{27} \mathrm{~N}_{2} \mathrm{O}_{2} \mathrm{~S}$ $[\mathrm{M}+\mathrm{H}]^{+}: 383.1793$, found: $m / z$ 383.1790.

\section{Compound 11a (NIRLuc1)}

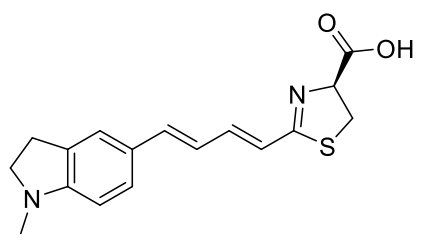

Luciferin ester 10a (33.1 mg, $0.101 \mathrm{mmol})$ was treated with $4 \mathrm{M} \mathrm{HCl}$ aq. $(1.5 \mathrm{~mL})$ at room temperature for $24 \mathrm{~h}$. The reaction mixture was neutralized by the addition of saturated $\mathrm{NaHCO}_{3}$ aq. at $0{ }^{\circ} \mathrm{C}$, and concentrated under reduced pressure. The residue was purified by ODS column chromatography $\left(20-100 \%\right.$ acetonitrile/ $\left.\mathrm{H}_{2} \mathrm{O}\right)$ to afford $11 \mathrm{a}(18.8 \mathrm{mg}, 59 \%)$ as a yellow solid. ${ }^{1} \mathrm{H}$ NMR (500 MHz, CD $\left.{ }_{3} \mathrm{OD}\right) \delta 7.26(\mathrm{~s}, 1 \mathrm{H}), 7.17$ (dd, $\left.J=8.0,1.5 \mathrm{~Hz}, 1 \mathrm{H}\right), 6.93(\mathrm{td}, J=10.0,5.2 \mathrm{~Hz}$, $1 \mathrm{H}), 6.79-6.73(\mathrm{~m}, 2 \mathrm{H}), 6.50(\mathrm{~d}, J=15.0 \mathrm{~Hz}, 1 \mathrm{H}), 6.43(\mathrm{~d}, J=8.5 \mathrm{~Hz}, 1 \mathrm{H}), 4.94(\mathrm{t}, J=9.3 \mathrm{~Hz}, 1 \mathrm{H})$, $3.57(\mathrm{dd}, J=10.9,9.2 \mathrm{~Hz}, 1 \mathrm{H}), 3.47(\mathrm{dd}, J=10.7,9.6 \mathrm{~Hz}, 1 \mathrm{H}), 3.33(\mathrm{t}, J=8.0 \mathrm{~Hz}, 2 \mathrm{H}), 2.93(\mathrm{t}, J=8.2$ $\mathrm{Hz}, 2 \mathrm{H}), 2.77$ (s, 3H) ppm; ${ }^{13} \mathrm{C}$ NMR (125 MHz, CD $\left.{ }_{3} \mathrm{OD}\right) \delta$ 178.3, 170.9, 155.6, 144.5, 141.0, 132.3, 129.5, 127.8, 123.6, 123.5, 107.8, 107.7, 82.1, 56.8, 36.7, 35.8, 29.1 ppm; HRMS (ESI+) calcd for $\mathrm{C}_{17} \mathrm{H}_{19} \mathrm{~N}_{2} \mathrm{O}_{2} \mathrm{~S}[\mathrm{M}+\mathrm{H}]^{+}: 315.1167$, found: $\mathrm{m} / \mathrm{z} 315.1158$; The optical purity was determined by CSP HPLC analysis (CHIRALCEL OZ-3R, eluent: $10-90 \% \mathrm{CH}_{3} \mathrm{CN} / \mathrm{H}_{2} \mathrm{O}$, flow $0.6 \mathrm{~mL} / \mathrm{min}$ ) $67 \%$ e.e. [ $t_{R}$ $($ minor $)=14.8 \mathrm{~min}, t_{R}($ major $\left.)=16.1 \mathrm{~min}\right]$.

\section{Compound 11b (NIRLuc2)}

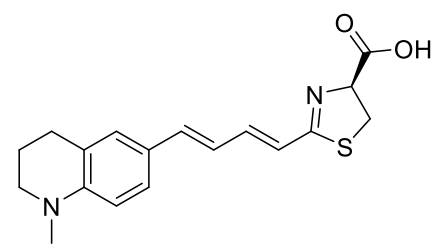

11b was synthesized in the same manner as described for the preparation of $11 \mathrm{a}$; yield $93 \%$, a yellow solid. ${ }^{1} \mathrm{H} \mathrm{NMR}\left(500 \mathrm{MHz}, \mathrm{CD}_{3} \mathrm{OD}\right)$ $\delta 7.16(\mathrm{dd}, J=8.5,2.0 \mathrm{~Hz}, 1 \mathrm{H}), 7.07(\mathrm{~s}, 1 \mathrm{H}), 6.92(\mathrm{dd}, J=15.0,8.5 \mathrm{~Hz}$, $1 \mathrm{H}), 6.76-6.68(\mathrm{~m}, 2 \mathrm{H}), 6.54(\mathrm{~d}, J=8.5 \mathrm{~Hz}, 1 \mathrm{H}), 6.49(\mathrm{~d}, J=15.5 \mathrm{~Hz}, 1 \mathrm{H})$, $4.94(\mathrm{t}, J=9.0 \mathrm{~Hz}, 1 \mathrm{H}), 3.56(\mathrm{dd}, J=10.5,9.0 \mathrm{~Hz}, 1 \mathrm{H}), 3.46(\mathrm{dd}, J=10.5,9.5 \mathrm{~Hz}, 1 \mathrm{H}), 3.26(\mathrm{t}, J=5.8$ $\mathrm{Hz}, 2 \mathrm{H}), 2.90(\mathrm{~s}, 3 \mathrm{H}), 2.73(\mathrm{t}, J=6.5 \mathrm{~Hz}, 2 \mathrm{H}), 1.94$ (quint, $J=6.0 \mathrm{~Hz}, 2 \mathrm{H}) \mathrm{ppm} ;{ }^{13} \mathrm{C} \mathrm{NMR}(125 \mathrm{MHz}$, 
$\left.\mathrm{CD}_{3} \mathrm{OD}\right) \delta 178.4,170.9,148.7,144.6,140.9,128.6,128.0,125.7,123.9,123.2,123.1,111.7,82.1$, 52.2, 39.1, 36.7, 28.8, 23.4 ppm; HRMS (ESI+) calcd for $\mathrm{C}_{18} \mathrm{H}_{21} \mathrm{~N}_{2} \mathrm{O}_{2} \mathrm{~S}[\mathrm{M}+\mathrm{H}]^{+}: 329.1324$, found: $\mathrm{m} / \mathrm{z}$ 329.1325; The optical purity was determined by CSP HPLC analysis (CHIRALCEL OZ-3R, eluent: 10$90 \% \mathrm{CH}_{3} \mathrm{CN} / \mathrm{H}_{2} \mathrm{O}$, flow $0.6 \mathrm{~mL} / \mathrm{min}$ ) $76 \%$ e.e. $\left[t_{R}(\right.$ minor $)=16.6 \mathrm{~min}, t_{R}$ (major) $=18.3 \mathrm{~min}$ ].

Compound 11c (NIRLuc3)

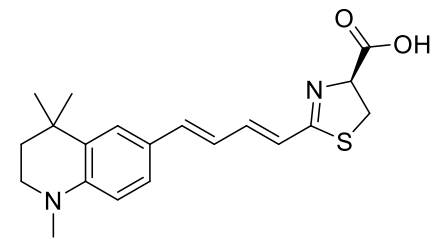

11c was synthesized in the same manner as described for the preparation of $11 \mathrm{a}$; yield $97 \%$, a yellow solid. ${ }^{1} \mathrm{H} \mathrm{NMR}\left(500 \mathrm{MHz}, \mathrm{CD}_{3} \mathrm{OD}\right) \delta 7.31(\mathrm{~d}, J$ $=2.0 \mathrm{~Hz}, 1 \mathrm{H}), 7.20(\mathrm{dd}, J=8.5,2.0 \mathrm{~Hz}, 1 \mathrm{H}), 6.94(\mathrm{td}, J=10.0,5.2 \mathrm{~Hz}$, $1 \mathrm{H}), 6.75(\mathrm{~d}, J=5.0 \mathrm{~Hz}, 1 \mathrm{H}), 6.56(\mathrm{~d}, J=8.5 \mathrm{~Hz}, 1 \mathrm{H}), 6.50(\mathrm{~d}, J=15.0$ $\mathrm{Hz}, 1 \mathrm{H}), 4.94(\mathrm{t}, J=9.0 \mathrm{~Hz}, 1 \mathrm{H}$ ), 3.57 (dd, $J=10.5,9.0 \mathrm{~Hz}, 1 \mathrm{H}), 3.47$ (dd, $J=10.5,9.5 \mathrm{~Hz}, 1 \mathrm{H}$ ), 3.29 $(\mathrm{t}, J=6.0 \mathrm{~Hz}, 2 \mathrm{H}), 2.93(\mathrm{~s}, 3 \mathrm{H}), 1.75(\mathrm{t}, J=6.0 \mathrm{~Hz}, 2 \mathrm{H}), 1.28(\mathrm{~s}, 6 \mathrm{H}) \mathrm{ppm} ;{ }^{13} \mathrm{C}$ NMR $\left(125 \mathrm{MHz}, \mathrm{CD}_{3} \mathrm{OD}\right)$ $\delta 178.3,171.0,147.5,144.6,141.1,132.5,127.5,126.1,125.6,123.2,123.0,112.0,82.0,39.4,38.1$, 36.7, 32.9, 31.3, 31.0 ppm; HRMS (ESI+) calcd for $\mathrm{C}_{20} \mathrm{H}_{25} \mathrm{~N}_{2} \mathrm{O}_{2} \mathrm{~S}[\mathrm{M}+\mathrm{H}]^{+}: 357.1637$, found: $\mathrm{m} / \mathrm{z}$ 357.1630; The optical purity was determined by CSP HPLC analysis (CHIRALCEL OZ-3R, eluent: 10$90 \% \mathrm{CH}_{3} \mathrm{CN} / \mathrm{H}_{2} \mathrm{O}$, flow $\left.0.6 \mathrm{~mL} / \mathrm{min}\right) 98 \%$ e.e. [ $t_{R}$ (minor) $=18.6 \mathrm{~min}, t_{R}($ major $)=20.2 \mathrm{~min}$ ]

\section{Compound 11d (NIRLuc4)}

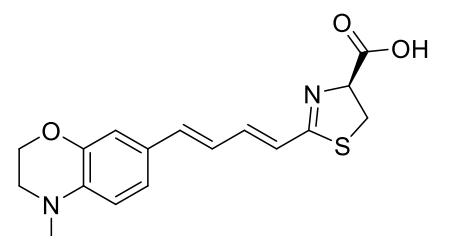

11d was synthesized in the same manner as described for the preparation of $11 \mathrm{a}$; yield $75 \%$, a yellow solid. ${ }^{1} \mathrm{H}$ NMR $\left(500 \mathrm{MHz}, \mathrm{CD}_{3} \mathrm{OD}\right) \delta 6.95-6.87$ $(\mathrm{m}, 3 \mathrm{H}), 6.74(\mathrm{dd}, J=15.5,9.5 \mathrm{~Hz}, 1 \mathrm{H}), 6.69(\mathrm{~d}, J=15.0 \mathrm{~Hz}, 1 \mathrm{H}), 6.63$ $(\mathrm{d}, J=8.5 \mathrm{~Hz}, 1 \mathrm{H}), 6.52(\mathrm{~d}, J=15.5 \mathrm{~Hz}, 1 \mathrm{H}), 4.94(\mathrm{t}, J=9.3 \mathrm{~Hz}, 1 \mathrm{H}), 4.23$ (t, $J=4.5 \mathrm{~Hz}, 2 \mathrm{H}$ ), 3.56 (dd, $J=10.6,9.2 \mathrm{~Hz}, 1 \mathrm{H}$ ), 3.47 (dd, $J=10.7,9.6 \mathrm{~Hz}, 1 \mathrm{H}), 3.28$ (t, $J=4.3 \mathrm{~Hz}$, 2H), 2.90 (s, 3H) ppm; ${ }^{13} \mathrm{C} \mathrm{NMR}\left(125 \mathrm{MHz}, \mathrm{CD}_{3} \mathrm{OD}\right) \delta 178.3,170.7,145.5,144.1,140.3,139.0,127.7$, $124.4,124.1,122.9,114.6,113.1,82.2,65.8,50.0,38.6,36.7$ ppm; HRMS (ESI+) calcd for $\mathrm{C}_{17} \mathrm{H}_{19} \mathrm{~N}_{2} \mathrm{O}_{3} \mathrm{~S}[\mathrm{M}+\mathrm{H}]^{+}: 331.1116$, found: $\mathrm{m} / \mathrm{z} 331.1104$; The optical purity was determined by CSP HPLC analysis (CHIRALCEL OZ-3R, eluent: $10-90 \% \mathrm{CH}_{3} \mathrm{CN} / \mathrm{H}_{2} \mathrm{O}$, flow $0.6 \mathrm{~mL} / \mathrm{min}$ ) $81 \%$ e.e. [ $t_{R}$ $($ minor $)=13.2 \mathrm{~min}, t_{R}($ major $\left.)=14.3 \mathrm{~min}\right]$. 
Compound 11e (NIRLuc5)

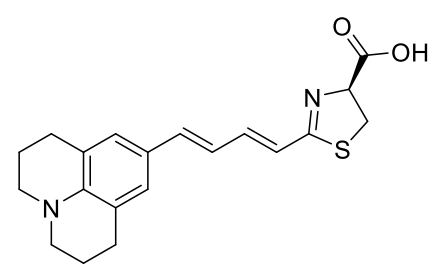

11e was synthesized in the same manner as described for the preparation of $11 \mathrm{a}$; yield $60 \%$, a yellow solid. ${ }^{1} \mathrm{H}$ NMR $\left(500 \mathrm{MHz}, \mathrm{CD}_{3} \mathrm{OD}\right) \delta 6.90$ (dd, $J=15.5,10.0 \mathrm{~Hz}, 1 \mathrm{H}), 6.88(\mathrm{~s}, 2 \mathrm{H}), 6.68(\mathrm{dd}, J=15.0,9.5 \mathrm{~Hz}, 1 \mathrm{H}), 6.63$ (d, $J=15.5 \mathrm{~Hz}, 1 \mathrm{H}), 6.46(\mathrm{~d}, J=15.5 \mathrm{~Hz}, 1 \mathrm{H}), 4.93(\mathrm{t}, J=9.2 \mathrm{~Hz}, 1 \mathrm{H})$, 3.55 (dd, $J=10.7,9.0 \mathrm{~Hz}, 1 \mathrm{H}), 3.46$ (dd, $J=10.7,9.6 \mathrm{~Hz}, 1 \mathrm{H}), 3.18$ (t, $J$ $=5.6 \mathrm{~Hz}, 4 \mathrm{H}), 2.70(\mathrm{t}, J=6.4 \mathrm{~Hz}, 4 \mathrm{H}), 1.97-1.89(\mathrm{~m}, 4 \mathrm{H}) \mathrm{ppm} ;{ }^{13} \mathrm{C}$ NMR $\left(125 \mathrm{MHz}, \mathrm{CD}_{3} \mathrm{OD}\right) \delta 178.3$, 170.9, 144.9, 144.7, 141.2, 127.3, 125.1, 122.9, 122.6, 122.5, 82.1, 51.0, 36.7, 28.7, 23.0 ppm; HRMS (ESI+) calcd for $\mathrm{C}_{20} \mathrm{H}_{23} \mathrm{~N}_{2} \mathrm{O}_{2} \mathrm{~S}[\mathrm{M}+\mathrm{H}]^{+}: 355.1480$, found: $\mathrm{m} / \mathrm{z} 355.1480$; The optical purity was determined by CSP HPLC analysis (CHIRALCEL OZ-3R, eluent: 10-90\% $\mathrm{CH}_{3} \mathrm{CN} / \mathrm{H}_{2} \mathrm{O}$, flow 0.6 $\mathrm{mL} / \mathrm{min}) 85 \%$ e.e. $\left[t_{\mathrm{R}}(\operatorname{minor})=19.9 \mathrm{~min}, t_{\mathrm{R}}(\right.$ major $\left.)=22.9 \mathrm{~min}\right]$.

Compound 11f (NIRLuc6)

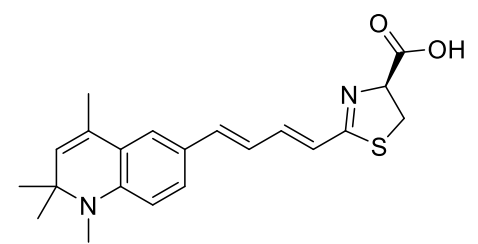

$11 f$ was synthesized in the same manner as described for the preparation of $11 \mathrm{a}$; yield $86 \%$, a yellow solid. ${ }^{1} \mathrm{H}$ NMR $(500 \mathrm{MHz}$, $\left.\mathrm{CD}_{3} \mathrm{OD}\right) \delta 7.23(\mathrm{dd}, J=8.5,2.0,1 \mathrm{H}), 7.16(\mathrm{~d}, J=2.0 \mathrm{~Hz}, 1 \mathrm{H}), 6.99$ $6.90(\mathrm{~m}, 1 \mathrm{H}), 6.81-6.70(\mathrm{~m}, 2 \mathrm{H}), 6.56-6.46(\mathrm{~m}, 2 \mathrm{H}), 5.35(\mathrm{~d}, J=1.0$, $1 \mathrm{H}), 4.95$ (t, $J=9.5 \mathrm{~Hz}, 1 \mathrm{H}$ ), 3.57 (dd, $J=10.9,9.2 \mathrm{~Hz}, 1 \mathrm{H}), 3.47$ (dd, $J=10.7,9.7 \mathrm{~Hz}, 1 \mathrm{H}$ ), 2.83 (s, $3 \mathrm{H}), 1.99(\mathrm{~d}, J=1.0 \mathrm{~Hz}, 3 \mathrm{H}), 1.31(\mathrm{~s}, 6 \mathrm{H}) \mathrm{ppm} ;{ }^{13} \mathrm{C}$ NMR (125 MHz, CD $\left.{ }_{3} \mathrm{OD}\right) \delta 178.3,170.9,147.5$, $144.5,140.7,131.3,129.6,128.8,125.7,124.1$, 123.5, 123.4, 123.1, 111.6, 82.0, 57.8, 36.7, 31.2, 27.9, 18.8 ppm; HRMS (ESI+) calcd for $\mathrm{C}_{21} \mathrm{H}_{25} \mathrm{~N}_{2} \mathrm{O}_{2} \mathrm{~S}[\mathrm{M}+\mathrm{H}]^{+}: 369.1637$, found: $\mathrm{m} / \mathrm{z}$ 369.1648; The optical purity was determined by CSP HPLC analysis (CHIRALCEL OZ-3R, eluent: 10-90\% $\mathrm{CH}_{3} \mathrm{CN} / \mathrm{H}_{2} \mathrm{O}$, flow $\left.0.6 \mathrm{~mL} / \mathrm{min}\right) 96 \%$ e.e. $\left[t_{R}(\right.$ minor $)=19.5 \mathrm{~min}, t_{R}$ (major) $\left.=20.1 \mathrm{~min}\right]$. 


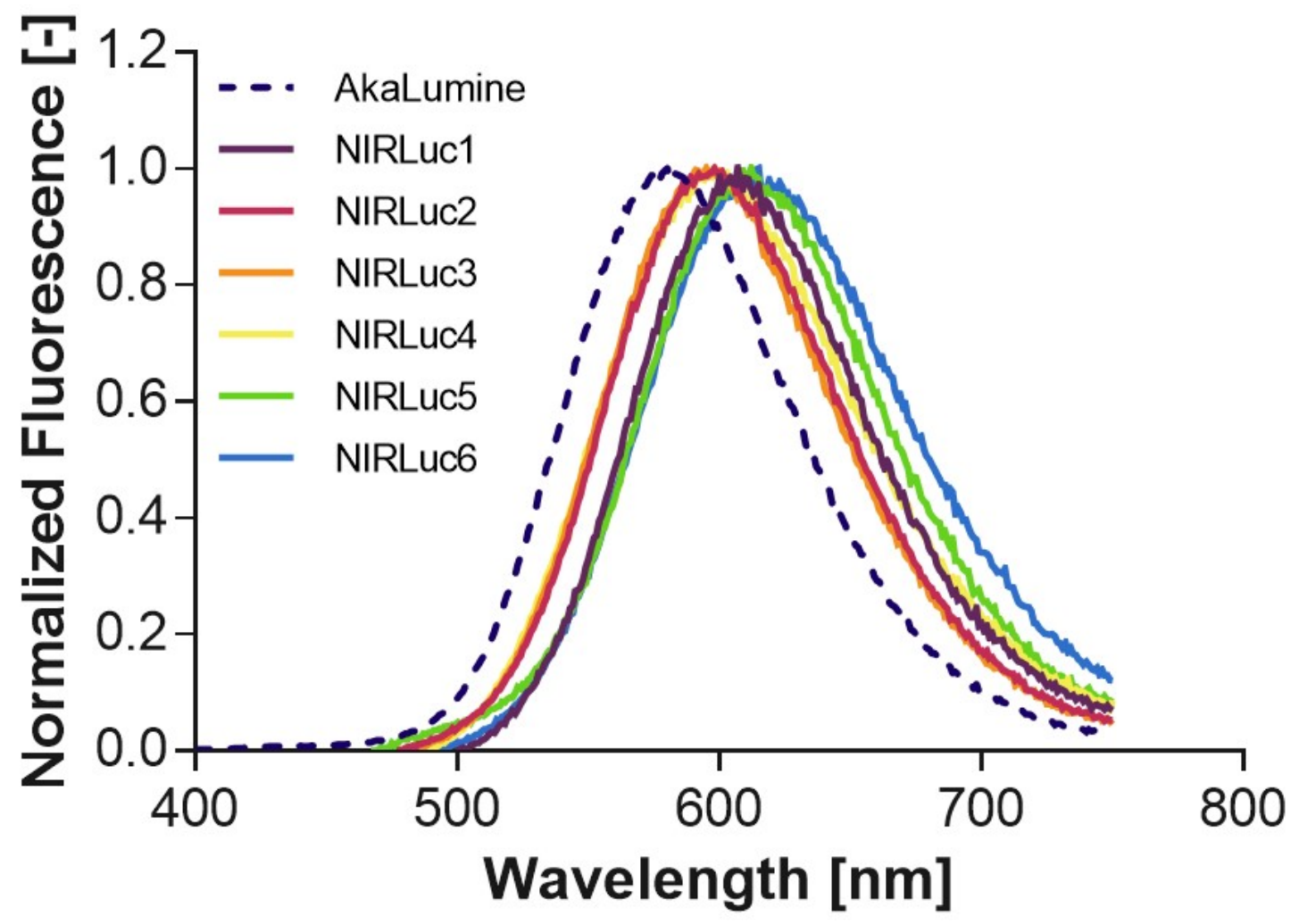

Figure S1. Normalized fluorescence emission spectra of AkaLumine and NIRLucs in $50 \mathrm{mM}$ GTA buffer ( $\mathrm{pH} 8.0) \cdot \lambda_{\mathrm{Ex}}=375 \mathrm{~nm}$ 


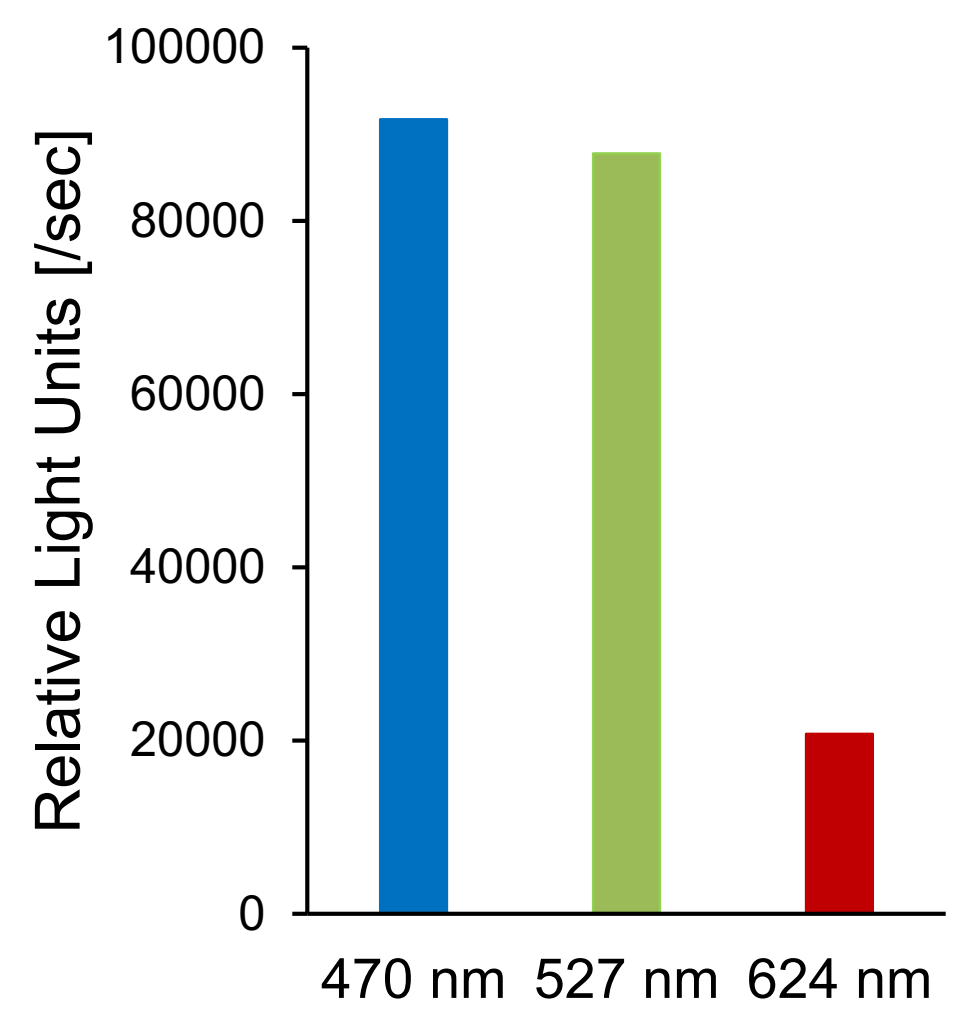

Figure S2. Photomultiplier spectral sensitivity of the TriStar ${ }^{2}$ LB942 luminometer evaluated by standard LED light sources. The LED power for each wavelength was set at $10 \mathrm{pW}$. 


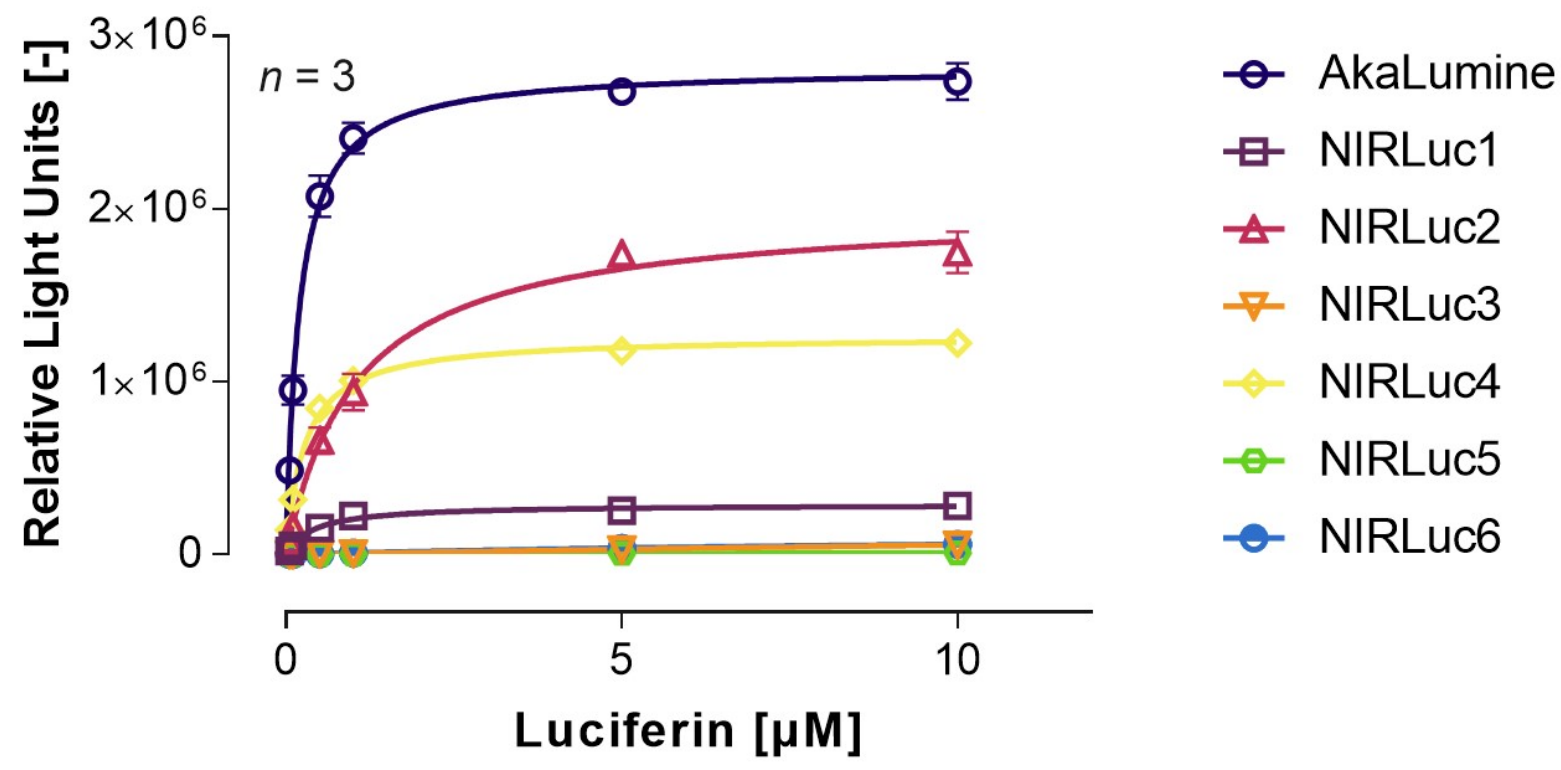

Figure S3. Luciferin saturation assay with increasing concentration of luciferins $(0.05-10 \mu \mathrm{M})$. The $K_{m}$ and $V_{\max }$ values of each luciferin were determined by Michaelis-Menten nonlinear regression analyses in GraphPad Prism (version 7.03 for Windows, GraphPad Software). The theoretical equation is described as follows:

$$
v=\frac{V_{\max }[\mathrm{S}]}{K_{\mathrm{m}}+[\mathrm{S}]}
$$

Error bars represent the standard deviation of the mean for triplicate experiments. 

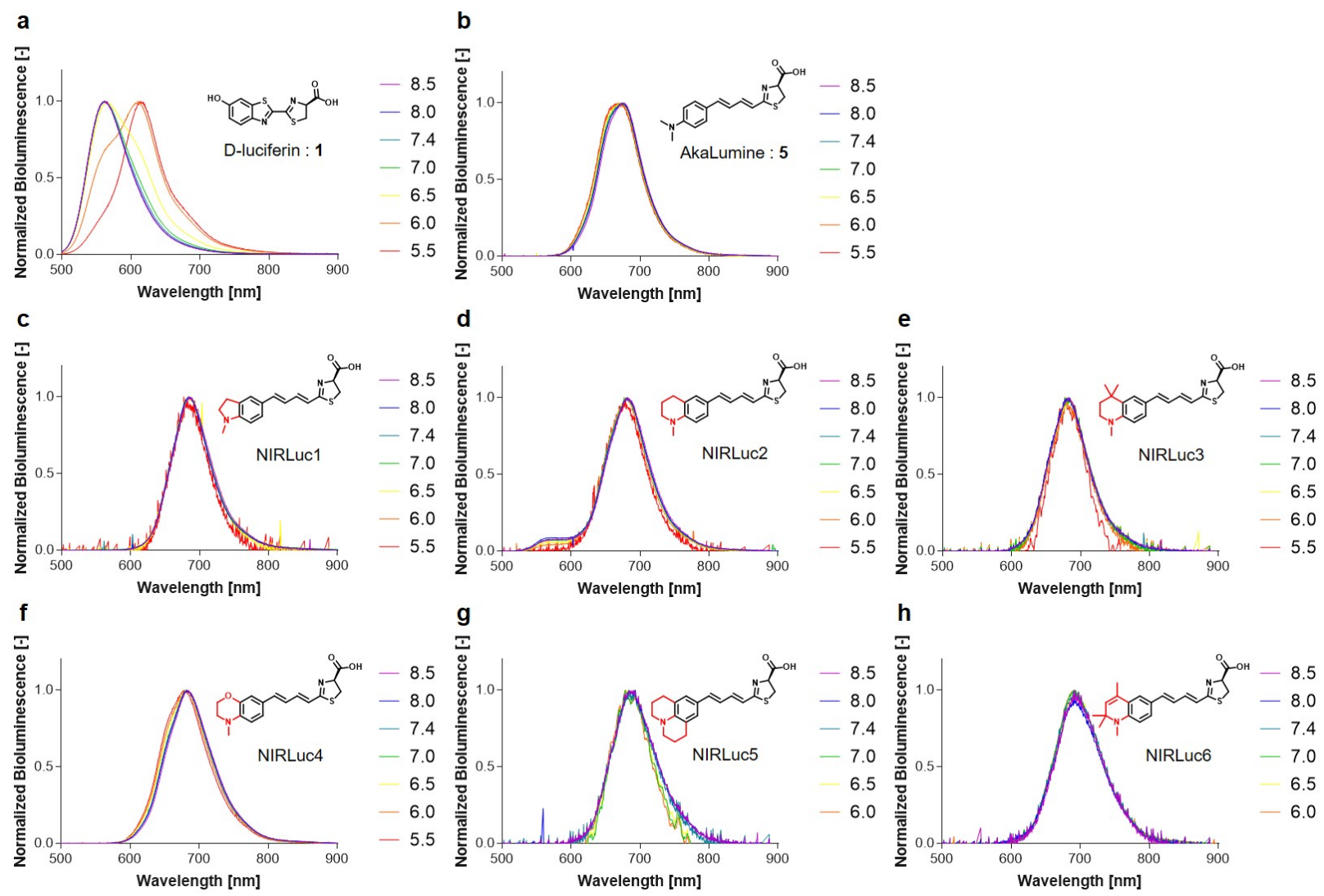

Figure S4. pH-Dependence of bioluminescence spectra of D-luciferin (a), AkaLumine (b) and NIRLucs (c-h) with Fluc in $50 \mathrm{mM}$ GTA buffer (pH 5.5-8.5). The emission wavelength of Dluciferin with Fluc changes from green to red under acidic condition. In contrast, the bioluminescence emission wavelengths of AkaLumine and NIRLucs were $\mathrm{pH}$ independent. The spectra for NIRLuc5 and NIRLuc6 at pH 5.5 could not obtained due to poor light emission. 


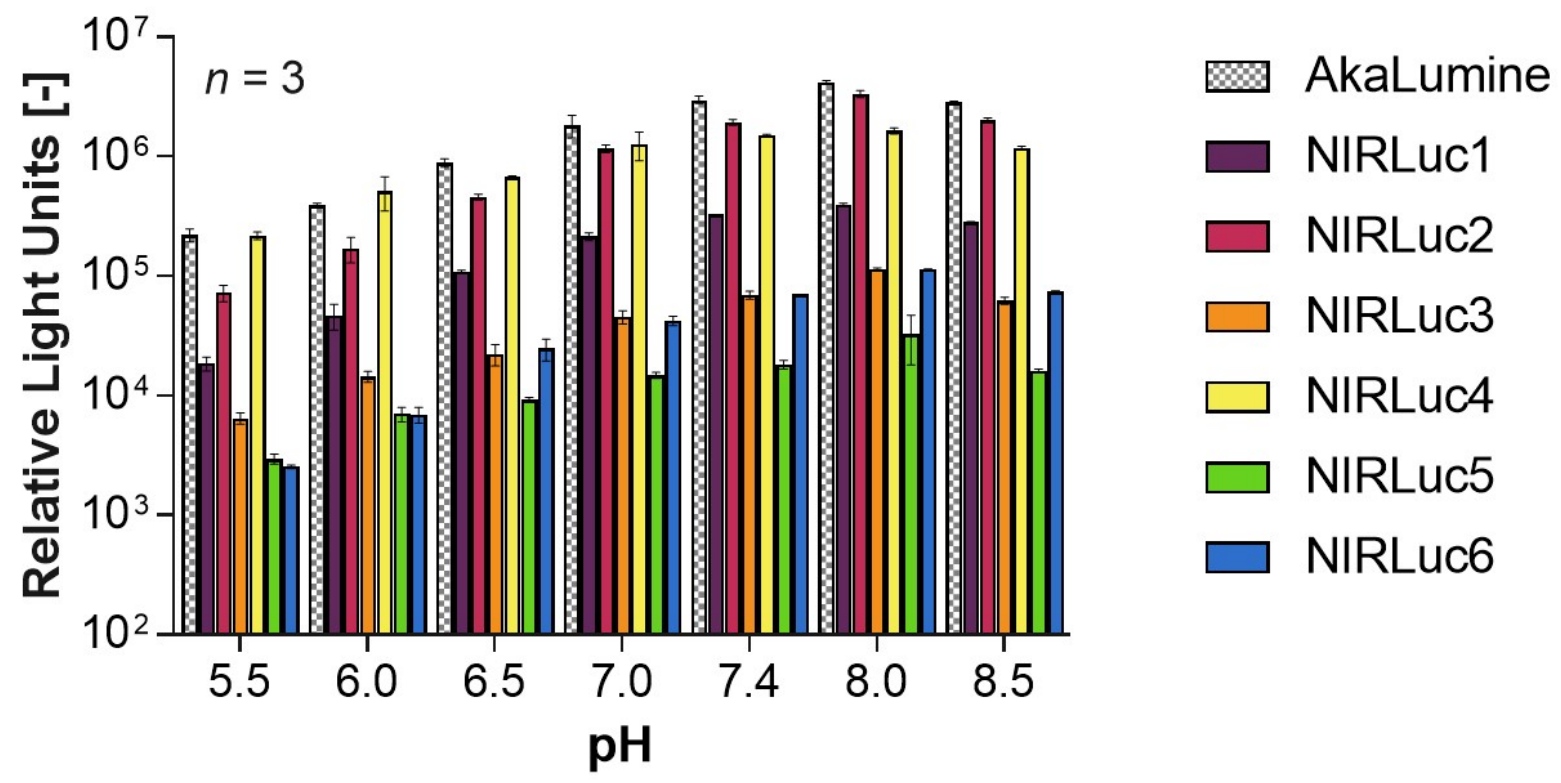

Figure S5. $\mathrm{pH}$-Dependence of bioluminescence emission intensities: $10 \mu \mathrm{M}$ luciferins incubated with $5.0 \mu \mathrm{g} / \mathrm{mL}$ native Fluc in $50 \mathrm{mM}$ GTA buffer ( $\mathrm{pH}$ 5.5-8.5). Light emission intensities integrated over $60 \mathrm{~s}$. Error bars represent the standard deviation of the mean for triplicate experiments. 
<smiles>CN(C)c1ccc(/C=C/C=C/C2=NC(=O)CS2)cc1</smiles>

\section{Ox-AkaLumine}<smiles>CN1CCc2cc(/C=C/C=C/C3=NC(=O)CS3)ccc21</smiles>

Ox-NIRLuc1<smiles>CN1CCOc2cc(/C=C/C=C/C3=NC(=O)CS3)ccc21</smiles>

Ox-NIRLuc4<smiles>CN1CCCc2cc(/C=C/C=C/C3=NC(=O)CS3)ccc21</smiles>

Ox-NIRLuc2<smiles>O=C1CSC(/C=C/C=C/c2cc3c4c(c2)CCCN4CCC3)=N1</smiles>

Ox-NIRLuc5<smiles>CN1CCC(C)(C)c2cc(/C=C/C=C/C3=NC(=O)CS3)ccc21</smiles>

\section{Ox-NIRLuc3}

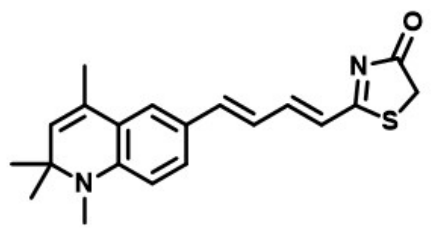

Ox-NIRLuc6

Figure S6. Chemical structures of oxidized forms of AkaLumine and NIRLucs. 
Table S1. Calculated Frontier orbitals and oscillator strengths of AkaLumine and NIRLucs at the basis of B3LYP/6-31+G(d)

\begin{tabular}{|c|c|c|c|c|c|c|}
\hline Compound & $\begin{array}{l}\mathrm{HOMO} \\
\text { [eV] }\end{array}$ & $\begin{array}{l}\text { LUMO } \\
{[\mathrm{eV}]}\end{array}$ & $\begin{array}{l}\Delta E^{\mathrm{a}} \\
{[\mathrm{eV}]}\end{array}$ & $\begin{array}{l}\lambda_{\mathrm{tr}}^{\mathrm{b}} \\
{[\mathrm{nm}]}\end{array}$ & $\begin{array}{l}\text { Oscillator strength } \\
\qquad f[-]\end{array}$ & $\begin{array}{r}\varphi_{\mathrm{Fl}}^{\mathrm{c}} \\
{[-]}\end{array}$ \\
\hline AkaLumine & -5.54 & -2.65 & 2.89 & 429 & 1.38 & 0.025 \\
\hline NIRLuc1 & -5.53 & -2.66 & 2.86 & 433 & 1.33 & 0.017 \\
\hline NIRLuc2 & -5.46 & -2.63 & 2.83 & 439 & 1.34 & 0.029 \\
\hline NIRLuc3 & -5.46 & -2.63 & 2.83 & 438 & 1.34 & 0.030 \\
\hline NIRLuc4 & -5.55 & -2.68 & 2.87 & 432 & 1.20 & 0.021 \\
\hline NIRLuc5 & -5.28 & -2.54 & 2.74 & 452 & 1.39 & 0.021 \\
\hline NIRLuc6 & -5.34 & -2.60 & 2.74 & 452 & 1.25 & 0.025 \\
\hline
\end{tabular}

${ }^{a}$ Energy band gap between HOMO-LUMO, ${ }^{b}$ calculated transition wavelengths from energy band gap,

${ }^{c}$ Absolute fluorescence quantum yield in 50 mM GTA buffer ( $\left.\mathrm{pH} 8.0\right)$. 


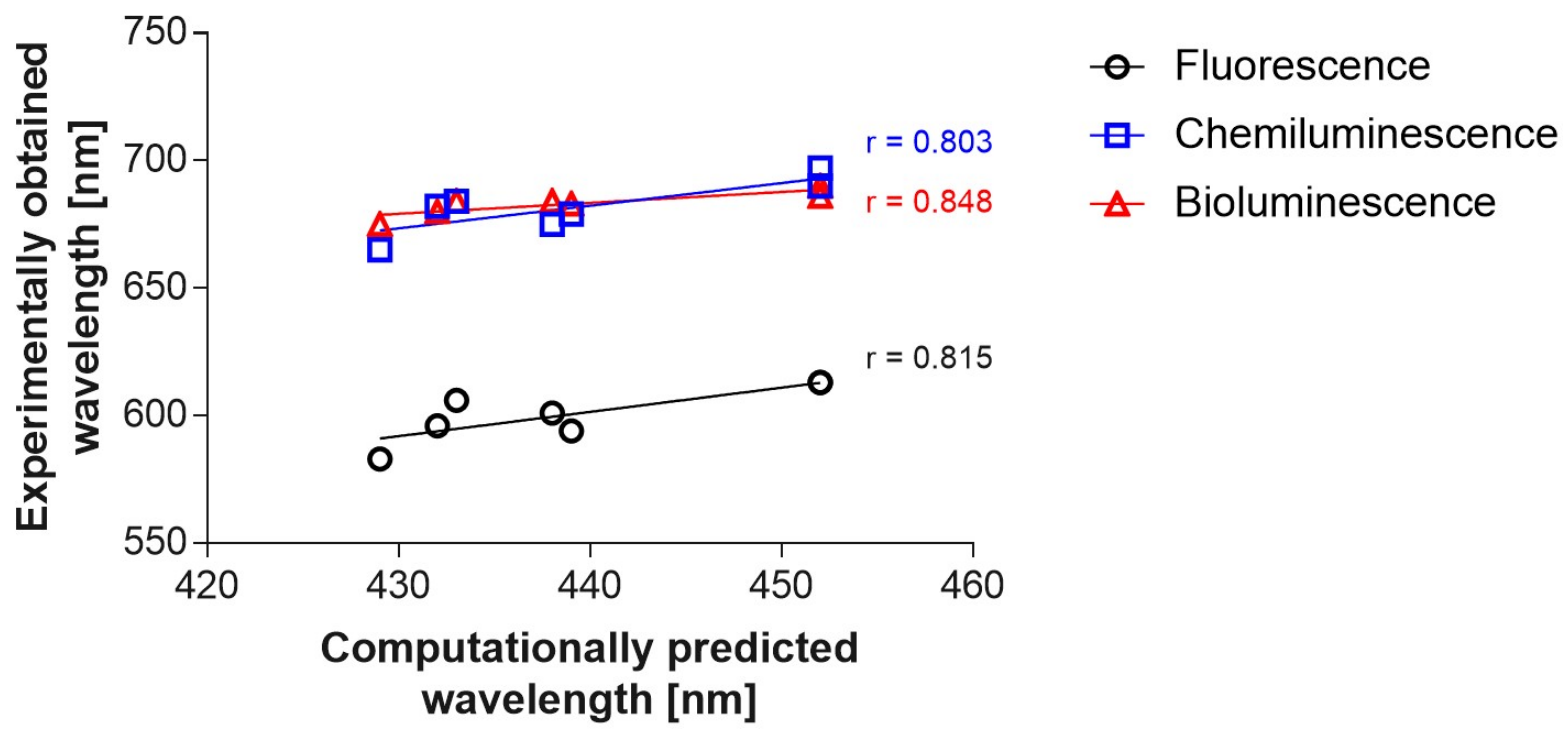

Figure S7. Experimental and computational emission wavelengths of luciferins. Computationally predicted wavelengths were calculated at the B3LYP/6-31+G(d) level without inclusion of solvent effects using the Gaussian 09 program.

r: Pearson correlation value. 


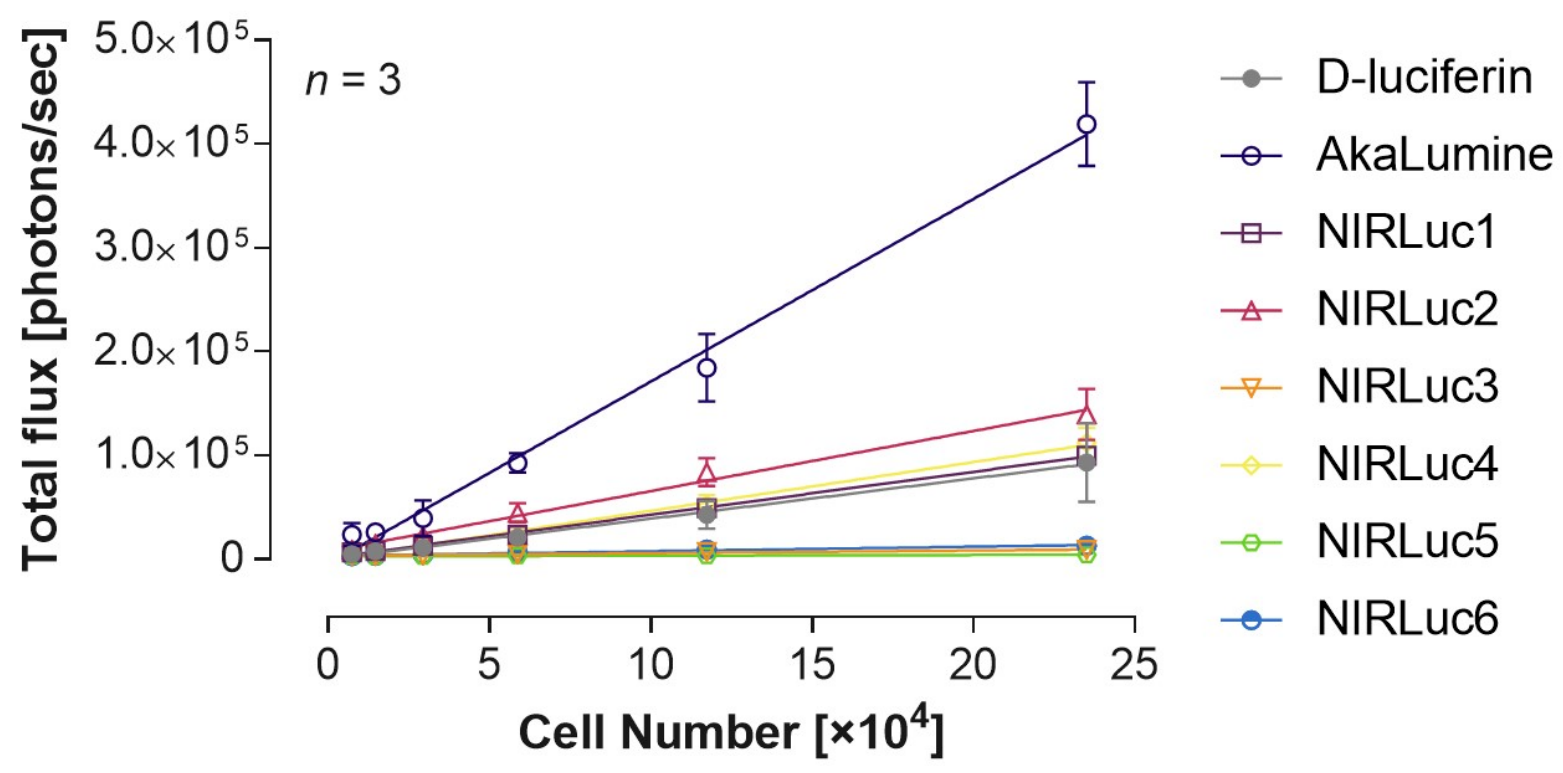

Figure S8. Cell number-dependent bioluminescence of stably luciferase-expressing B16F10 cells with $25 \mu \mathrm{M}$ luciferins. Error bars represent the standard error of the mean. Exposure time: $180 \mathrm{sec}$. 
Table S2. Fraction of NIR light emission from stably luciferase-expressing B16-F10 cells.

\begin{tabular}{cc} 
Compound & Fraction of NIR emission ${ }^{\mathrm{a}}[\%]$ \\
\hline D-luciferin & $3.0 \pm 2.9$ \\
AkaLumine & $18.1 \pm 0.6$ \\
NIRLuc1 & $18.2 \pm 0.9$ \\
NIRLuc2 & $19.4 \pm 2.0$ \\
NIRLuc3 & $21.2 \pm 2.9$ \\
NIRLuc4 & $16.1 \pm 3.2$ \\
NIRLuc5 & $11.1 \pm 1.6$ \\
NIRLuc6 & $14.7 \pm 6.6$
\end{tabular}

${ }^{\text {a }}$ Fractions of NIR light emission were calculated from the photon flux with open filter and NIR (680 \pm $10 \mathrm{~nm}$ ) filter. 

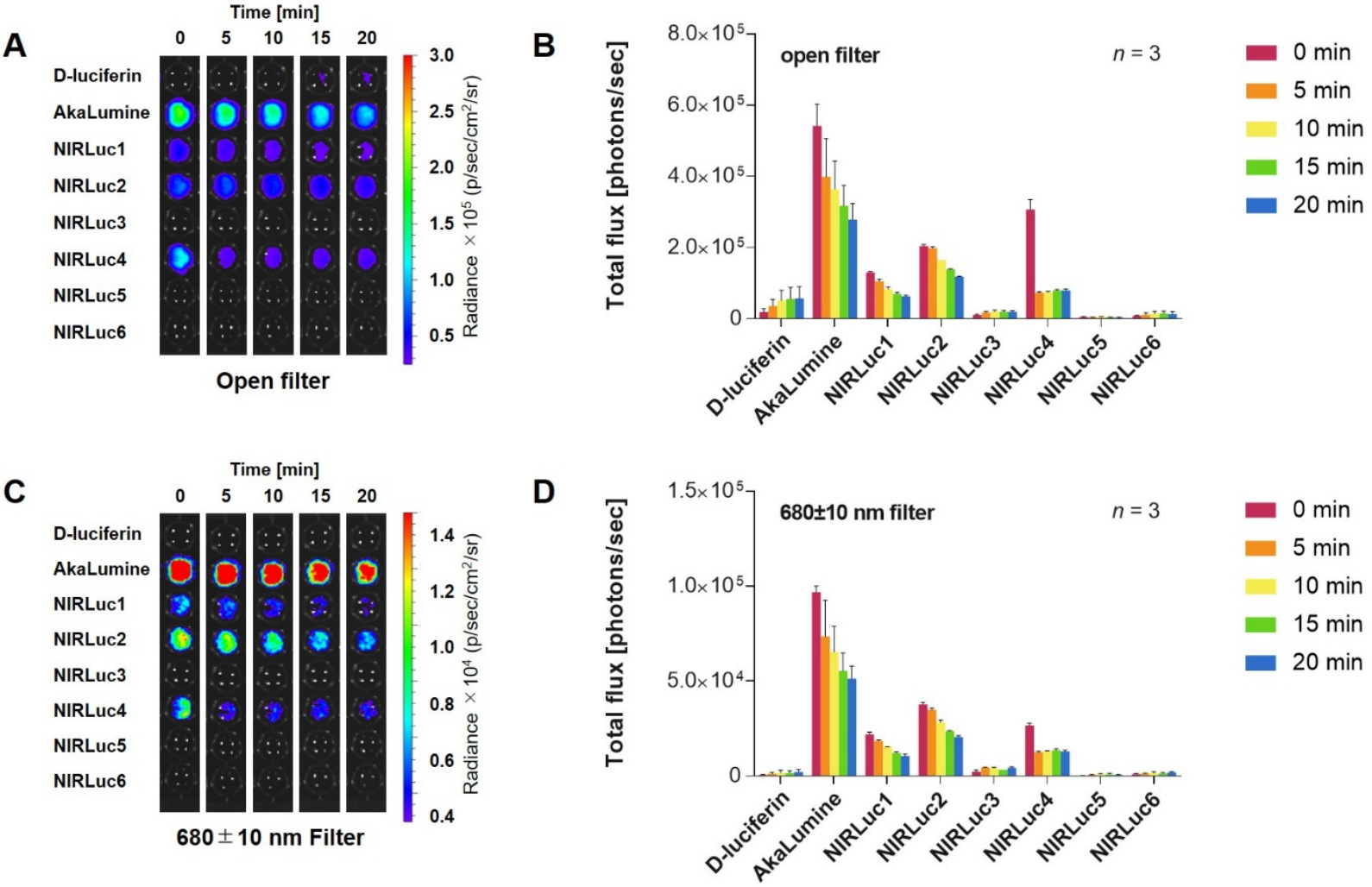

Figure S9. Time-dependent photon output from stably Fluc-expressing B16F10 cells treated with 0.25 $\mu \mathrm{M}$ luciferins. (A, C) Bioluminescence imaging of cells with open filter (A) or NIR (680 $\pm 10 \mathrm{~nm})$ filter (C). (B, D) Quantification of the imaged bioluminescent signals with open filter (B) or NIR (680 \pm 10 $\mathrm{nm}$ ) filter (D). Error bars represent the standard error of the mean for triplicate experiments. Exposure time: $60 \mathrm{sec}$. 
A

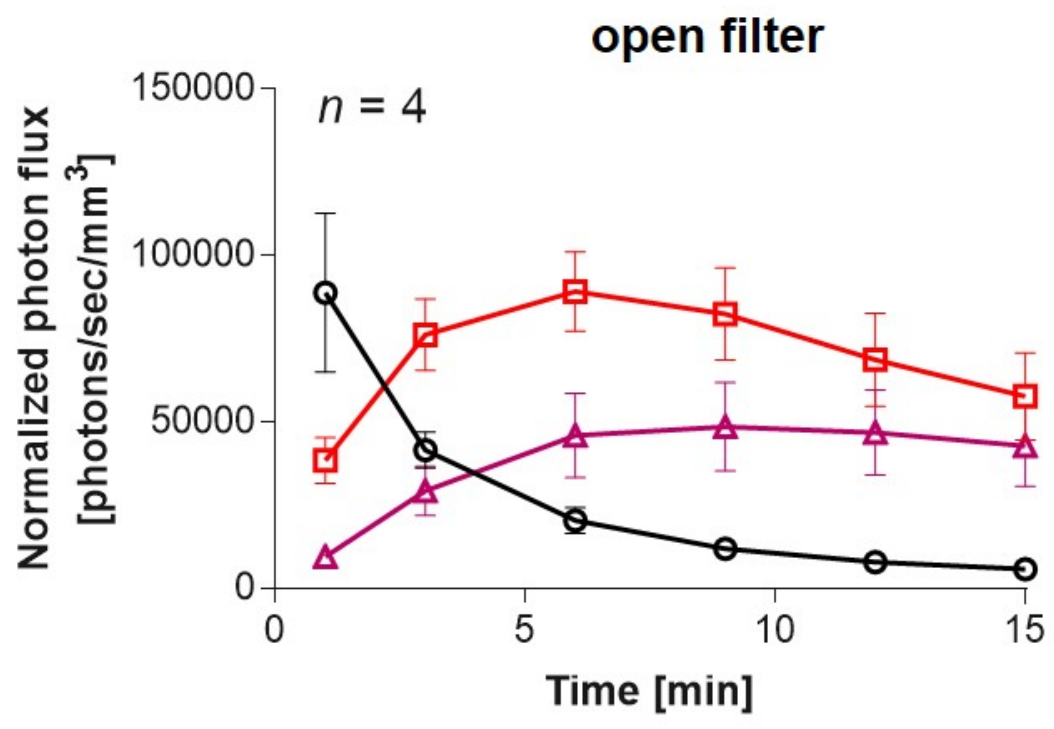

$\diamond$ D-luciferin $\square$ AkaLumine $\triangle$ NIRLuc2

B

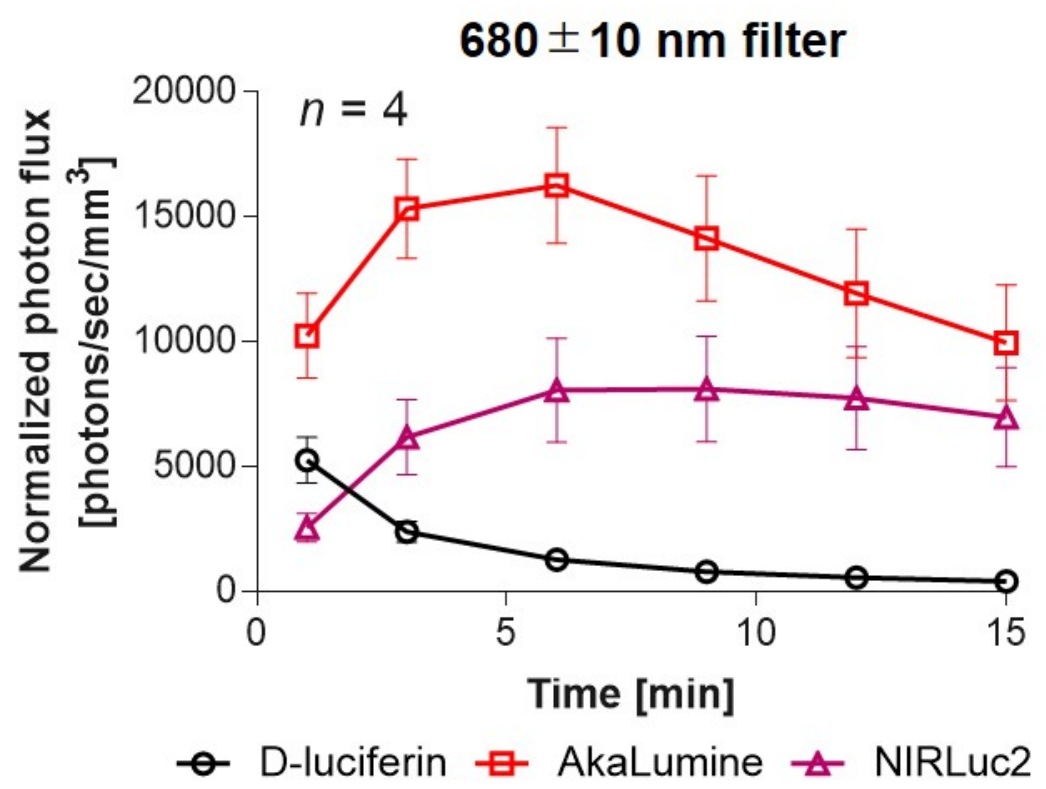

Figure S10. Time course of bioluminescent photon flux from subcutaneous tumors in vivo with open filter (A) or NIR $(680 \pm 10 \mathrm{~nm})$ filter $(B)$. Error bars represent the standard error of the mean for quadruplicate experiments. Photon flux was normalized by tumor volume. 


\section{References:}

1. Mayer, R. J.; Hampel, N.; Mayer, P.; Ofial, A. R.; Mayr, H., (2019) Synthesis, Structure, and Properties of Amino-Substituted Benzhydrylium lons - A Link between Ordinary Carbocations and Neutral Electrophiles, Eur. J. Org. Chem., 2-3, 412-421.

2. Orchard, A.; Schamerhorn, G. A.; Calitree, B. D.; Sawada, G. A.; Loo, T. W.; Claire Bartlett, M.; Clarke, D. M.; Detty, M. R., (2012) Thiorhodamines containing amide and thioamide functionality as inhibitors of the ATP-binding cassette drug transporter P-glycoprotein (ABCB1), Bioorg. Med. Chem., 20 (14), 4290-4302.

3. Kotha, S.; Kuki, A., (1992) A new synthetic approach to unusually electron rich a-amino acids, Chem. Commun., 5, 404-406.

4. Tian, K.; Hu, D.; Hu, R.; Wang, S.; Li, S.; Li, Y.; Yang, G., (2011) Multiple fluorescence $\Delta$ CIE and $\triangle \mathrm{RGB}$ codes for sensing volatile organic compounds with a wide range of responses, Chem. Commun., 47 (36), 10052-10054. 
NMR Spectra:
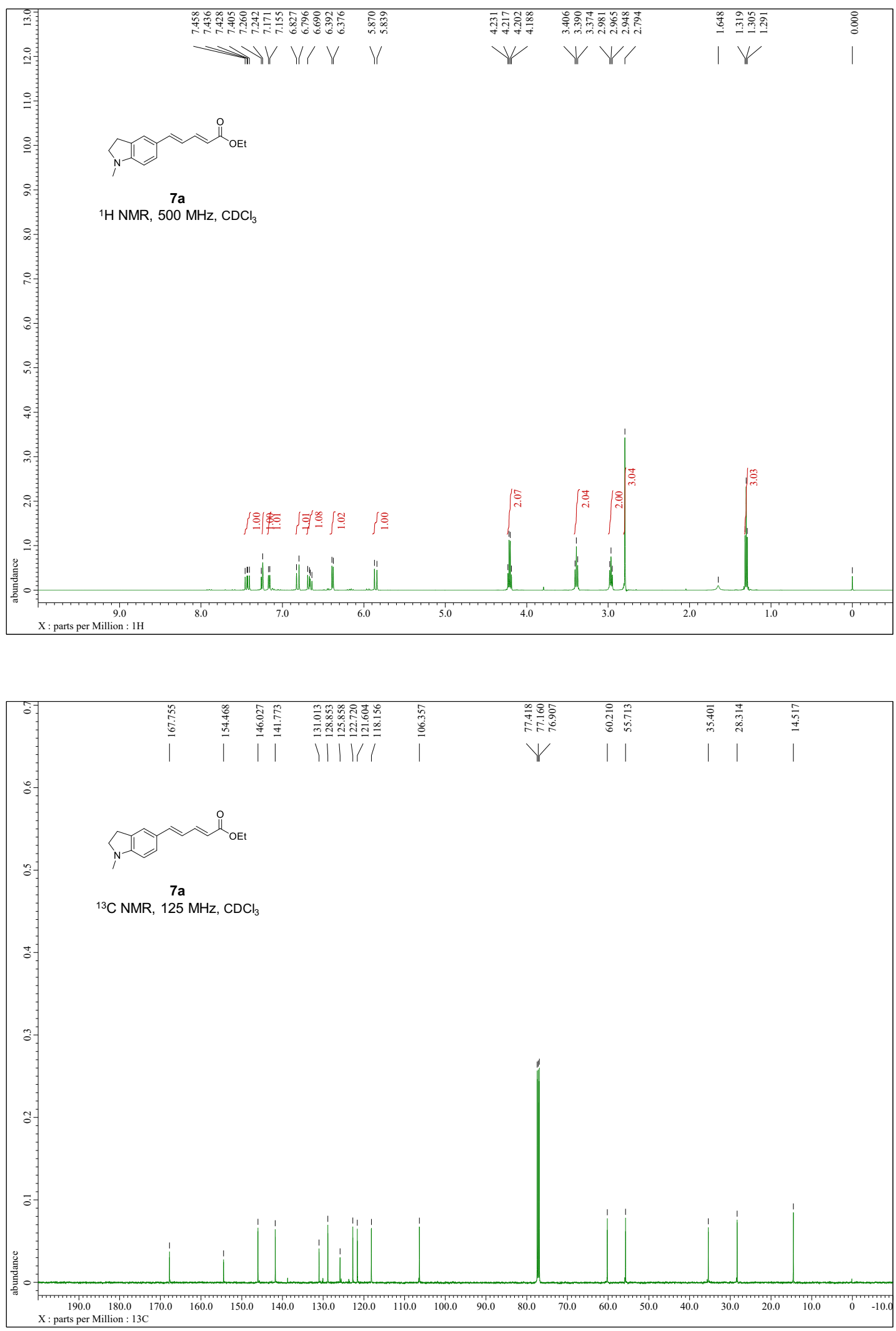

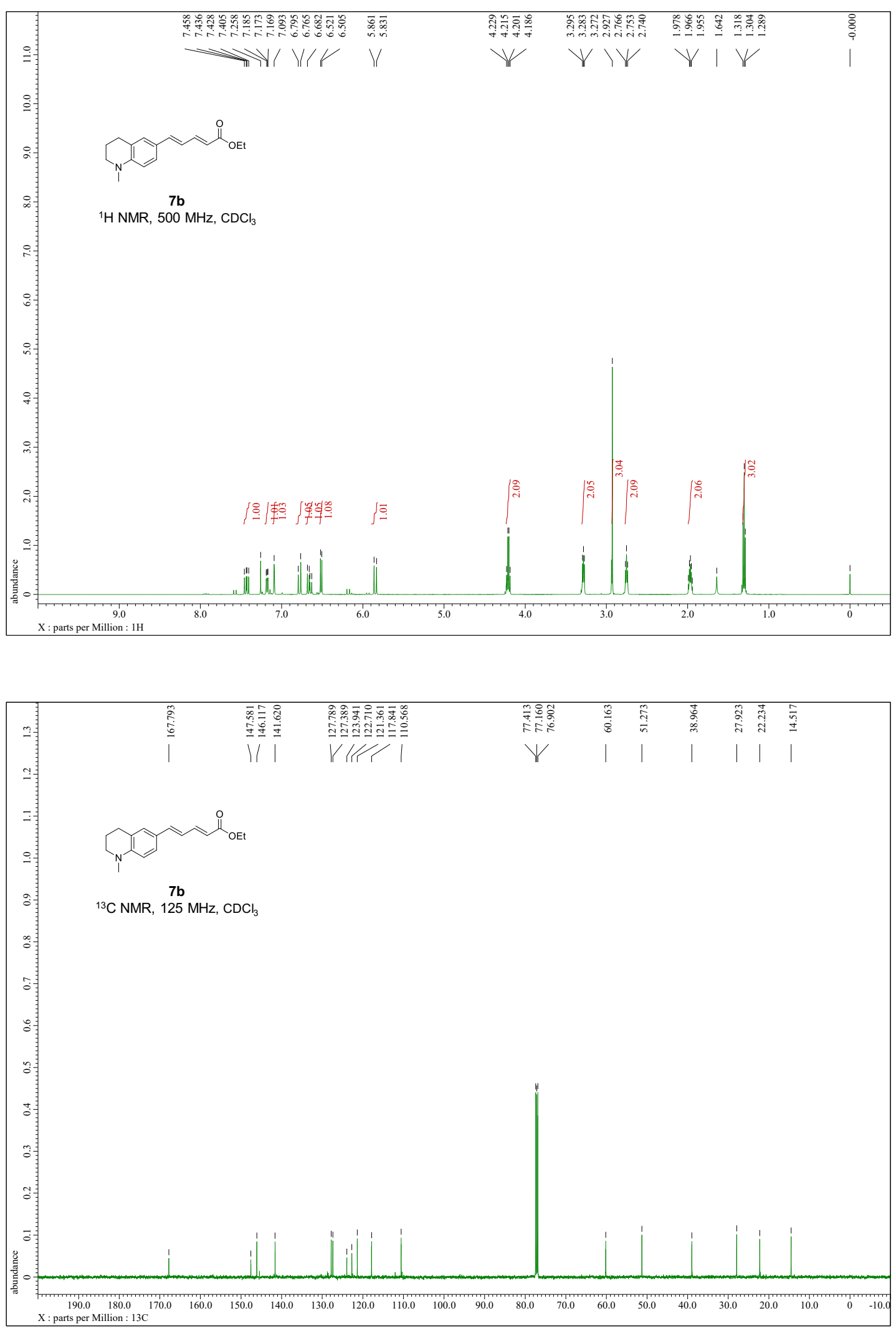

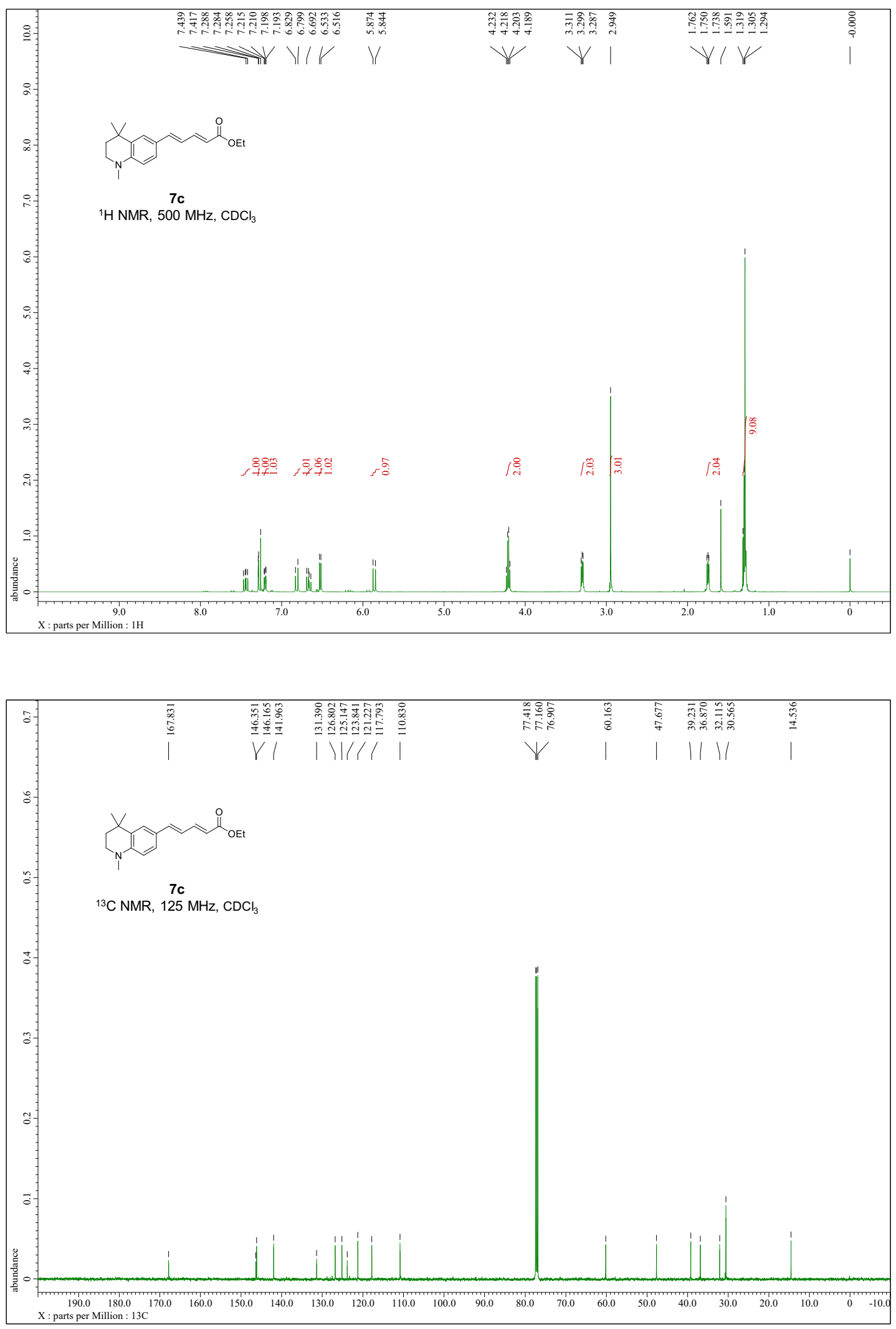

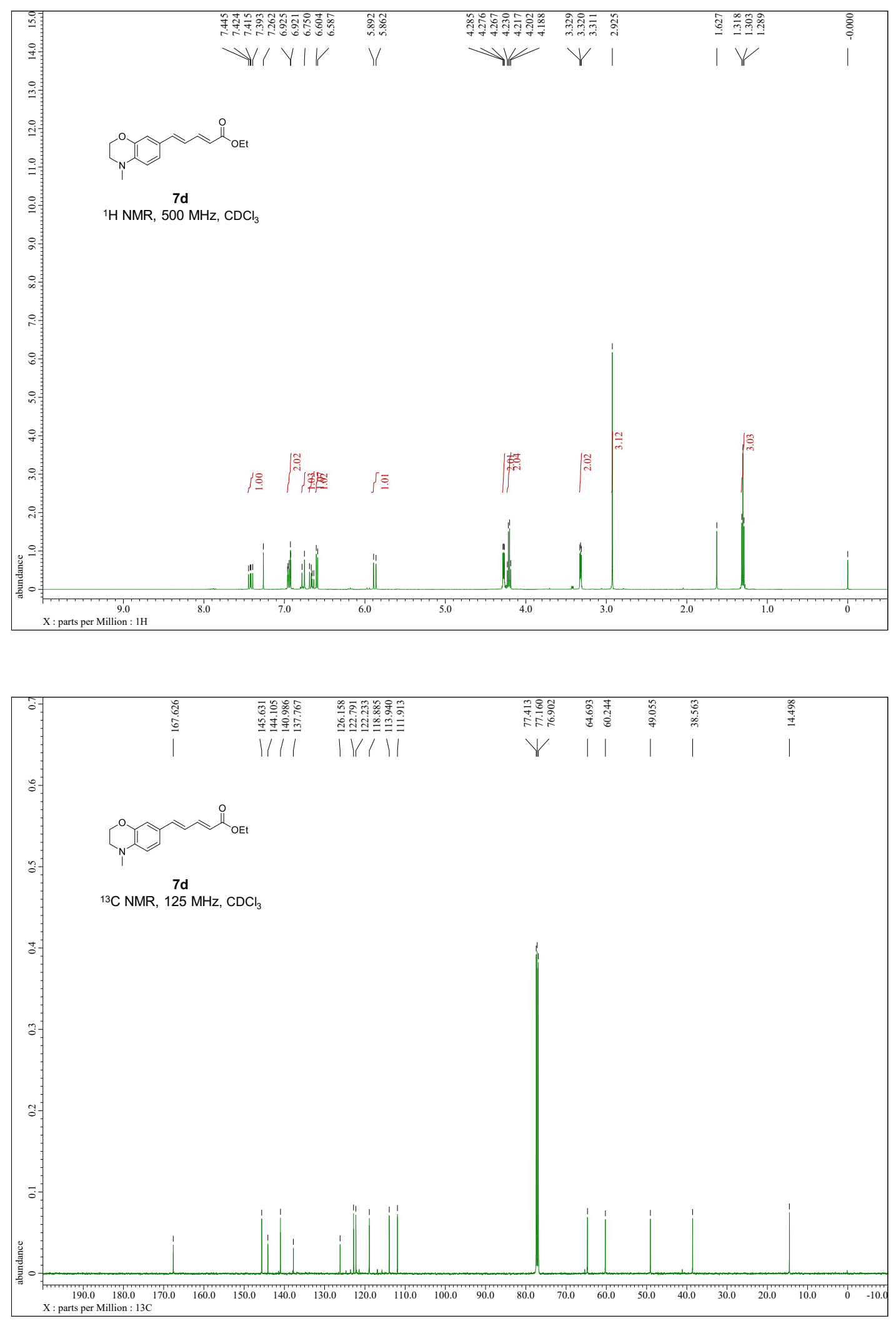

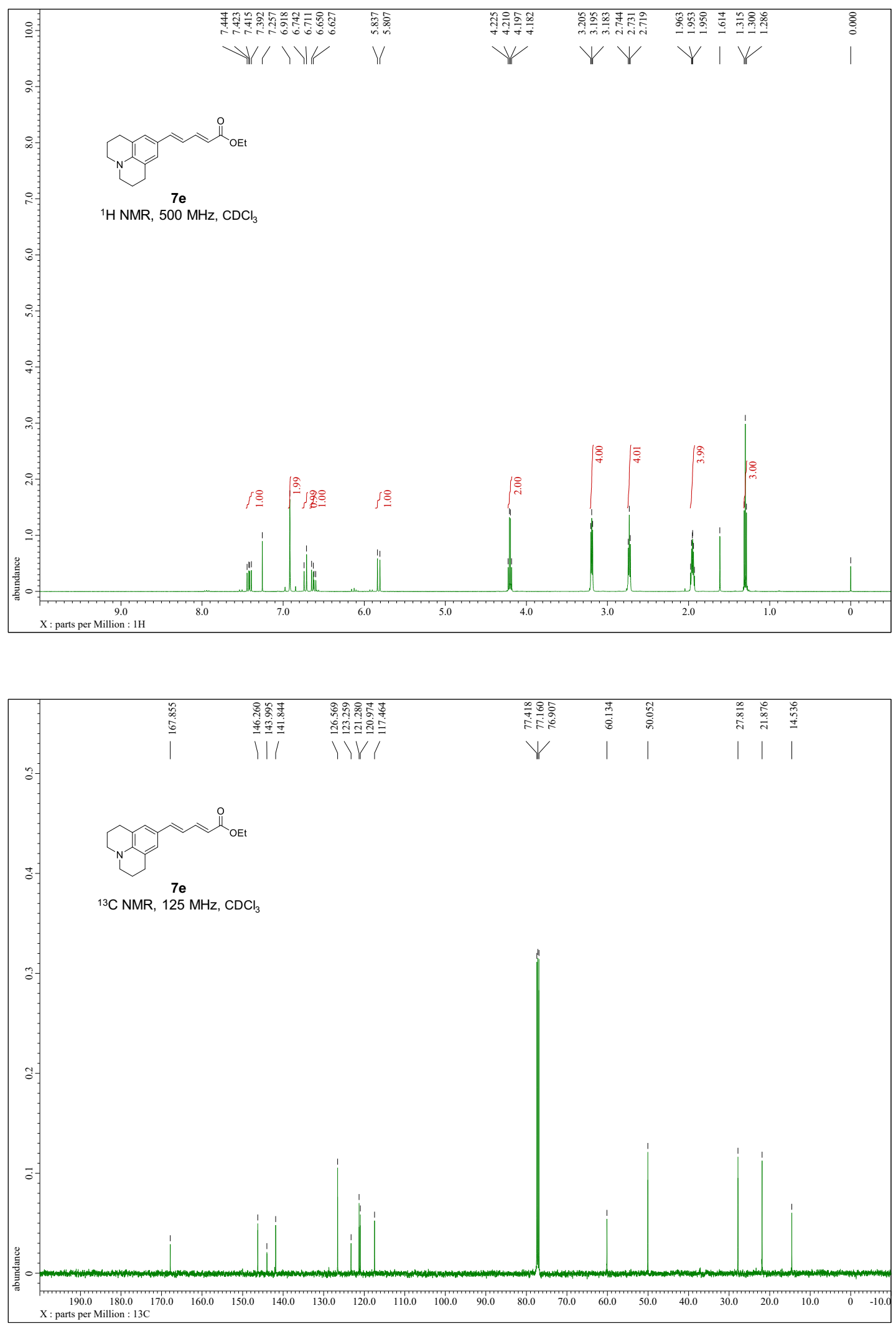

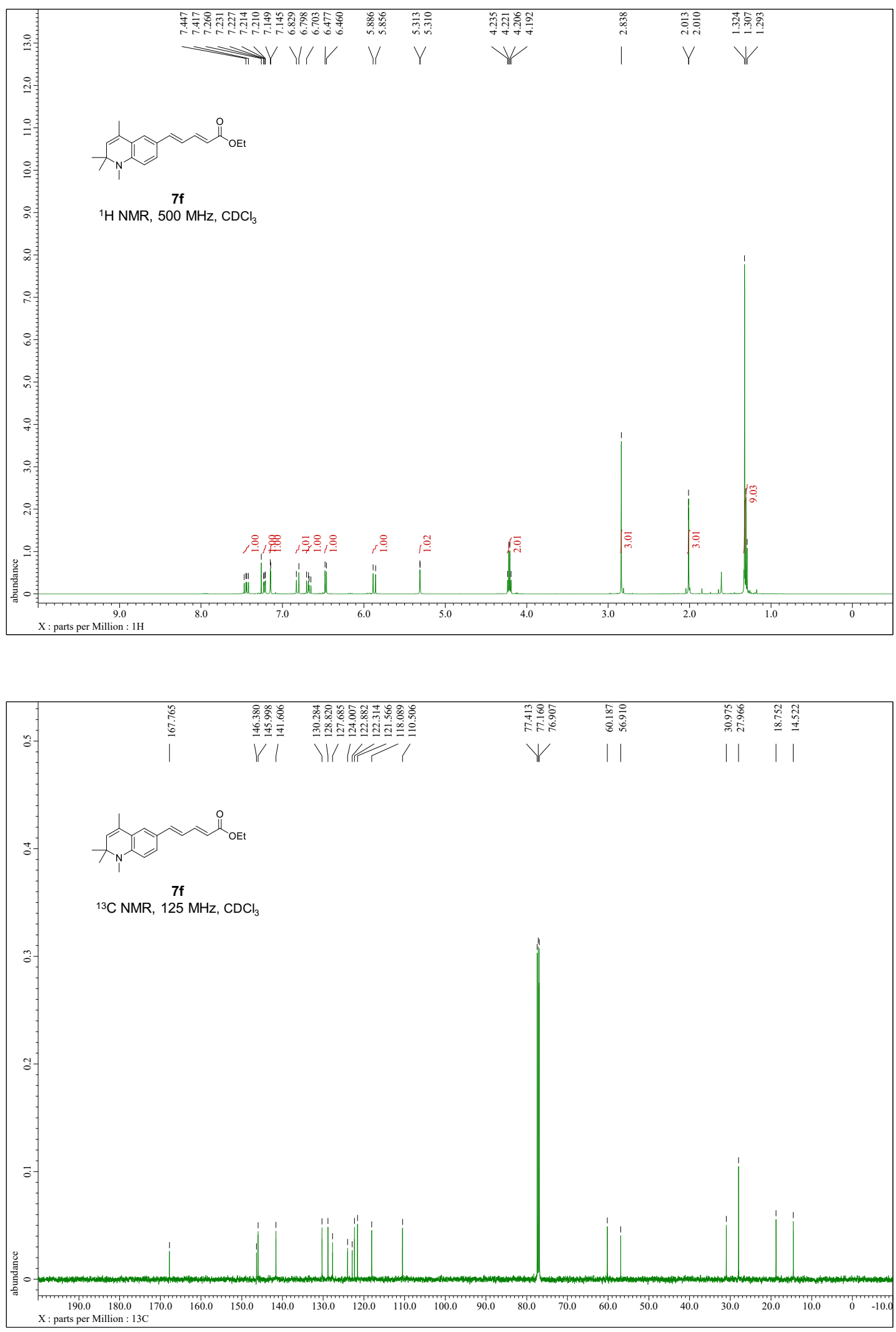

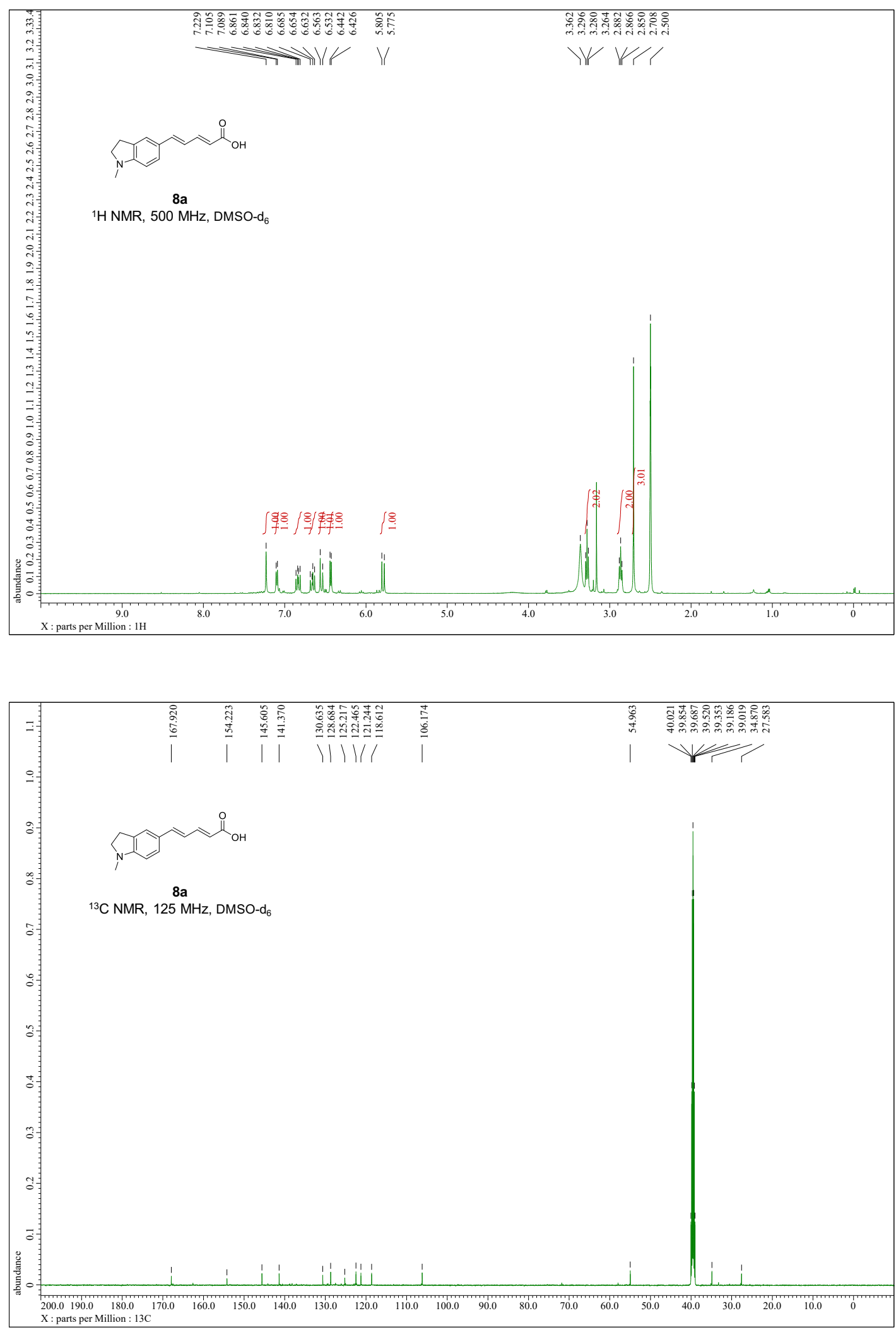

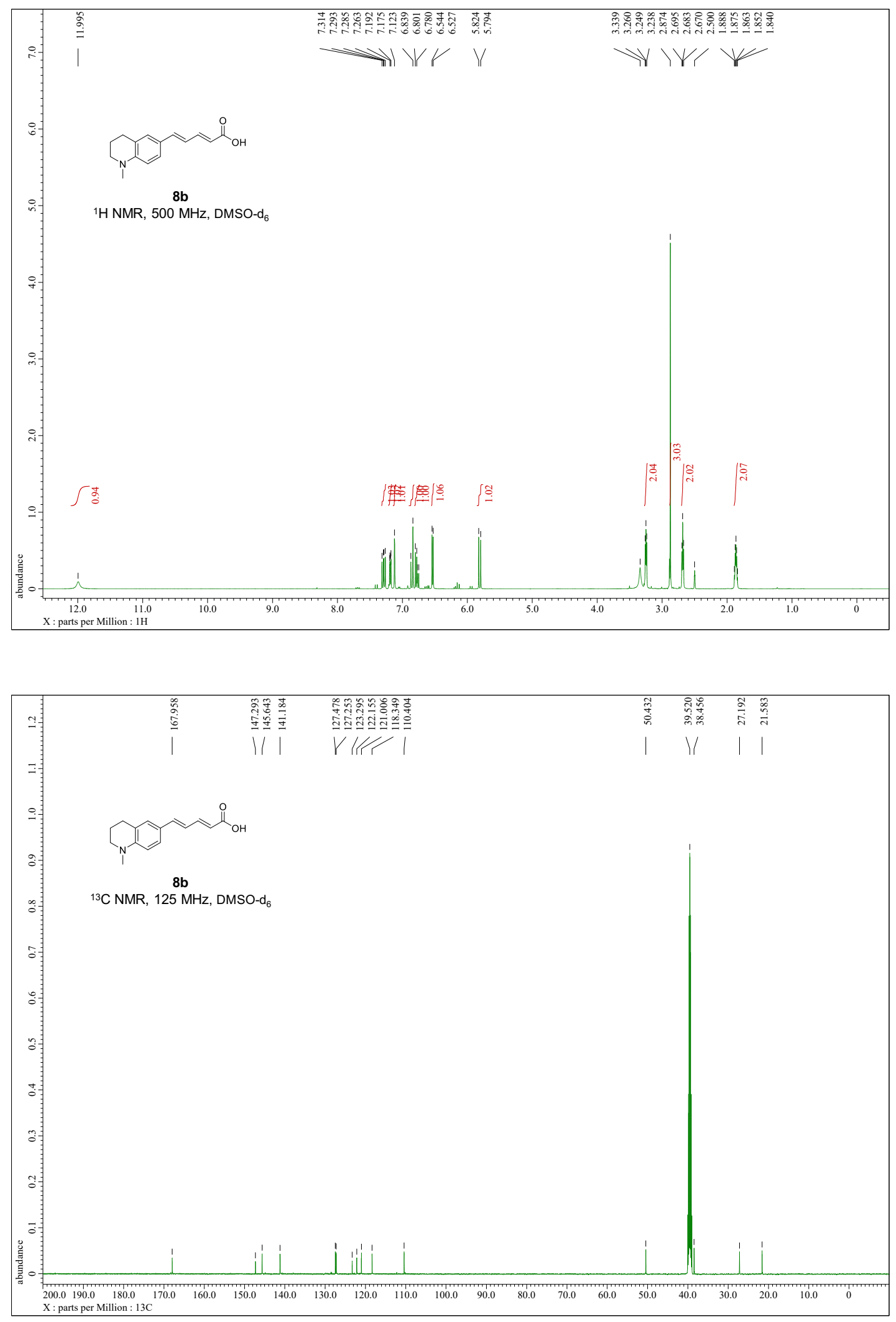

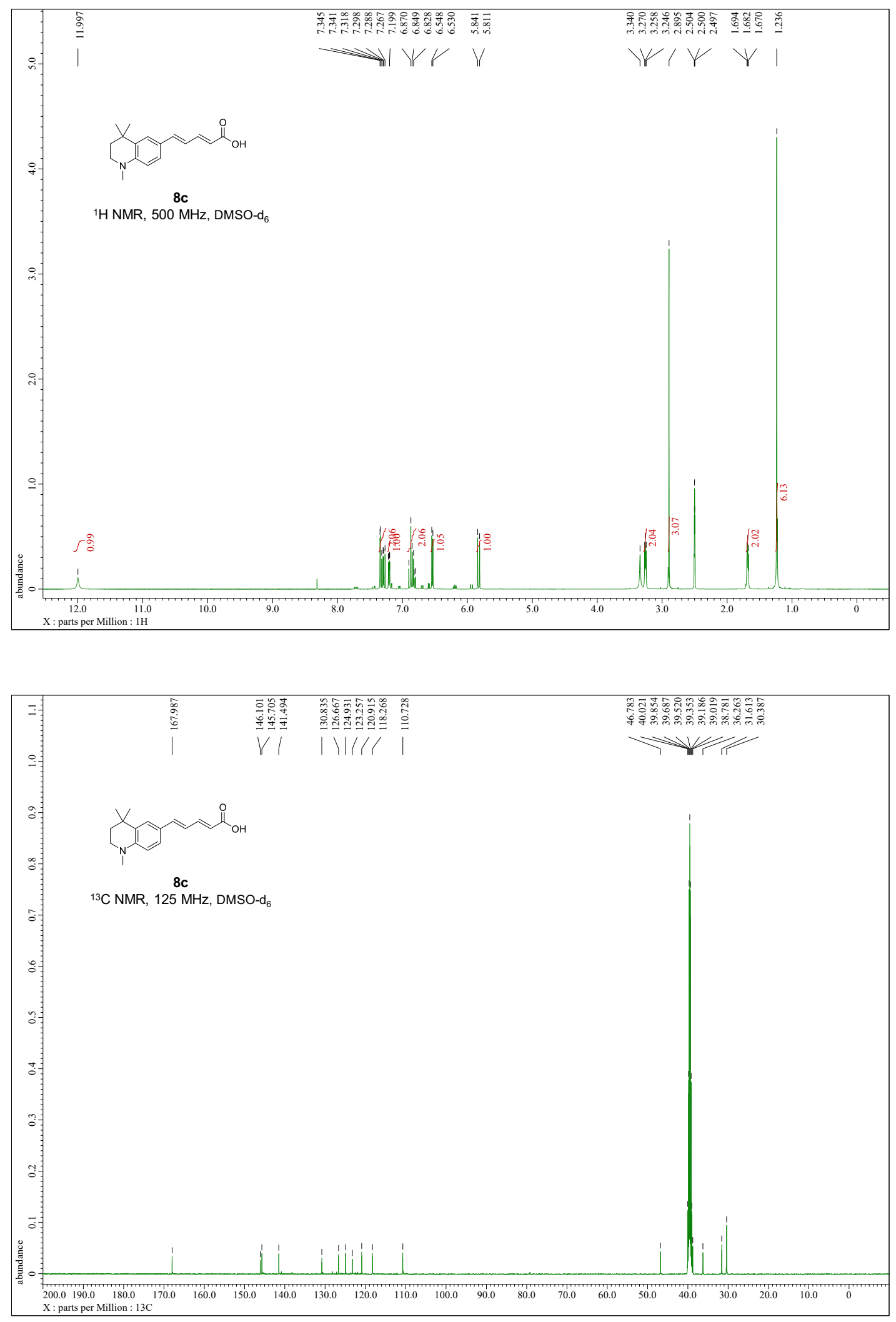

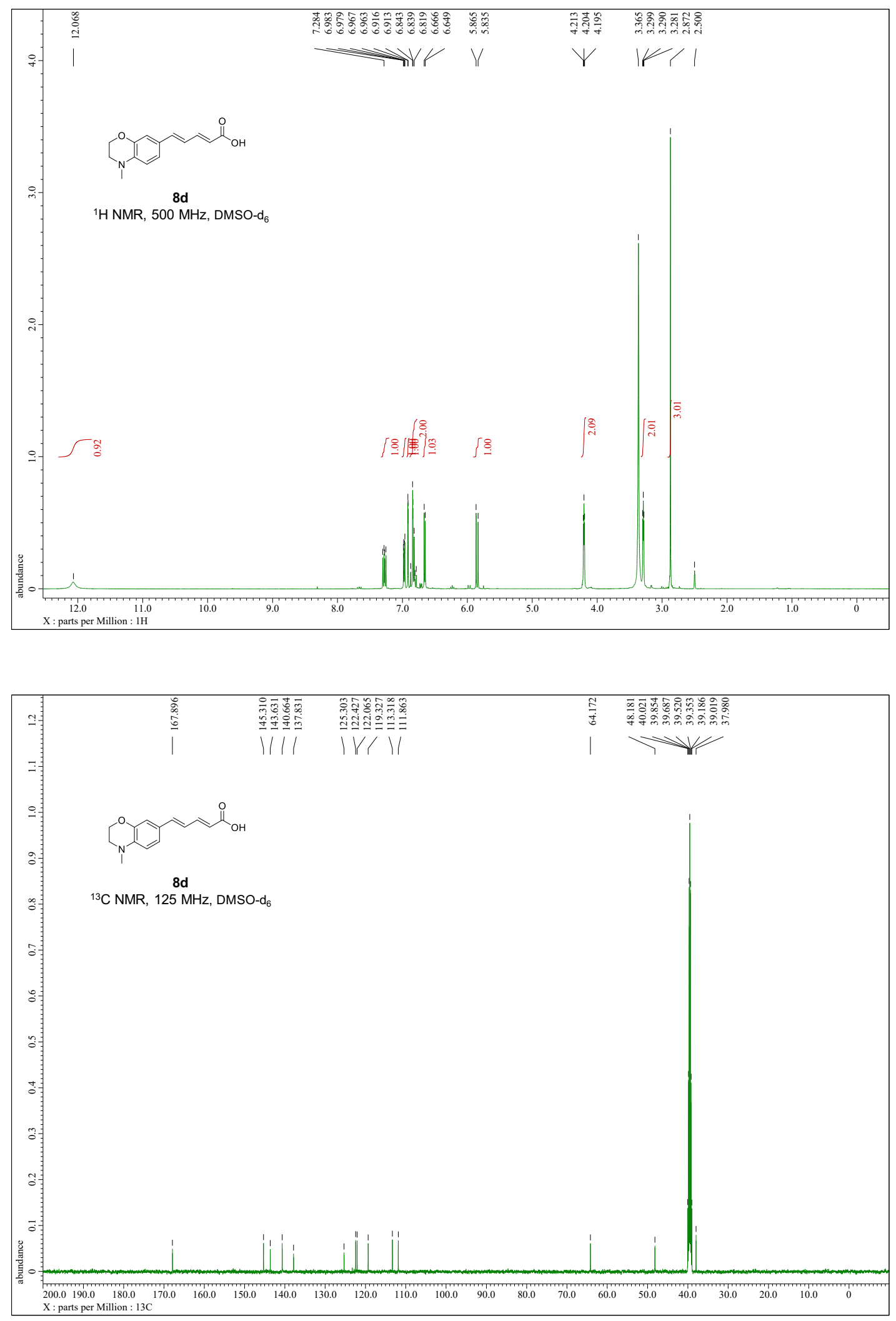

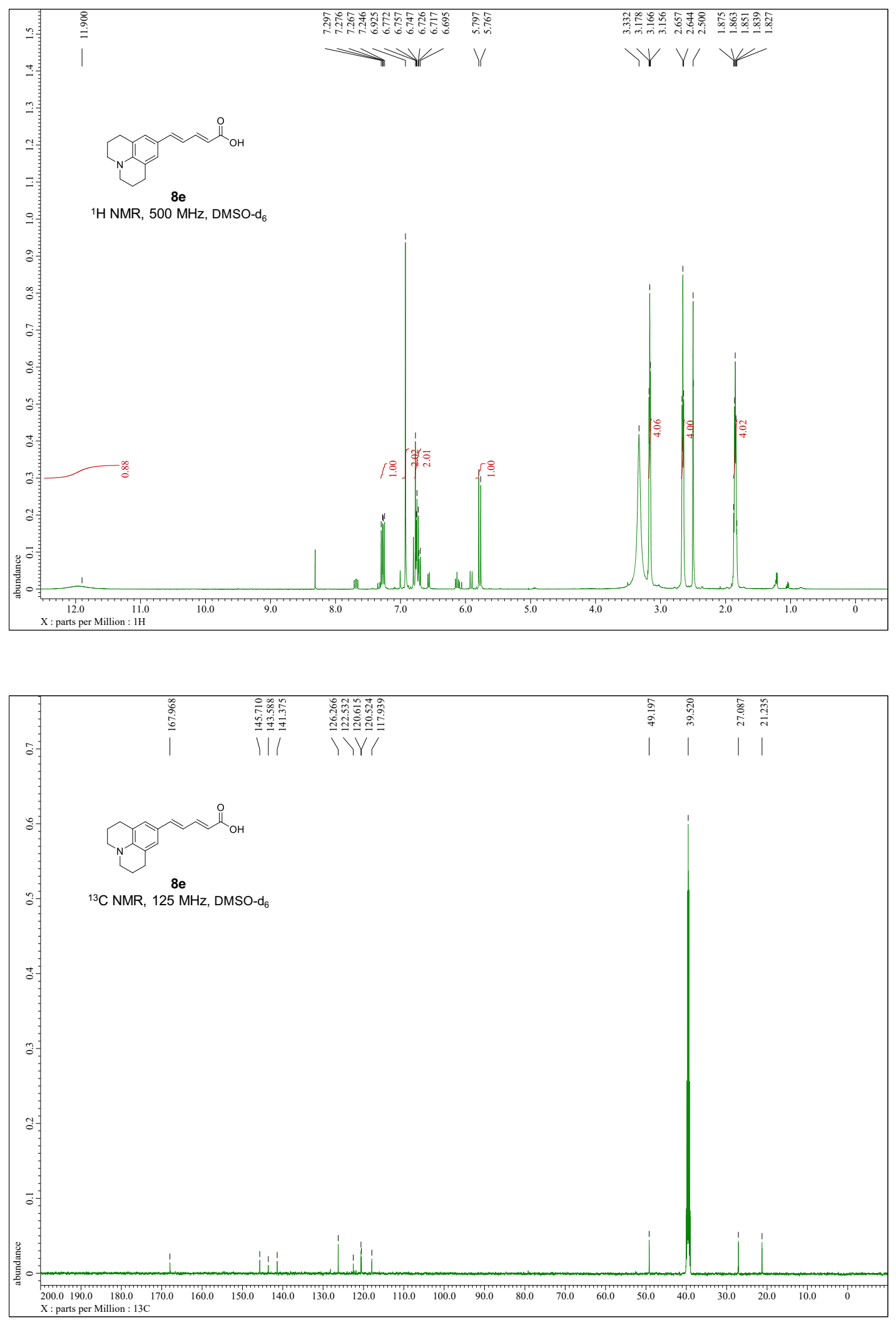

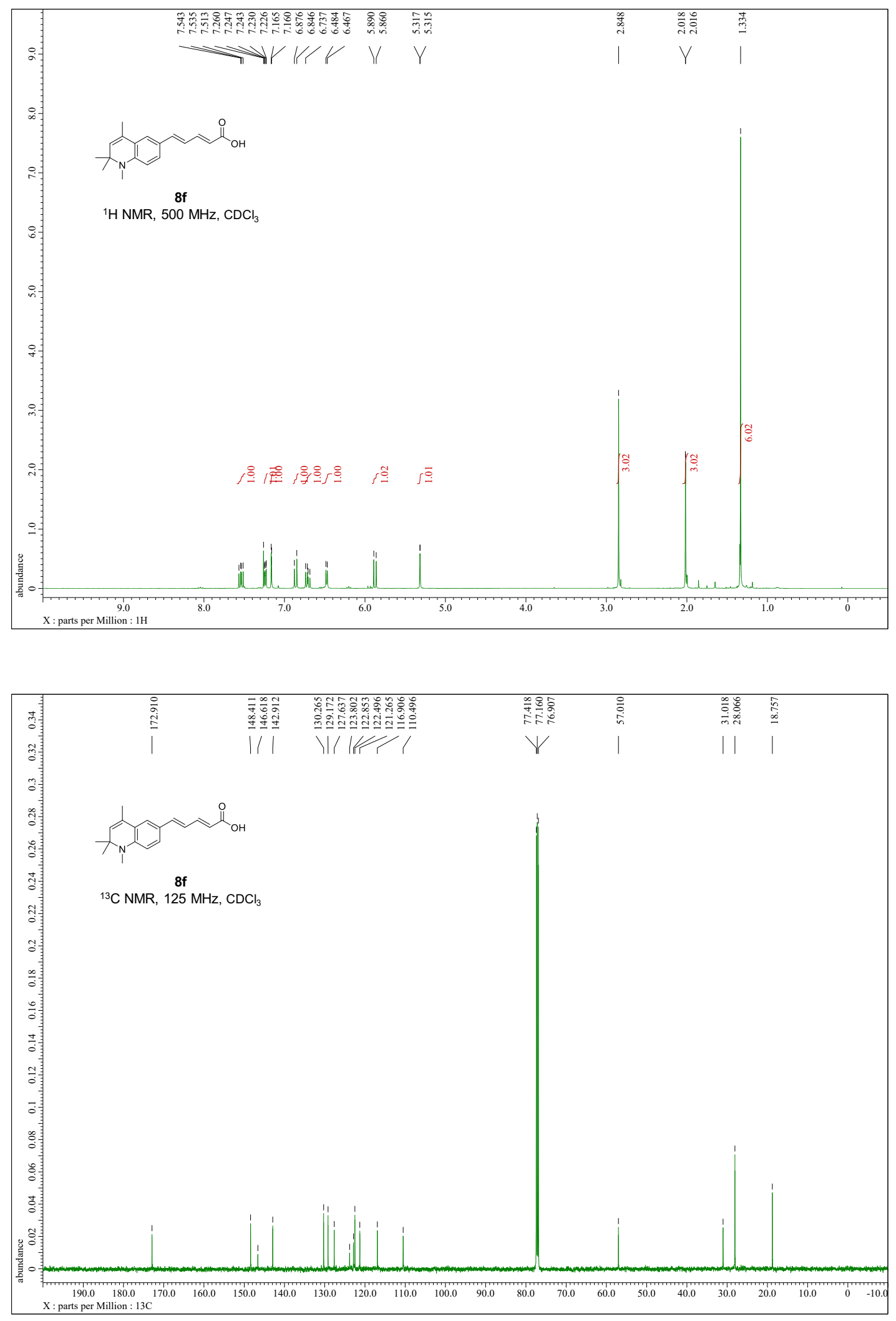

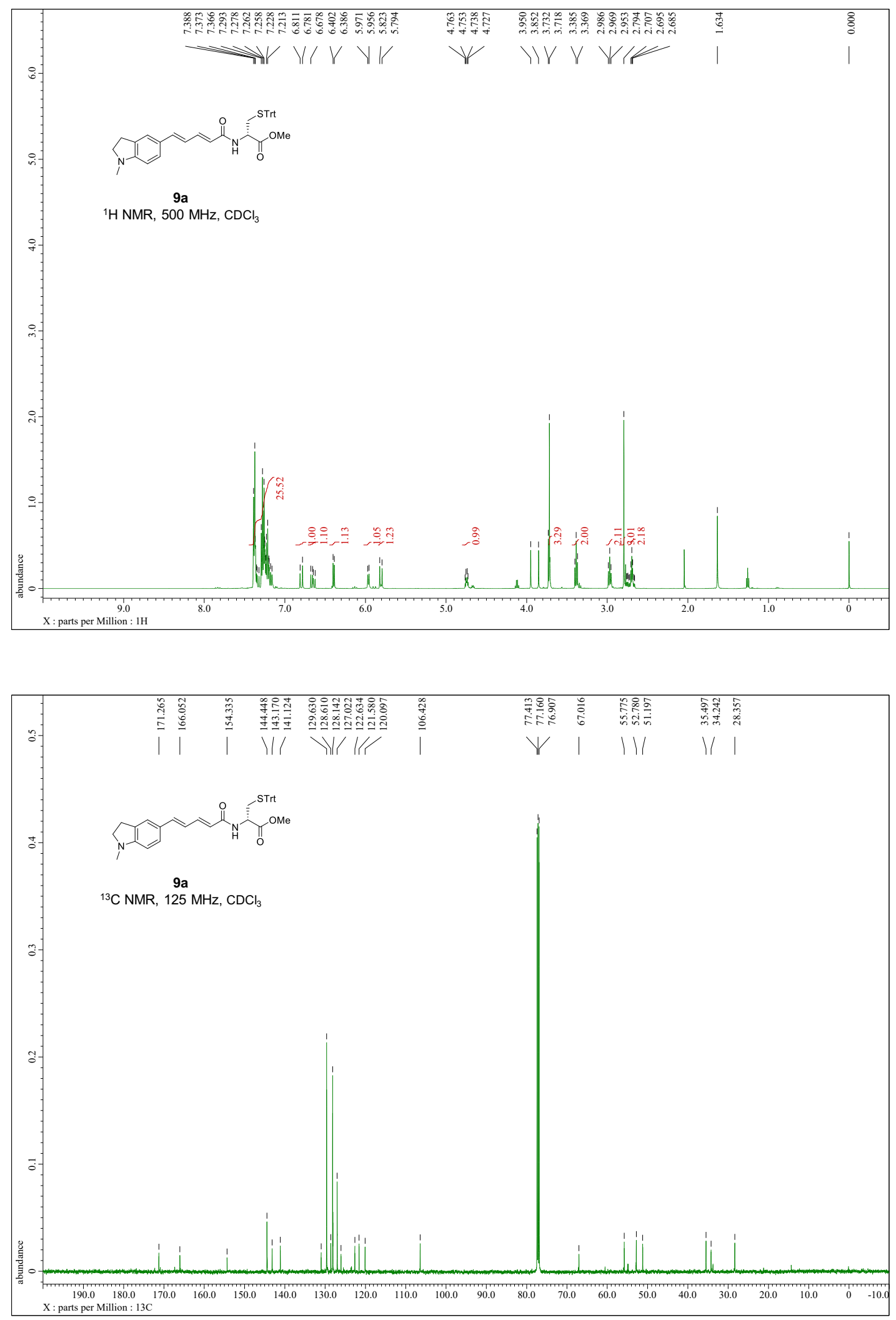

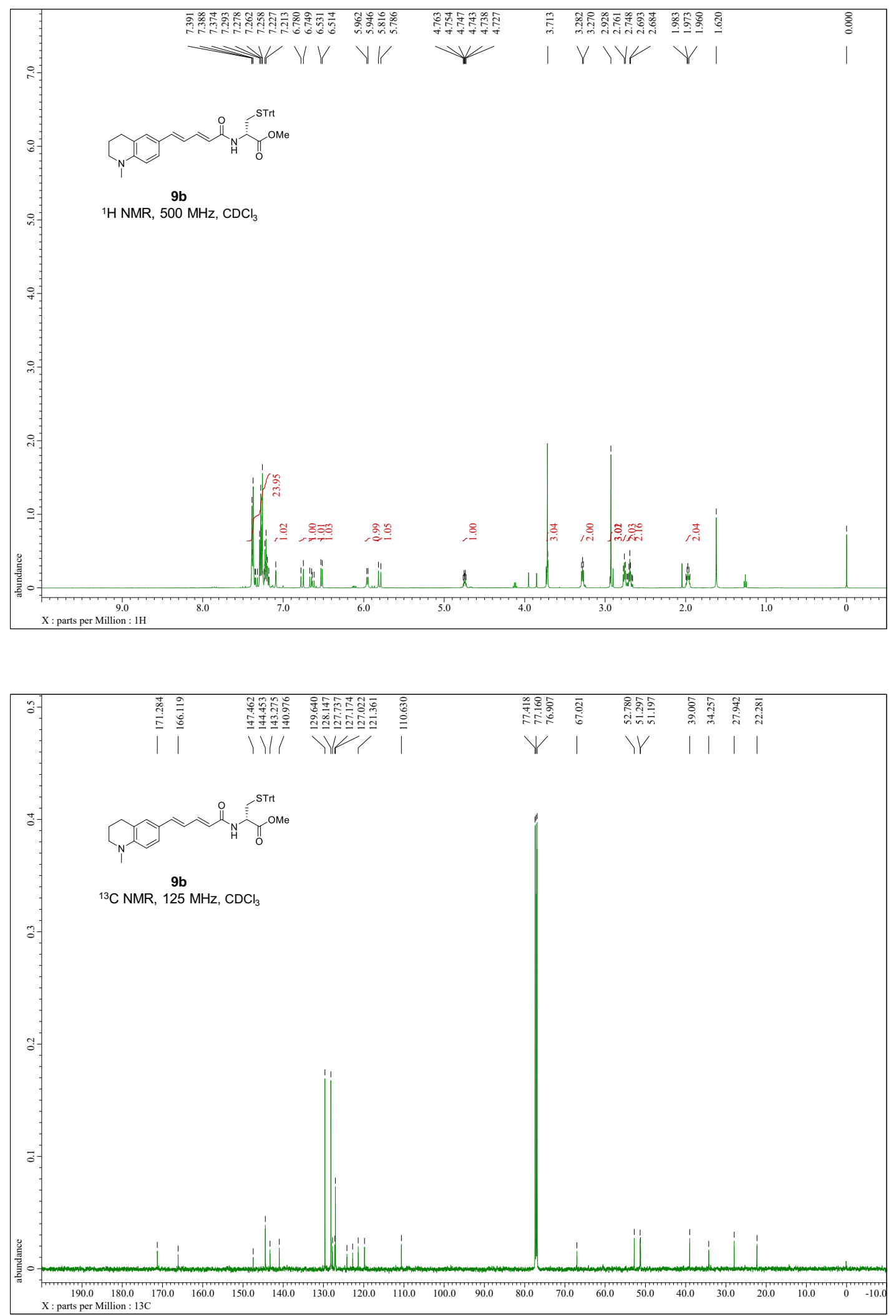

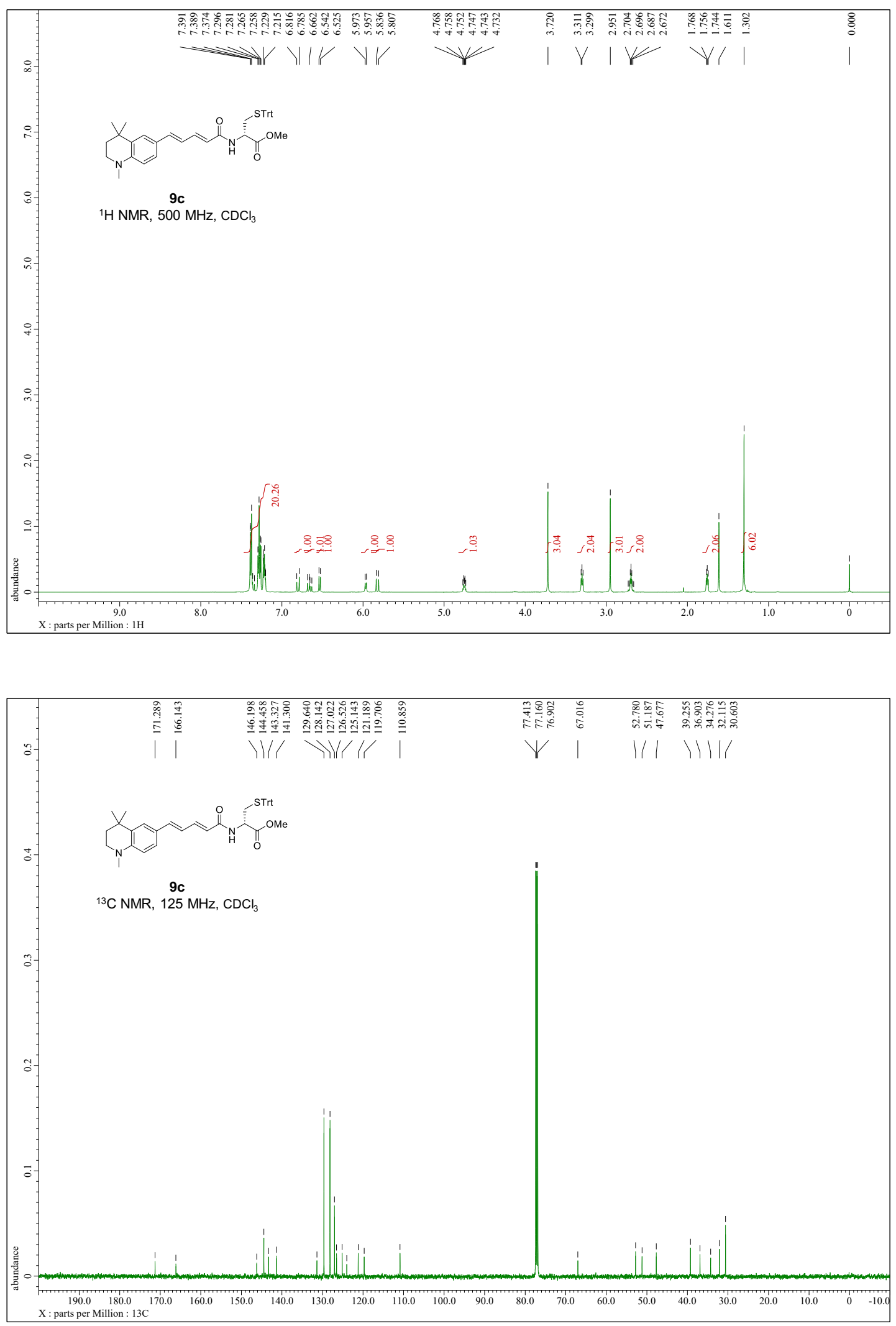

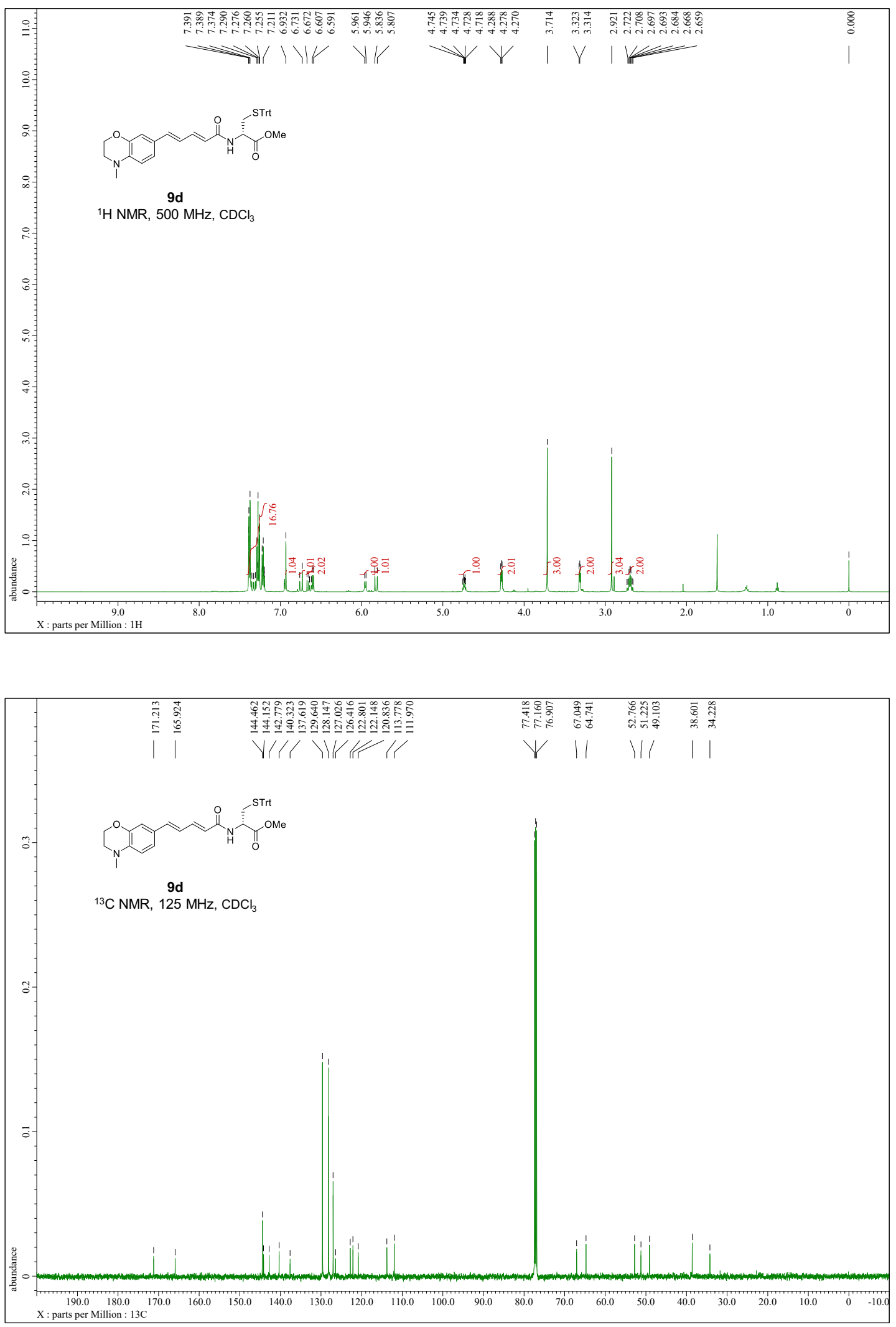

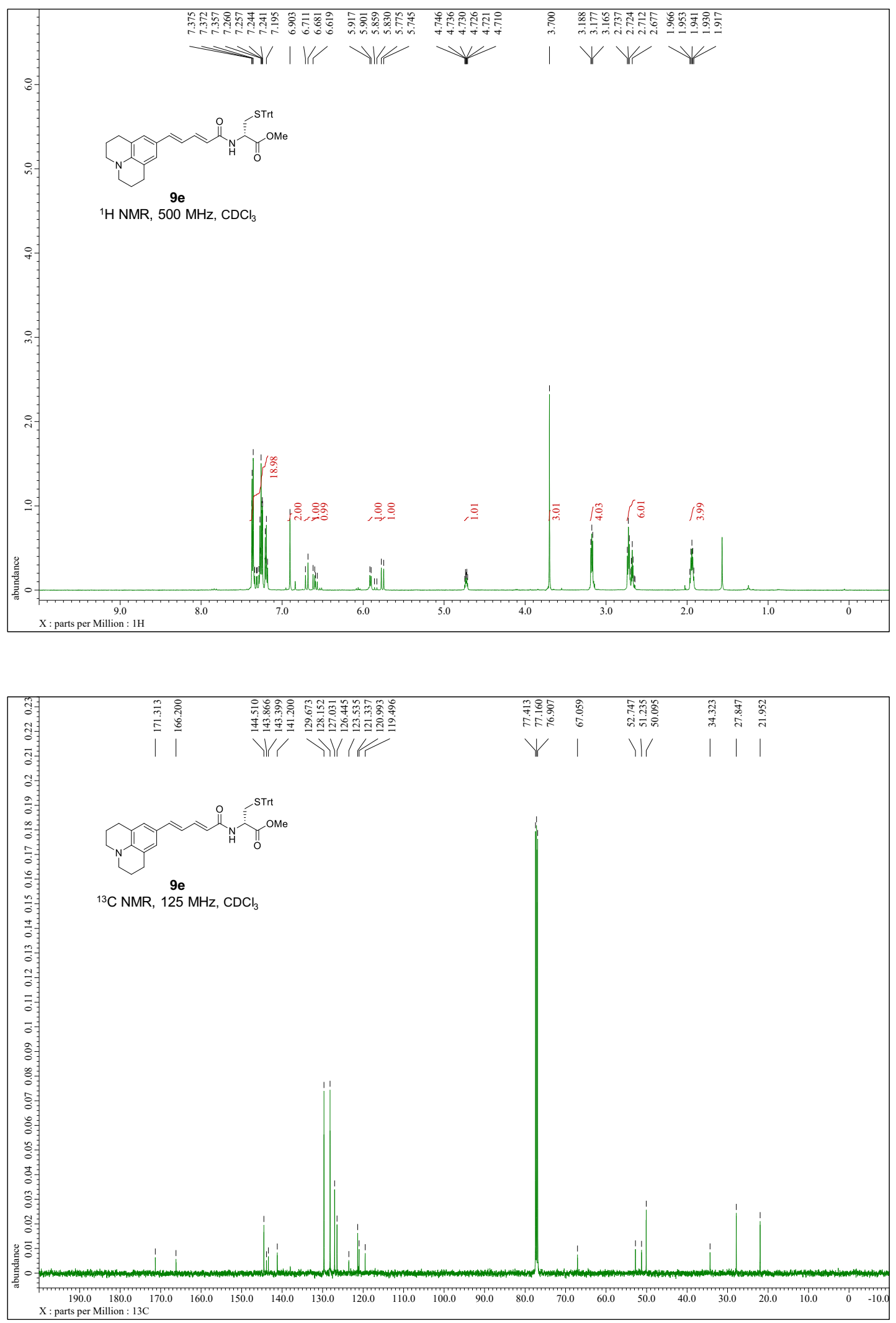

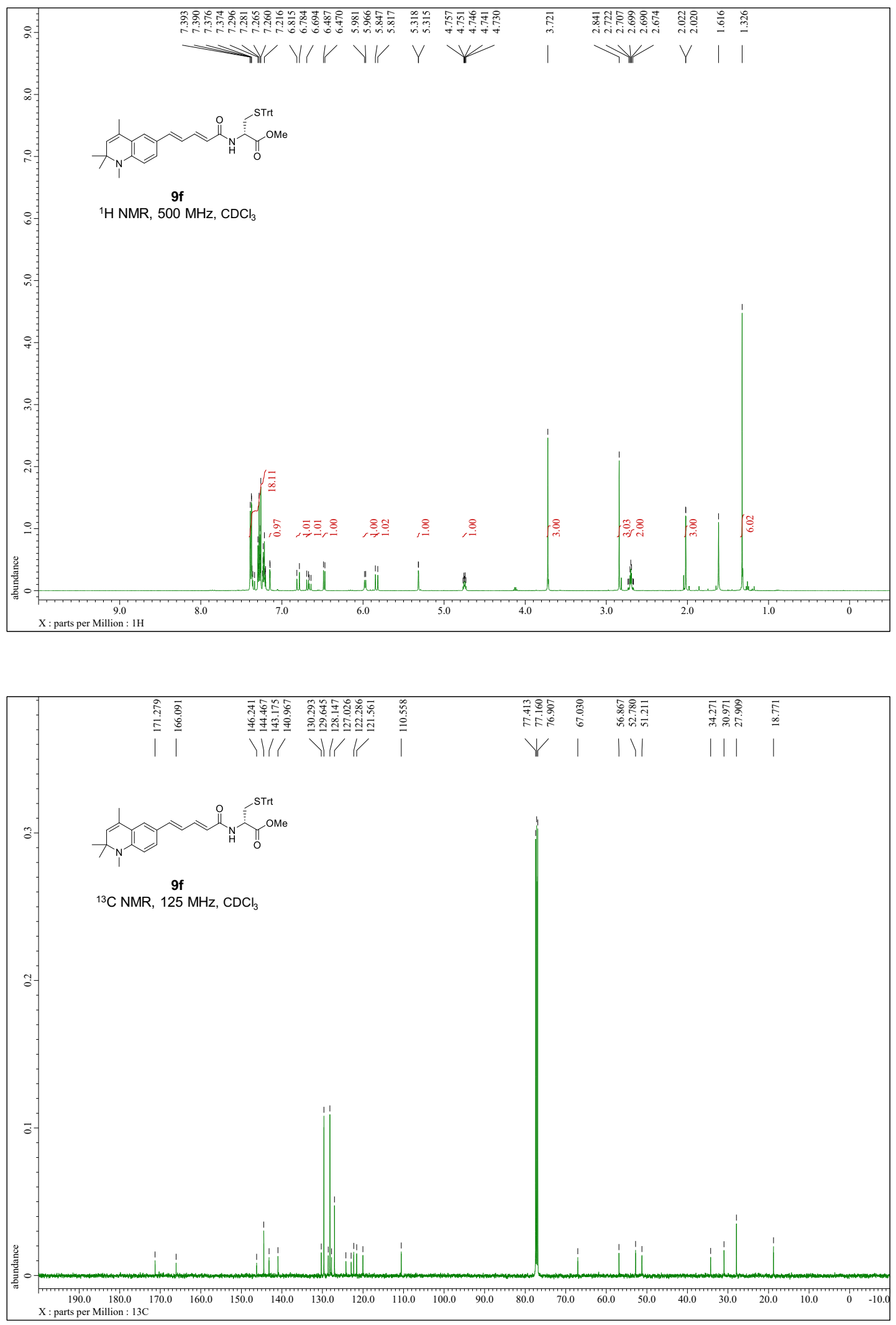

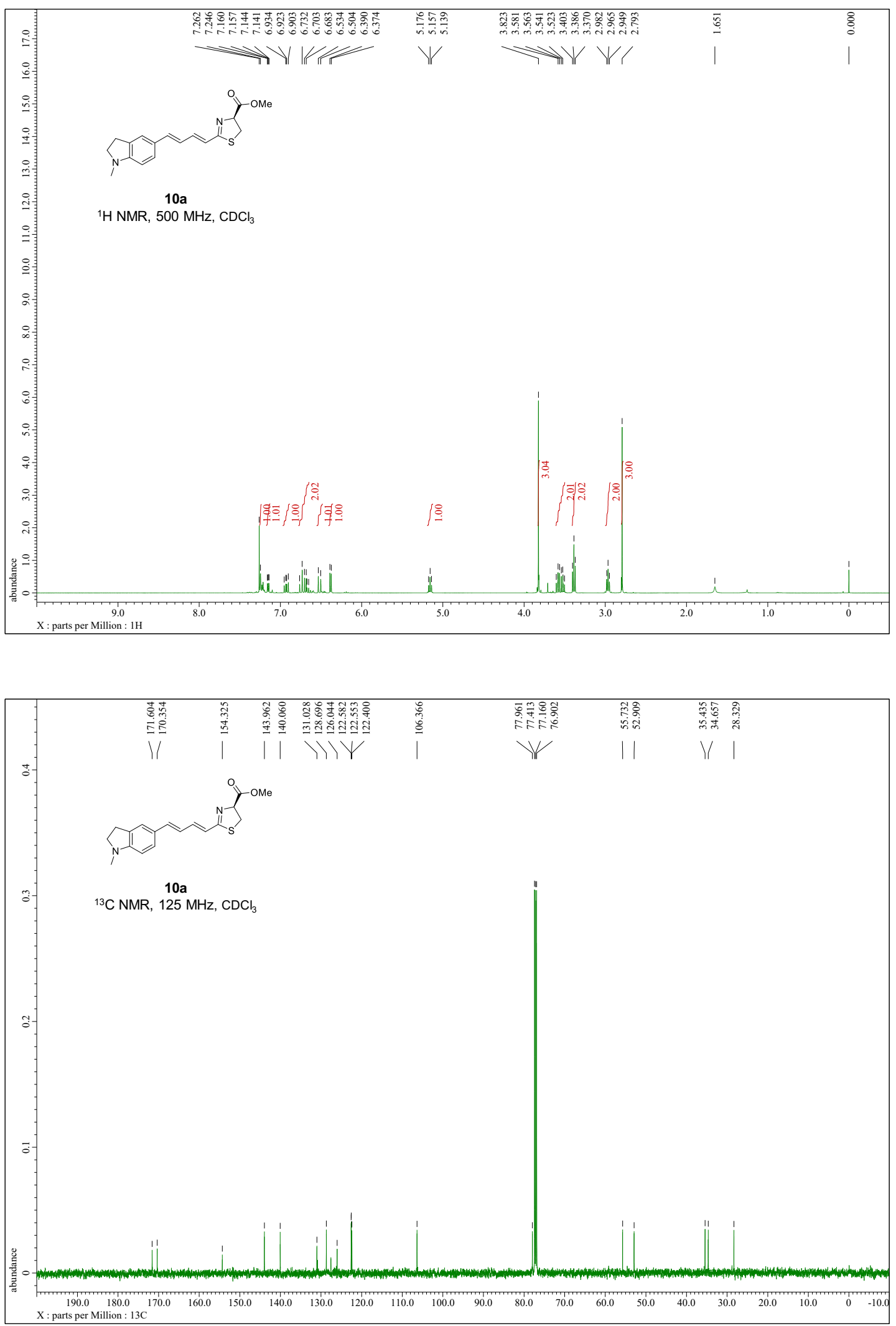

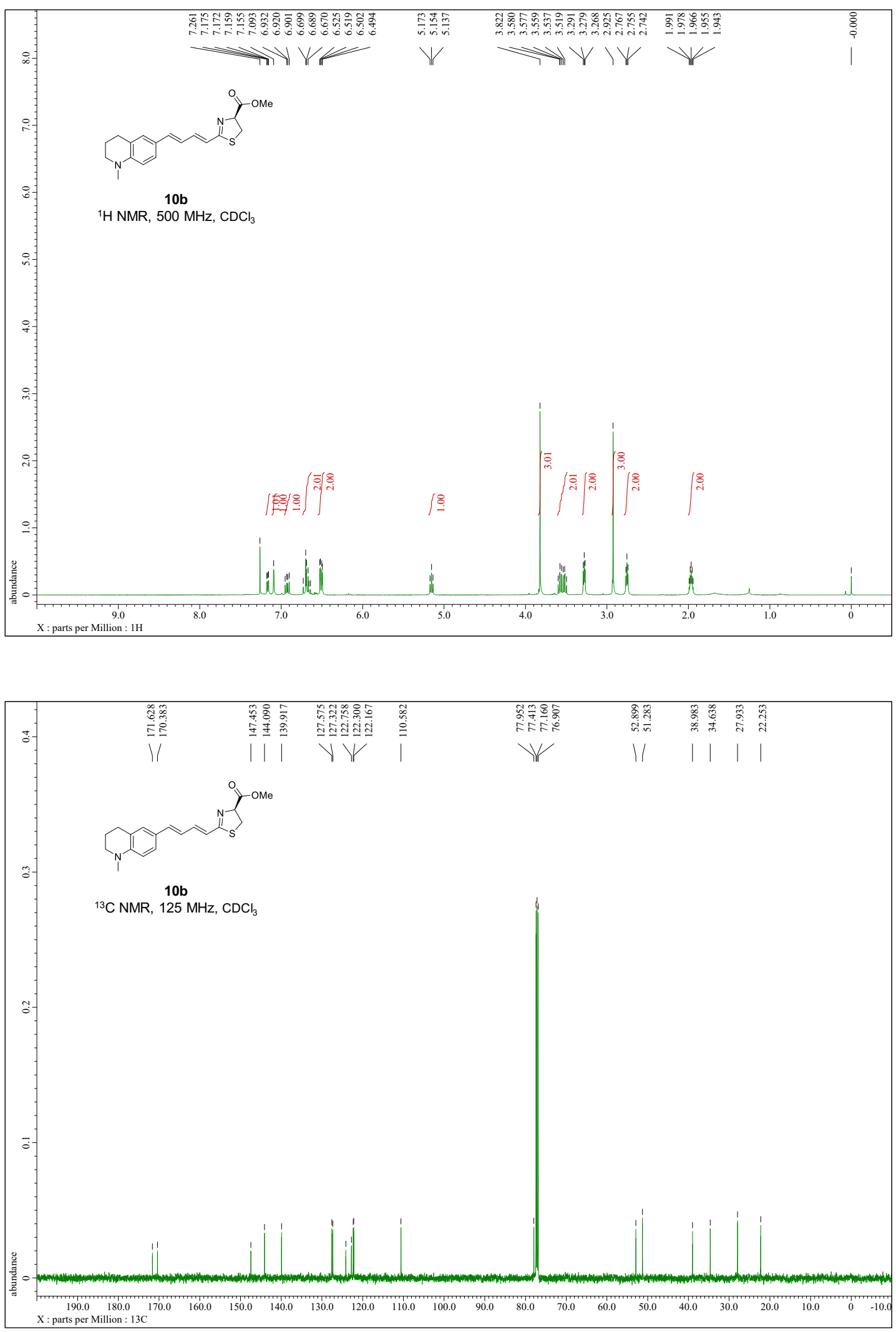

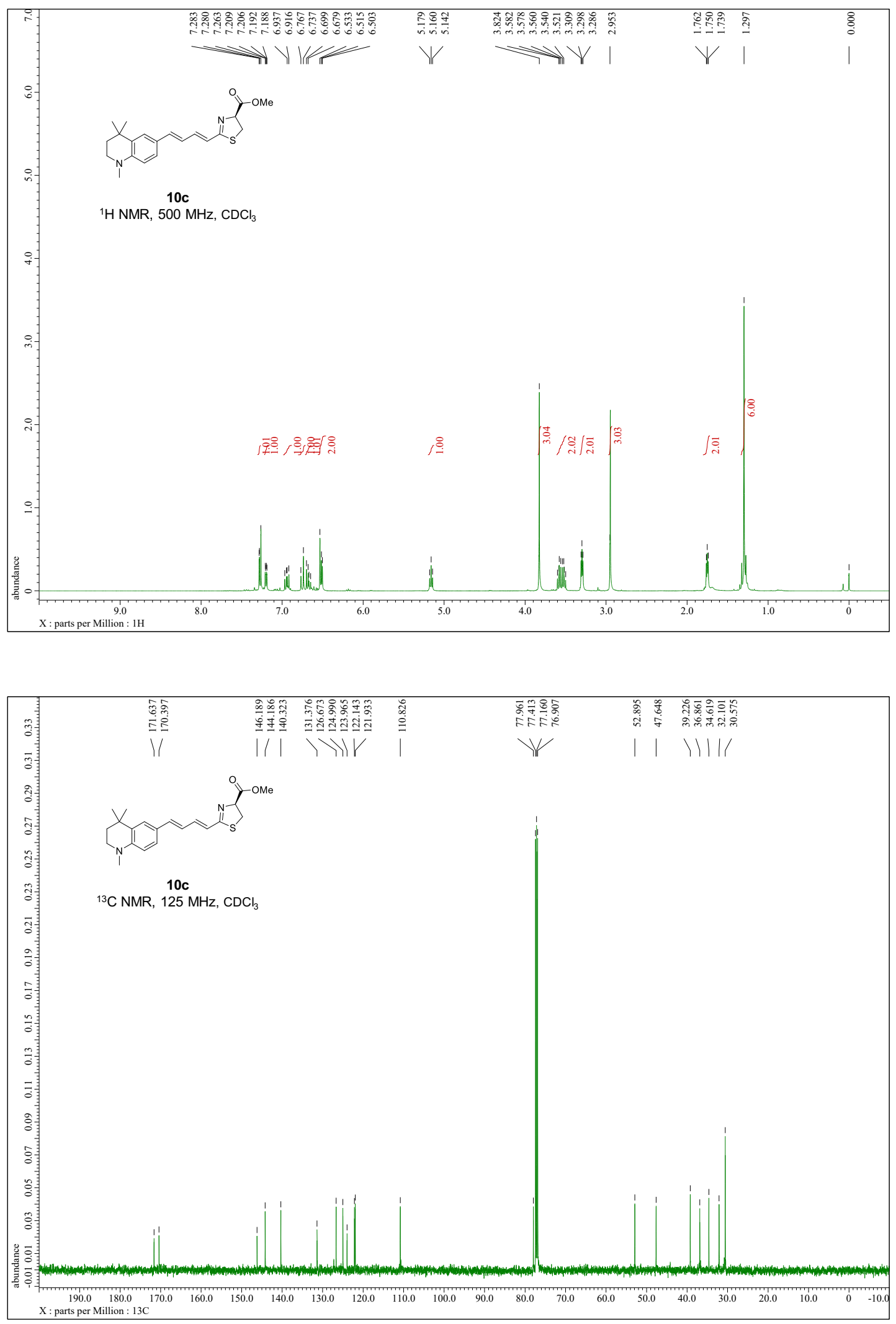

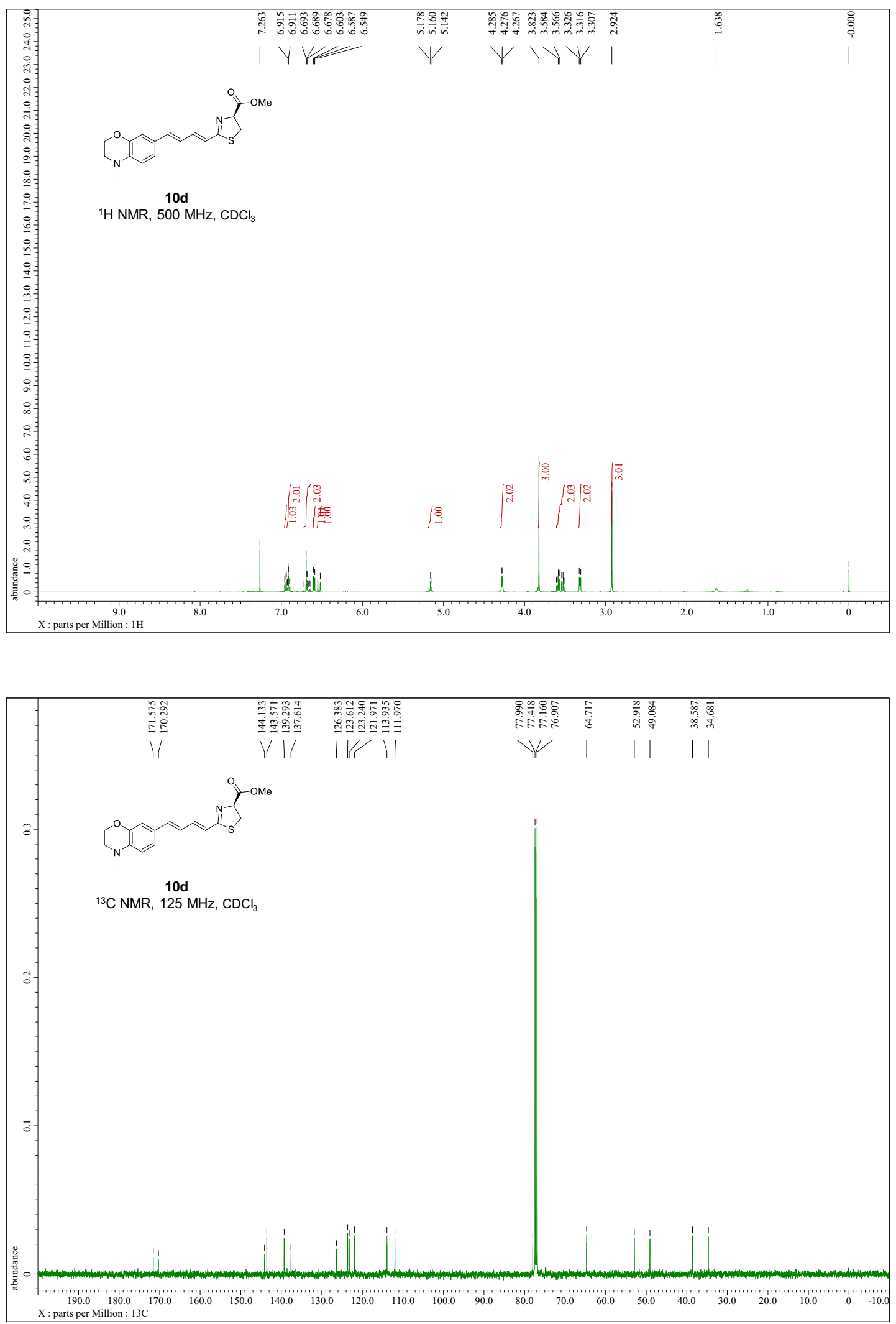

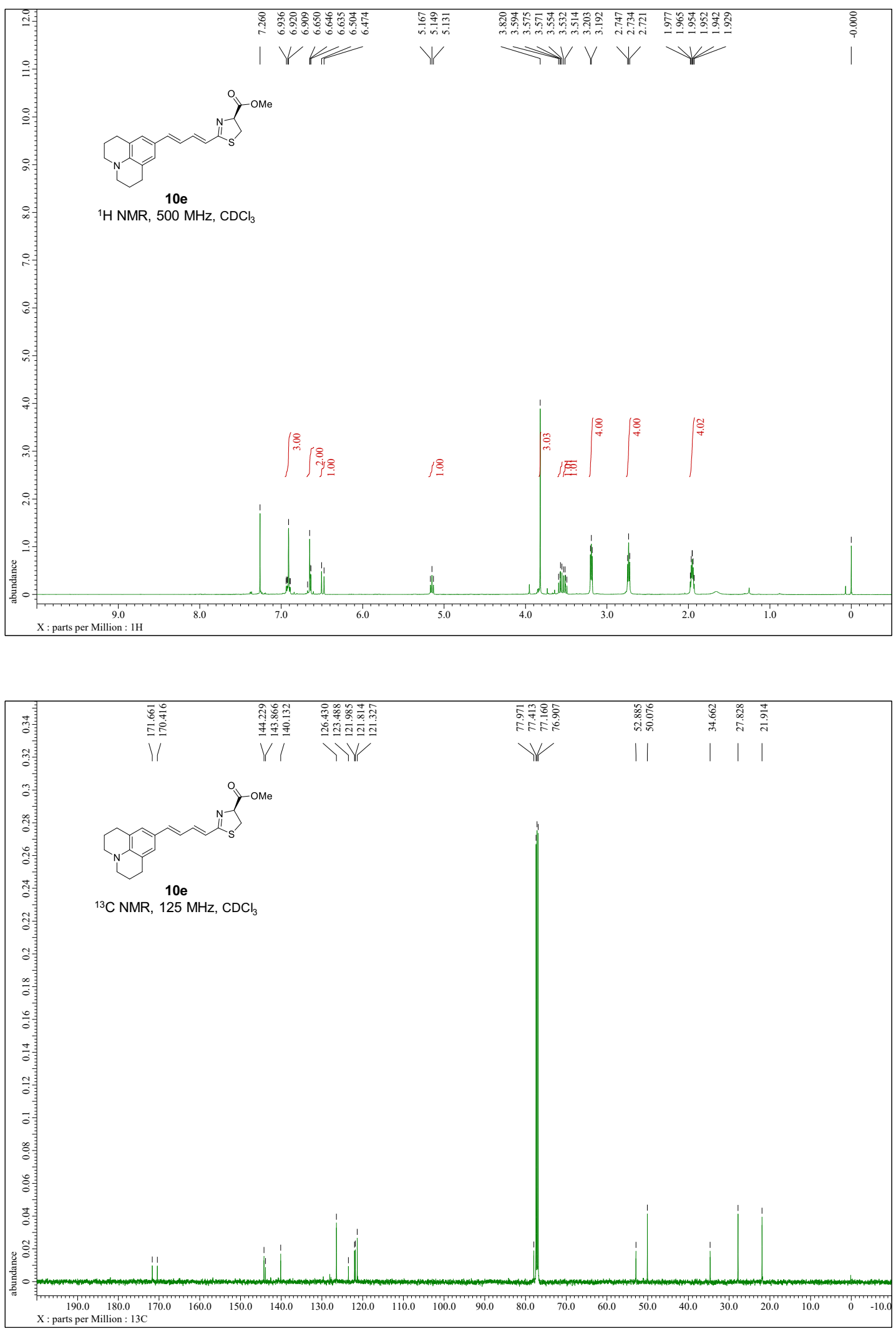

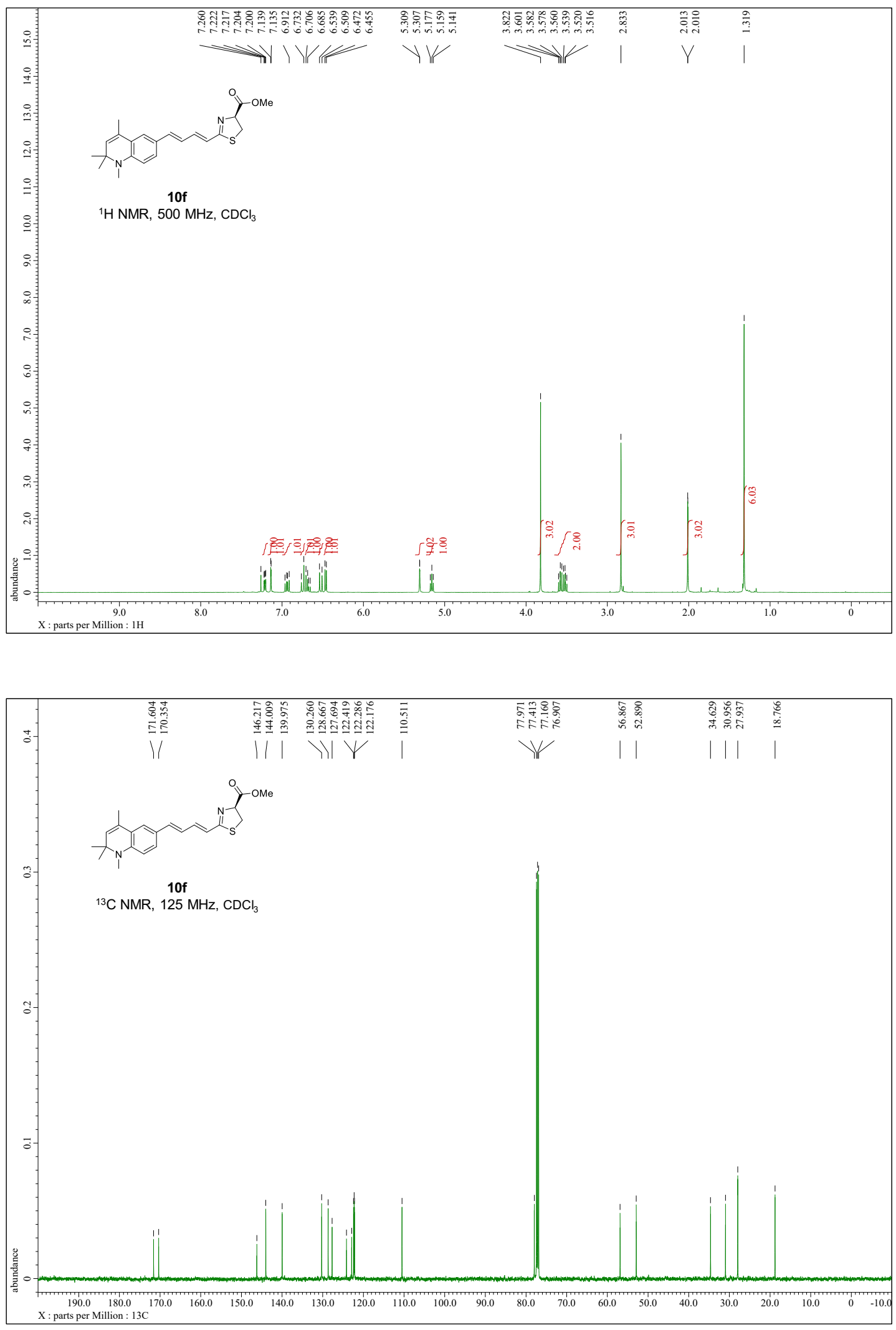

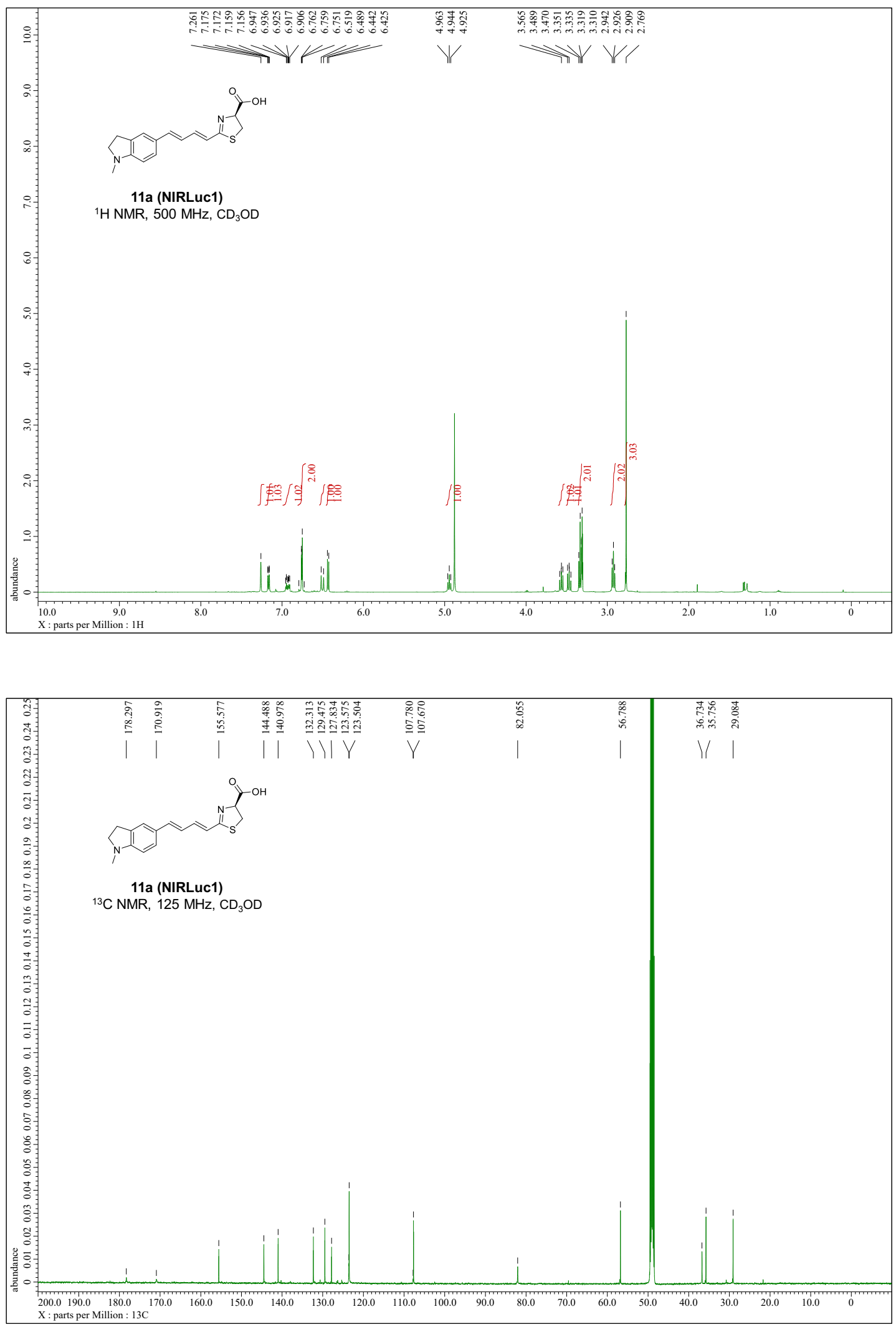

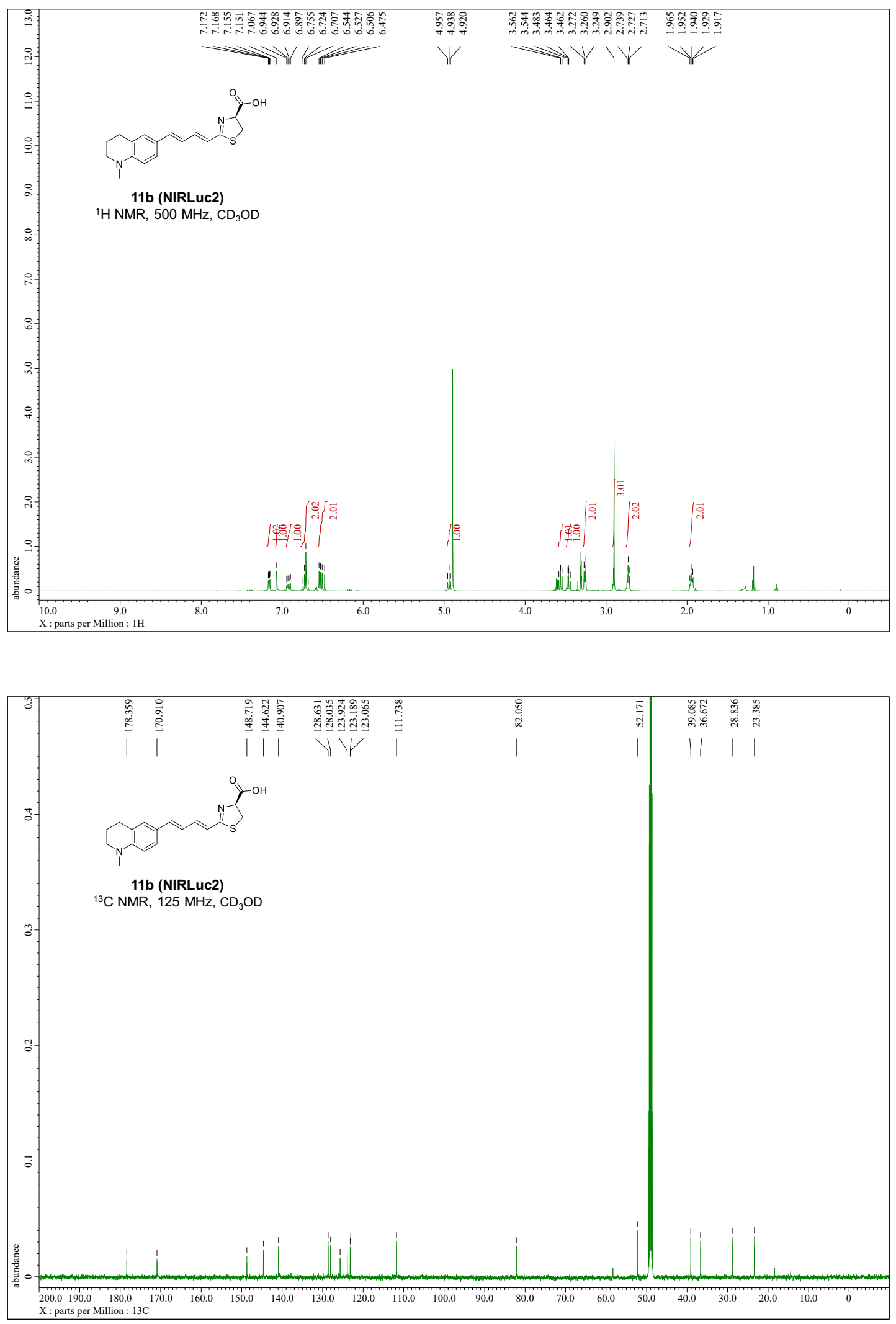

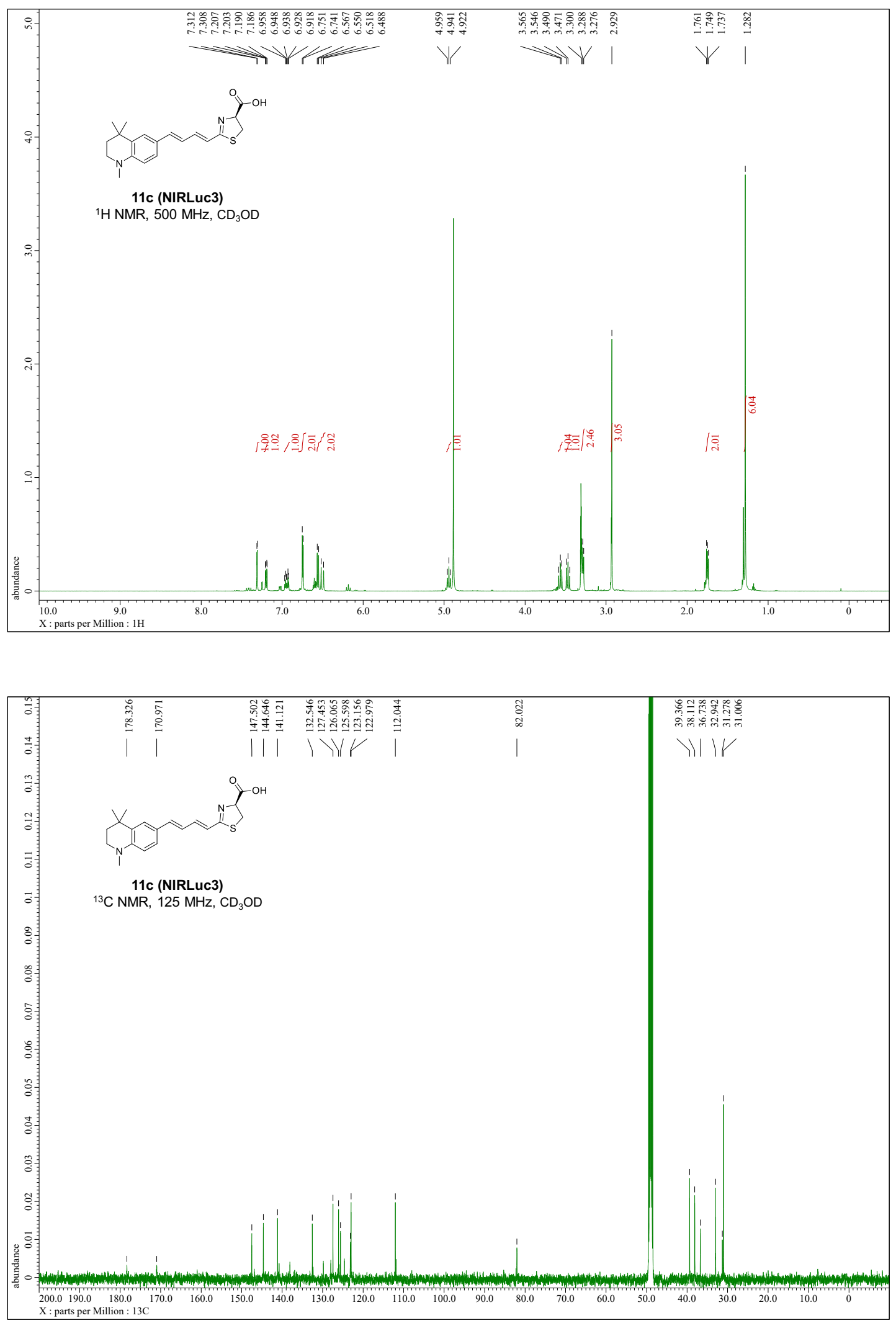

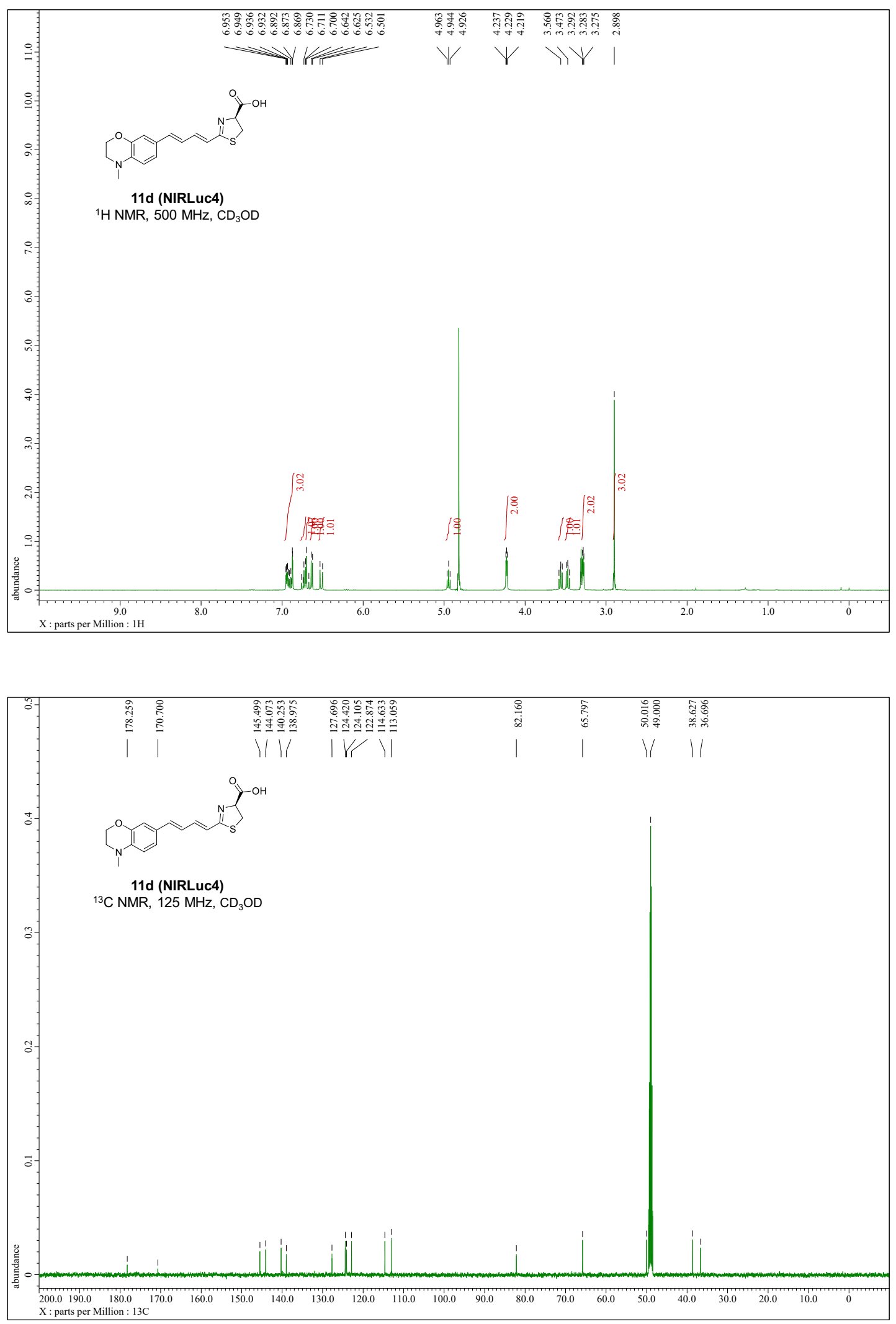

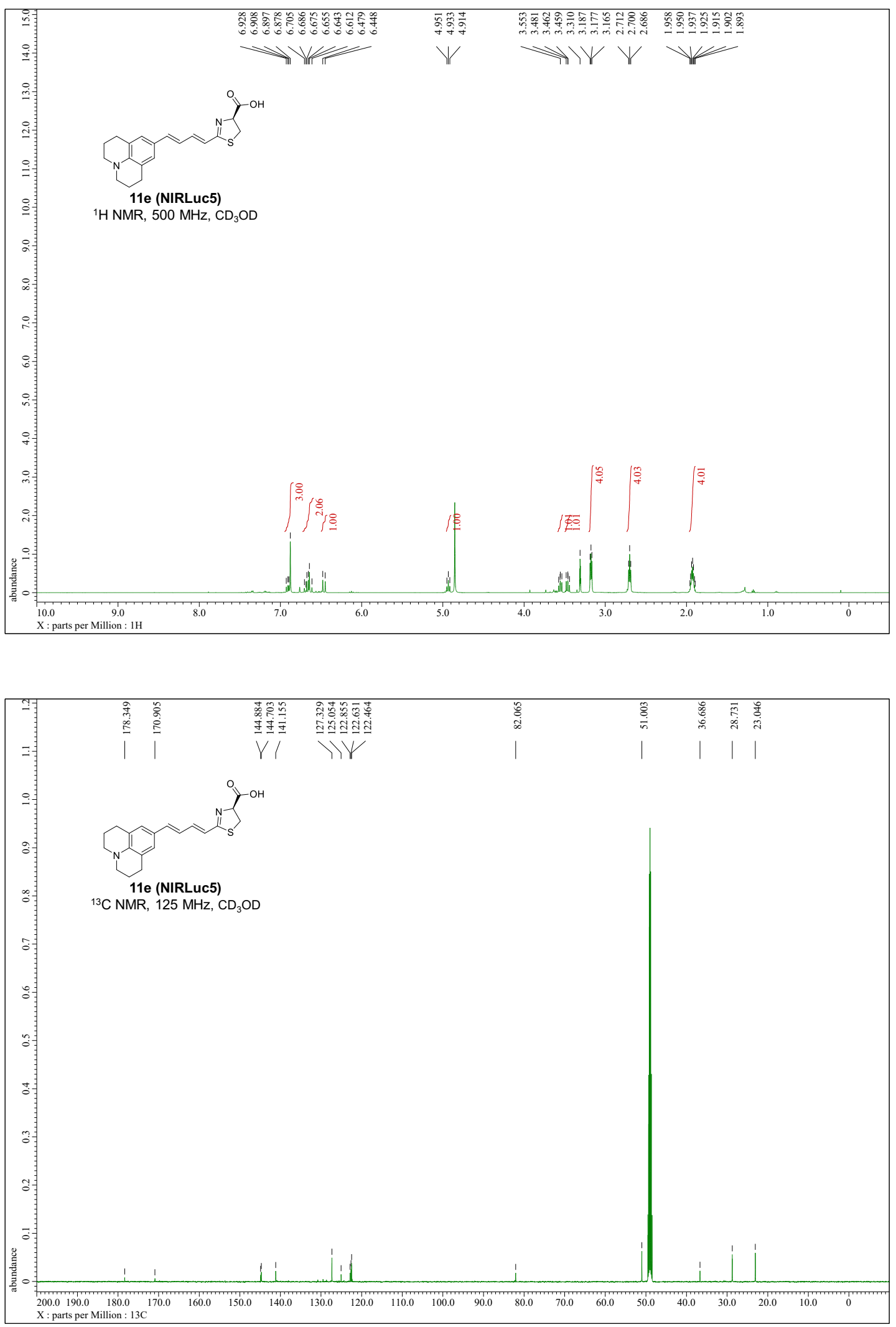

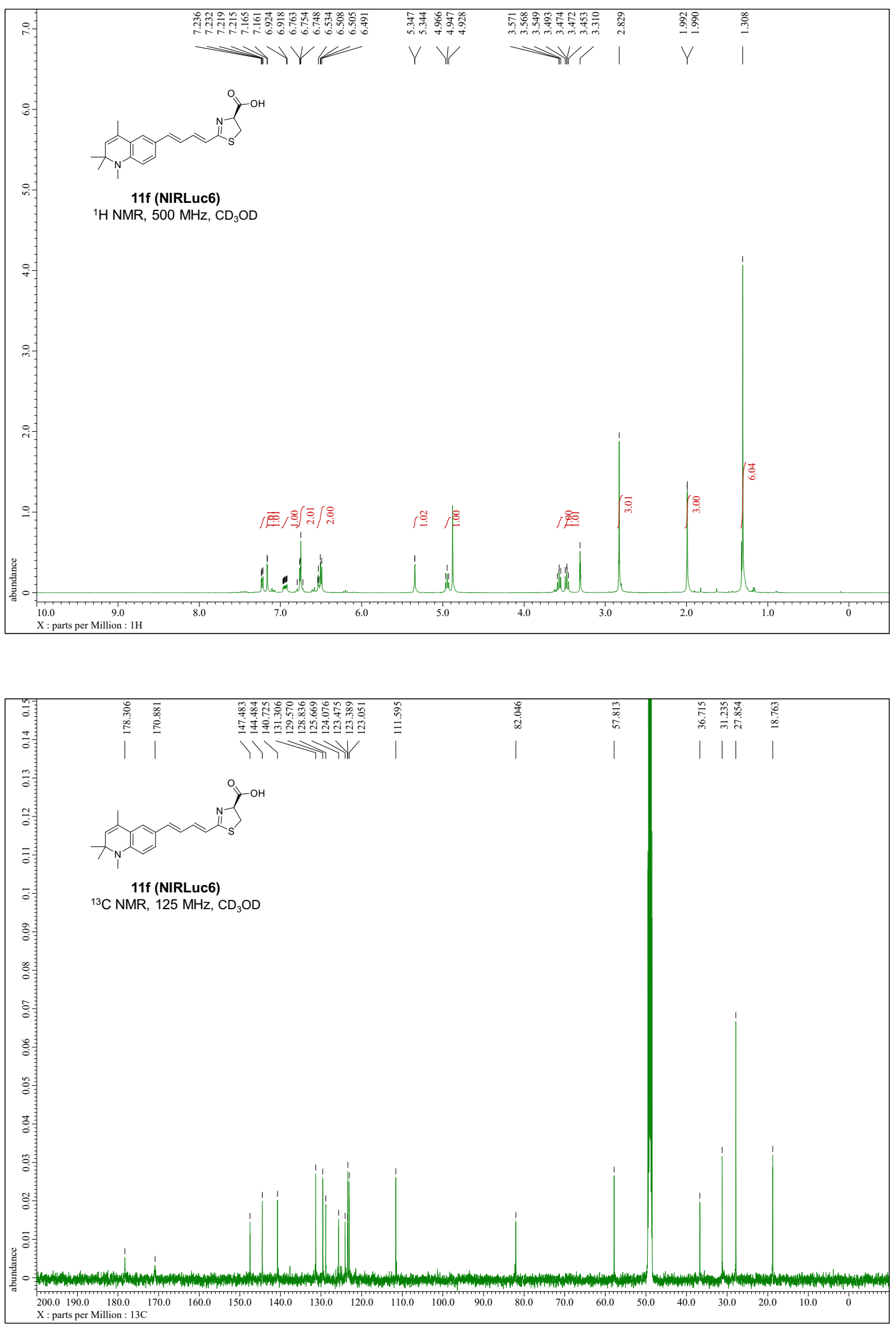